Article

\title{
Energy-Optimal Structures of HVAC System for Cleanrooms as a Function of Key Constant Parameters and External Climate
}

\author{
Mieczysław Porowski *(D) and Monika Jakubiak (D)
}

check for

updates

Citation: Porowski, M.; Jakubiak, M. Energy-Optimal Structures of HVAC System for Cleanrooms as a Function of Key Constant Parameters and External Climate. Energies 2022, 15, 313. https://doi.org/10.3390/ en15010313

Academic Editors: Roberto Alonso González Lezcano and

Fabrizio Ascione

Received: 24 November 2021 Accepted: 27 December 2021 Published: 3 January 2022

Publisher's Note: MDPI stays neutral with regard to jurisdictional claims in published maps and institutional affiliations.

Copyright: (C) 2022 by the authors. Licensee MDPI, Basel, Switzerland. This article is an open access article distributed under the terms and conditions of the Creative Commons Attribution (CC BY) license (https:// creativecommons.org/licenses/by/ $4.0 /)$.
Institute of Environmental Engineering and Building Installations, Poznan University of Technology, Pl. M. Sklodowskiej-Curie 5, 60-965 Poznan, Poland; monika.ja.mackowiak@doctorate.put.poznan.pl

* Correspondence: mieczyslaw.porowski@put.poznan.pl

\begin{abstract}
This article presents approximating relations defining energy-optimal structures of the HVAC (Heating, Ventilation, Air Conditioning) system for cleanrooms as a function of key constant parameters and energy-optimal control algorithms for various options of heat recovery and external climates. The annual unit primary energy demand of the HVAC system for thermodynamic air treatment was adopted as the objective function. Research was performed for wide representative variability ranges of key constant parameters: cleanliness class $-\mathrm{C}_{\mathrm{s}}$ (ISO5 $\div$ ISO8), unit cooling loads $-\dot{\mathrm{q}}_{\mathrm{j}}(100 \div 500) \mathrm{W} / \mathrm{m}^{2}$ and percentage of outdoor air- $\alpha_{\mathrm{o}}(5 \div 100) \%$. HVAC systems are described with vectors $\bar{x}$ with coordinates defined by constant parameters and decision variables, and the results are presented in the form of approximating functions illustrating zones of energy-optimal structures of the HVAC system $\bar{x}^{*}=f\left(C_{s}, \dot{q}_{j}, \alpha_{o}\right)$. In the optimization procedure, the type of heat recovery as an element of optimal structures of the HVAC system and algorithms of energy-optimal control were defined based on an objective function and simulation models. It was proven that using heat recovery is profitable only for HVAC systems without recirculation and with internal recirculation (savings of $5 \div 66 \%$, depending on the type of heat recovery and the climate), while it is not profitable (or generates losses)
\end{abstract} for HVAC systems with external recirculation or external and internal recirculation at the same time.

Keywords: cleanrooms; ventilation; air conditioning; energy consumption; optimization

\section{Introduction}

HVAC systems for cleanrooms generate very high energy consumption for thermodynamic treatment and forcing through air. The literature provides a lot of data confirming this thesis. According to Kircher et al. [1], the energy consumption of HVAC systems for cleanrooms in the USA is $30 \div 50 \%$ times higher than for commercial buildings. According to Tschudi et al. [2], as well as Zhuang et al. [3], this range is wider and equals $10 \div 100 \%$. Shan and Wang [4], as well as Tsao et al. [5,6], report that the percentage of energy consumption by HVAC systems in factories with advanced technologies equals $30 \div 65 \%$, while, according to $\mathrm{Hu}$ et al. [7] and Zhao et al. [8], the percentage for cleanrooms with semiconductor manufacturing equals $40 \div 50 \%$ of the total energy consumption. Highenergy inputs for air conditioning for cleanrooms inspire research aimed to reduce the energy consumption. Such studies address two issues: the optimization of the structure of the HVAC system or the optimization of control algorithms according to the energy criterion. The support tool here is software for determining energy consumption by the HVAC system of cleanrooms; significant results of work in this area were obtained by $\mathrm{Hu}$ et al. [9-11]. In Reference [9], the authors presented a validated FES (Fab Energy Simulation) simulation tool to determine energy consumption in an application for a semiconductor manufacturing fab. The mathematical model for the HVAC system was based on the energy balance equations for the individual components. In relation to the commercial comparable program "CleanCalc II", the FES program allowed for the definition of a few additional parameters by the user while showing excellent consistency of the results $(2.33 \%)$. The 
study [10] developed a new ECF (energy conversion factor) calculator in an application for high-tech factories, including HVAC systems. In turn, in article [11], the authors presented the integration of both tools: the FES program and the ECF calculator in order to optimize energy consumption by HVAC systems in technologically advanced factories (high-tech fabs).

Research on optimizing structures of the HVAC system for cleanrooms was performed by Lin et al. [12], who modified a classic MAU (Make-up Air Unit) + FFU (Filter Fan Unit) + DCC (Dry Cooling Coil) in the recirculation channel, replacing the DCC with FDCU (Fan Dry Cooling Unit) modules in the ceiling of a cleanroom. As a result of elimination of under pressure above the suspended ceiling and air infiltration, as well as the reduction of forcing through losses, they achieved a reduction in energy consumption of the HVAC system with FDCU by $4.3 \%$ compared to the system with the DCC. Hu and Tsao [13] investigated five cases of structures of HVAC system of semiconductor manufacturing rooms. The HVAC structures were different combinations of elements: RCU (Recirculation Air Unit), MAU, FCU (Fan Coil Unit), FFU and DCC. The authors compared the annual electricity consumption in each of these systems, calculating the "Energy Consumption Evaluation" coefficient with values of $1.08,1.12,1.19$ and 3.80 in relation to the optimal system-MAU + $\mathrm{DCC}+\mathrm{FFU}$.

Shan and Wang [4] presented simulation results for three typical options of the structure of the HVAC system for cleanrooms in the pharmaceutical industry: "Interactive option", "Partially decoupled option" and "Fully decoupled option". They proved, for the chosen application, that using the "Partially decoupled option" made it possible to reduce the consumption of electricity and gas for cooling and heating by $69.8 \%$ and $87.8 \%$, respectively.

Tsao et al. [14] presented simulation results for eight different combinations of a structure of the HVAC system of a semiconductor manufacturing room. These combinations included: the location of a fan in MAU (push-through vs. draft-through), one or two temperature levels of cooling water from chillers and using condensation heat recovery in chillers for reheating in MAU. They proved the possibility of reducing electricity consumption by $38.65 \%$ compared to the standard option.

Additionally, Kim et al. [15] simulated the operation of a HVAC system for cleanrooms for four options: Variable Air Volume (VAV), AIR WASHer System (AIRWASH), Dedicated Outdoor Air System (DOAS) and Integrated with Indirect and Direct Evaporative Coolers (IDECOAS). The simulation tool used was the EES (f-chart Software 2009) program. The scope of the simulation included two types of systems (type 1-percentage of outdoor air $\alpha=100 \%$ and type $2-\alpha \neq 100 \%$ ) and six types of climates. The simulation results proved that DOAS and IDECOAS applications make it possible to reduce the annual demand for cold and heat by $67.5 \%$ and $59.5 \%$, respectively, compared to a VAV system. Yin et al. [16,17] energetically optimized a classic HVAC system: MAU + FFU + DCC, in which, as part of the modification, only part of the recirculation air was cooled in the DCC, and reheating in MAU was replaced by a mixing operation in a space above the suspended ceiling. Eventually, the demand for cold in the DCC was decreased by $40 \div 52 \%$ compared to the classic system [17]. Similarly, Ma et al. [18] optimized the heat exchanger system in the MAU unit by resigning from reheating and achieving energy savings for pumping in the MAU unit in the range of 10.7-17.2\%. The mentioned authors also optimized the structure of the filtration system by filtering the return and outdoor air separately. They proved that, by replacing the HEPA filters on the return with fine filters, the energy consumption could be reduced from $25.8 \%$ to $45 \%$ due to the lower air flow resistance [19].

Additionally, Yin et al. [20] optimized an existing classic HVAC system (MAU + FFU + DCC) in a semiconductor manufacturing factory. Based on the results of the measurements and numerical simulations for a HVAC system upgrade option, they proved that, by implementing high-temperature chillers, heat recovery from DCC to MAU and resigning from reheating, the energy consumption can be reduced by $20.2 \%$ compared to the existing HVAC system. 
Chen et al. [21] analyzed the possibilities and energy effects of the application of adiabatic humidification for HVAC systems of selected cleanrooms. They indicated the system "spray nozzles using high-pressure water atomization" as the most advantageous in the case of adiabatic humidification. Xu et al. [22] presented the results of research on the efficiency of FFU fans. The evaluation criteria were the TPE (total pressure efficiency) and EPI (energy performance index) values. They proved that greater energy efficiency is usually associated with larger fans. Energy consumption for the various HVAC system structures of operating theaters was one of the criteria for multicriteria evaluating these systems presented by Fan et al. [23]. By solving the MCDM (multicriteria decision-making) problem, the authors proved a relationship between energy consumption, ventilation effectiveness and user satisfaction. Research in this area, especially with regards to recirculation and heat recovery, was also carried out by Ozyogurtcu et al. [24], who analyzed the energy consumption of four different HVAC systems in hospital operating rooms. They proved that the optimal energy is the HVAC system with a recuperator and regulated air recirculation.

The research on the optimization of the structure of the cooling system for HVAC systems of cleanrooms was conducted by Jia et al. [25]. The authors investigated two free cooling systems integrated with the central cooling system: tap water and cooling tower. They proved that the COP coefficients of a tap water free cooling system were about 7.4 and 2.2 times higher than that of mechanical cooling and tower cooling systems. In turn, the results of research on the optimization of an integrated cooling and heat generation system for HVAC systems in an electronics factory were presented by Zheng and $\mathrm{Li}$ [26]. The authors developed the GMEL (Grade Match Between Energy and Load) method that allows for the optimal use of cold and waste heat for the mutual compensation of loads. For the case study, they achieved energy savings of $26.7 / 52.4 \%$ in the summer and winter, respectively.

Research on the optimization of the control of HVAC systems of cleanrooms with the structure MAU + DCC was led by Wang et al. [27], demonstrating savings of 7.09\% compared to the classic PDI controller. In turn, Zhuang et al. [28] developed and implemented an energy-optimized control strategy for multizone HVAC systems in a pharmaceutical plant on a simulation platform, achieving $20 \%$ energy savings compared to the standard control strategy.

A series of papers dedicated to research concerning the energy-optimal control of a HVAC system for cleanrooms, mainly in the pharmaceutical industry, was published by Zhuang, Wang and Shan [3,29-31].

In paper [29], the authors presented a probabilistic method of optimal control of HVAC systems based on the ADV strategy ("Adaptive Full-Range Decoupled Ventilation Strategy"). They proved that the implementation of this strategy makes it possible to reduce the annual average energy cost compared to the DV (Dedicated Outdoor Air Ventilation), PD (Partially Decoupled Control) and IC (Interactive Control) strategies by 18.2\%, 13.6\% and $6.5 \%$, respectively.

In another study [31], the authors showed savings of $6.8 \div 40.8 \%$ as a result of the implementation of the ADV over IC strategy.

Using a simulation platform, Zhuang et al. [30] also tested and implemented the ADV strategy for a HVAC system for cleanrooms of a pharmaceutical factory in Hong Kong. In this case, they proved that the implementation of this strategy makes it possible to reduce the annual energy consumption by $21.64 \%, 15.63 \%$ and $7.77 \%$, respectively, compared to the PD, IC and DV strategies.

In paper [3], the authors addressed solving the problem of energy-optimal control of a multizone HVAC system of a classic structure (MAU + AHU) and different loads in individual zones (rooms). They proposed the Coordinated Demand-Controlled Ventilation (CDCV) strategy, the implementation of which made it possible to reduce the demand for reheating by $89.6 \%$ and to reduce the total energy demand by $63.3 \%$. 
In turn, Chang et al. [32] investigated six strategies for controlling a cleanroom HVAC system, indicating the energy-optimal variant. They proved that the setting of the required room temperature is of key importance here; increasing this temperature by $1{ }^{\circ} \mathrm{C}$ resulted in a reduction of energy consumption by $1 \%$. Loomans et al. [33,34] and Molnaar [35], on the other hand, simulated and experimentally tested three ventilation strategies in pharmaceutical cleanrooms: Fine-tuning, DCF (Demand Controlled Filtration) and Optimizing airflow pattern. They proved that, using the DCF strategy, it is possible to reduce the energy consumption of fans by up to $70 \%$ and $93.6 \%$ in the case studies under consideration.

Shao et al. [36] investigated experimentally the effect of airflow reduction as a factor of reducing energy consumption on the relative concentration of particles in a cleanroom. The obtained results and correlations allowed for optimal energetic determination of the air stream as a function of the cleanliness class of the room.

To summarize the current state of research concerning the optimization of HVAC system for cleanrooms, the following can be stated:

- until now, researchers have mainly focused on case studies in pharmaceutical and semiconductor industries;

- $\quad$ optimal structures of the HVAC system are calculated by performing simulations for several predetermined acceptable variants and indicating the variant for which the annual energy consumption is minimal;

- there is no global approach to calculating the optimal structures of the HVAC system as a function of key constants parameters being the input data and describing the HVAC system.

Therefore, there is a methodological gap at the stage of determining the set of acceptable structures of HVAC systems of cleanrooms fulfilling the functional function described by: cleanliness class, temperature, relative humidity, air velocity, degree of turbulence, overpressure, concentration of pollutants and share of outside air.

At the same time, there is a need to undertake research on support tools in order to determine, from a set of acceptable variants, the optimal structure and algorithms of HVAC system control.

Therefore, for the needs of the application, methods and tools are sought that allow, at the starting point, to define a set of acceptable structures of HVAC systems on the basis of output data - the standard parameters defining the utility function, decision variables and limiting conditions. Next, relationships are sought on the basis of which optimal structures and algorithms for controlling HVAC systems can be determined. In applications, it is important that the arguments in these relations are constant parameters constituting the output data in the optimization procedure.

The aim of the presented paper is to calculate approximating functions describing optimal structures of the HVAC system for cleanrooms depending on key constant parameters (arguments): cleanliness class $\left(C_{S}\right)$, percentage of outdoor air $\left(\alpha_{0}\right)$ and unit cooling load $\left(\mathrm{q}_{\mathrm{j}}\right)$ and determination of the energy-optimal control algorithms for heat recovery options and the outdoor climate. The annual unit primary energy demand of the HVAC system for thermodynamic air treatment was adopted as the objective function.

The proposed method is an original approach, both from the scientific and the application points of view.

\section{Research Problem, General Algorithm}

Every HVAC system can be described by a vector with coordinates defined by constant parameters and decision variables. With regards to cleanrooms, the constant parameters are primarily temperature, relative humidity, cleanliness class, percentage of outdoor air, unit cooling load and pressure gradients.

For determined combinations of constant parameters values of a HVAC system, a single optimization problem can be defined concerning calculating the optimal HVAC system for which the annual energy demands (final, primary) reach the minimum values. 
The constant parameters of a HVAC system for cleanrooms are within realistic value ranges. In general, one can define a set of combinations of constant parameter values in which each constant parameter takes values representing the entire range of variability.

The research problem comes down to calculating the set of optimal structures of a HVAC system assigned to combinations of values of constant parameters representing realistic ranges of variability of these parameters in cleanrooms.

On this basis, it is possible to calculate approximating relations defining structures of HVAC systems as a function of combinations of constant parameter values.

The general algorithm of the optimization procedure partly based on the methodology presented earlier by the authors of References $[37,38]$ is presented in Figure 1 . The algorithm includes:

- calculating the set of constant parameters $\bar{x}_{i}$ and the set of decision variables $x_{j}$;

- two phases of analysis: calculating the matrix of all possible variants of limiting conditions and of acceptable variants, respectively, for:

- combinations of decision variables values $x_{j}$ for normalizing constant parameters (matrices $\mathbf{W}_{\mathrm{i}}, \mathbf{W}, \mathbf{G}_{\mathrm{i}}, \mathbf{G}_{\mathrm{j}}$ and $\mathbf{W}_{\mathrm{g}}$ ) and

- the HVAC system (matrices $\mathbf{X}^{\mathrm{J}}, \mathbf{G}$ and $\mathbf{X}$ );

- calculating the optimal structures of HVAC systems $\bar{x}_{n g k}^{*}$ for combinations of values of key constant parameters (arguments): cleanliness class $\left(\mathrm{C}_{\mathrm{sk}}\right)$, percentage of outdoor air $(\alpha \mathrm{ok})$ and unit cooling load $\left(\mathrm{q}_{\mathrm{jk}}\right), \mathrm{k}=1 \ldots \mathrm{K}$;

- defining approximation relations $\bar{x}_{n g k}^{*}=f\left(C_{s k}, \alpha_{o k}, q_{j k}\right)$;

- defining algorithms of energy-optimal control for optimal structures of HVAC systems $\overline{\mathrm{x}}_{\mathrm{n} \mathrm{k}}^{*}$ based on the objective function;

- calculating the optimal variant $\bar{x}^{*}$.

Constant parameters are by definition invariant in the optimization procedure, but in general, they can be functions of both time and space. The decision variables change during the optimization procedure and are the arguments of the $\bar{x}$ describing the HVAC system, the constraint conditions and the objective function. The fragment of the procedure in Figure 1, leading to the determination of the set of acceptable HVAC system structures, the $\mathbf{X}$ matrix, is based on the methodology described in detail in Reference [37]. After determining the $\mathbf{X}$ matrix, in the next step of the optimization procedure, the real required ranges for the variability of key fixed parameters in cleanroom applications, are determined: cleanliness class $\left(\mathrm{C}_{\mathrm{sk}}\right)$, share of outside air $\left(\alpha_{\mathrm{ok}}\right)$ and unit cooling load $\left(\mathrm{q}_{\mathrm{jk}}\right)$. Then, on this basis, a representative set of combinations of the values of the key parameters of the HVAC system constants is determined, and for each of these combinations, the optimal structure of the HVAC system $\bar{x}_{n g k}^{*}$ is determined based on an algorithm from the set of permissible structures ( $\mathbf{X}$ matrices). In the next step, on the basis of the obtained results, the general algorithm assumes the development of approximating relations defining energy-optimal structures of HVAC systems as a function of key constant parameters $\bar{x}_{n g k}^{*}=f\left(C_{s k}, \alpha_{o k}, q_{j k}\right)$. In the final stage of the optimization procedure, the objective function is determined-the minimum annual demand for primary energy for thermodynamic treatment, the optimal type of heat recovery for various outdoor climate options and the energy-optimal control algorithms.

The algorithm structure of the general optimization procedure includes three basic steps:

- determination of a set of permissible HVAC system structures-X matrix, based on the utility function (normalized constants and limiting conditions);

- determination of the optimal structure of the HVAC system- $\overline{\mathrm{x}}_{\mathrm{ng}}^{*}$ based on the key constants: $\mathrm{C}_{\mathrm{s}}$-cleanliness class, $\dot{\mathrm{q}}_{\mathrm{j}}$ - unit heat load and $\alpha_{\mathrm{o}}$-percentage of outside air;

- determination of the energy-optimal variant of the HVAC system-vector $\bar{x}^{*}$, taking into account the optimal structure and the optimal type of heat recovery. 


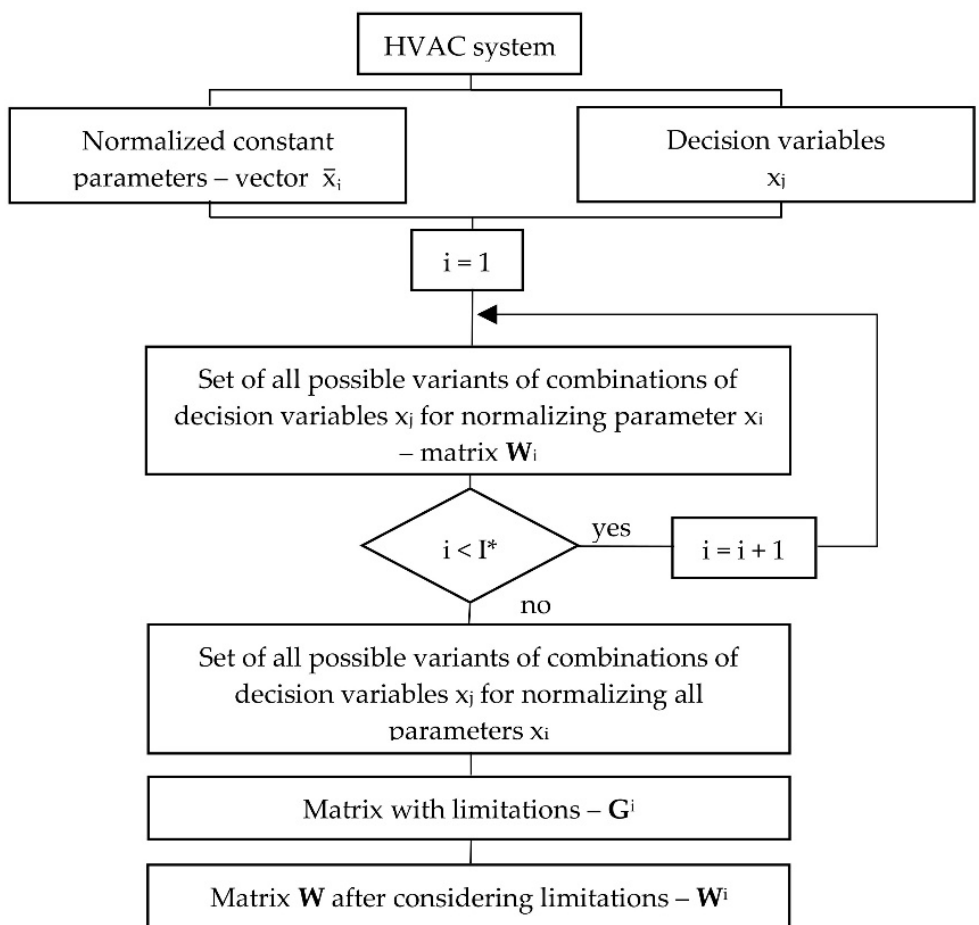

Matrix of elimination of unnecessary decision variables $-G^{j}$

Set of acceptable variants of combinations of decision variables values for normalizing all constant parameters $\mathrm{x}_{\mathrm{i}}-$ matrix $\mathbf{W}_{\mathrm{g}}\left(\mathbf{W}_{\mathrm{g}}^{\mathrm{g}}=\mathbf{G}^{\mathrm{i}} \times \mathbf{W} \times\right.$
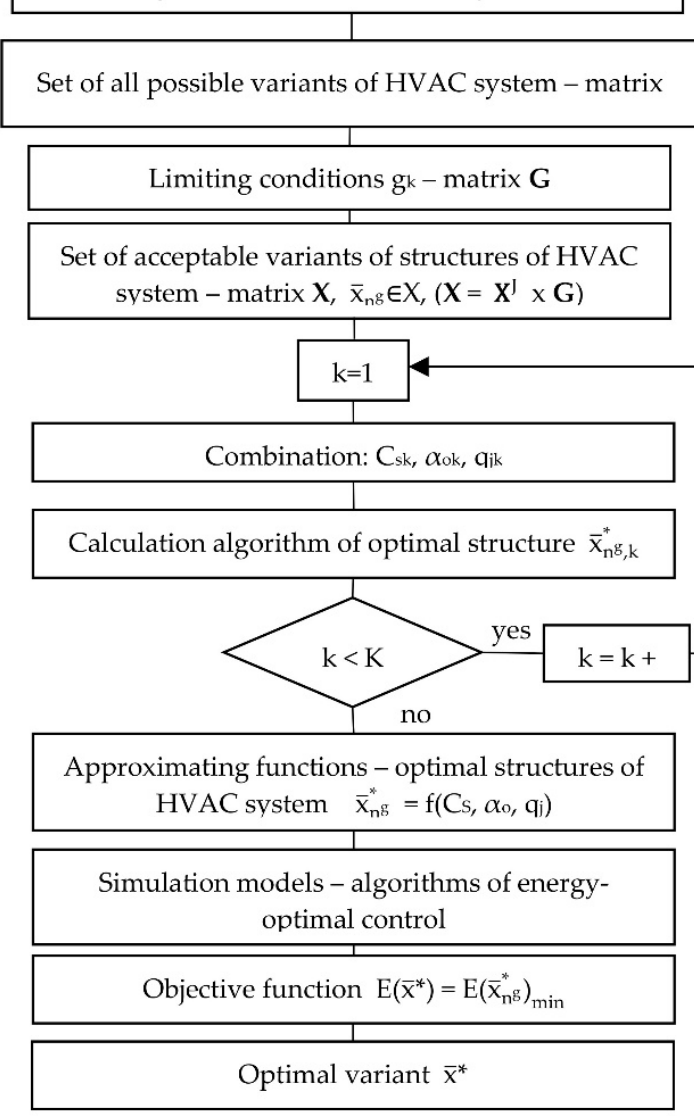

Figure 1. Optimization procedure-general algorithm. 


\section{Acceptable Structures of HVAC System}

The starting point in determining the permissible structures of the HVAC system is the determination of a set of parameters standardized by this system. A wide range of normalized constant parameters in a cleanroom was used:

- $\quad$ temperature, $t_{\mathrm{R}}$

- relative humidity $\varphi_{\mathrm{R}} \in\left(\varphi_{\mathrm{R} 1}, \varphi_{\mathrm{R} 2}\right)$

- acceptable concentration of contaminants, $\mathrm{k}_{\mathrm{d}}$

- cleanliness class, $\mathrm{C}_{\mathrm{S}}$

- $\quad$ overpressure, $\Delta \mathrm{p}$

- $\quad$ percentage of outdoor air, $\alpha_{o}$

The procedure leading to the determination of acceptable structures of the HVAC system based on the methodology previously developed by the authors of Reference [37] is presented in Appendix A. This procedure uses system analysis and matrix calculus. The forms of the determined matrices are listed in Appendix A; these matrices are described in the following order:

- $\quad$ normalized constant parameters;

- a set of all possible variants of a combination of decision variables for the normalization of each individual and all constant parameters together;

- limiting conditions for variants of combinations of decision variables for the standardization of constant parameters;

- $\quad$ set of eliminated decision variables;

- a set of all possible variants of the HVAC system for the standardization of constant parameters;

- limiting conditions for possible variants of the HVAC system;

- set of acceptable HVAC system structures.

Acceptable variants $\bar{x}_{n g}$ of the structure of the HVAC system for cleanrooms are presented synthetically in a form of a general model in Figure 2.

$\dot{\mathrm{V}}_{\mathrm{o}}, \dot{\mathrm{V}}_{\mathrm{c}}, \dot{\mathrm{V}}, \dot{\mathrm{V}}_{\mathrm{e}}, \dot{\mathrm{V}}_{1}, \dot{\mathrm{V}}_{2}, \Delta \mathrm{V}$-volume stream of outdoor air, processing air, supply air, exhaust air, external recirculation air, internal recirculation air and balance sheet difference.

$\alpha_{\mathrm{o}}=\frac{\dot{\mathrm{V}}_{\mathrm{o}}}{\dot{\mathrm{V}}}, \alpha_{\mathrm{c}}=\frac{\dot{\mathrm{V}}_{\mathrm{c}}}{\dot{\mathrm{V}}}, \alpha_{1}=\frac{\dot{\mathrm{V}}_{1}}{\dot{\mathrm{V}}}, \alpha_{2}=\frac{\dot{\mathrm{V}}_{2}}{\dot{\mathrm{V}}}$-percentage of outdoor air, processing air, external recirculation air and internal recirculation air;

$E_{1}, E_{2}, E_{3}$-filtration efficiency of the $1^{\circ}, 2^{\circ}$ and $3^{\circ}$ stages;

HR-heat recovery.

Acceptable variants $\bar{x}_{n g}$ of the HVAC system include:

$\overline{\mathrm{x}}_{1}-\mathrm{CAV}$ air system without recirculation:

a. AHU—thermodynamic treatment: heat recovery, primary heater, cooler, secondary heater and steam humidifier;

b. hygienic standard: three stages of filtration, 3rd stage filter integrated with a supply diffuser, hygienic design;

c. installation: variable flow regulators.

$\bar{x}_{2}-\mathrm{CAV}$ air system with external recirculation:

a. $\quad$ two air handling units in cascade at the supply: MAU + AHU;

b. MAU of outdoor air with heat recovery;

c. AHU—thermodynamic treatment: primary heater, cooler, secondary heater and steam humidifier;

d. hygienic standard: as with $\bar{x}_{1}$ point $b$;

e. installation: as with $\bar{x}_{1}$ point c.

$\overline{\mathrm{x}}_{3}-\mathrm{CAV}$ air system with internal recirculation (room):

a. two air handling units in cascade at the supply: AHU + RU (RDCU);

b. AHU—-thermodynamic treatment: heat recovery, primary heater, cooler, secondary heater and steam humidifier; 
c. RU (Recirculation Unit) or RDCU (Recirculation Dry Cooling Unit)—recirculation (recirculation with dry cooling);

d. hygienic standard: as with $\bar{x}_{1}$ point $b$;

e. installation: as with $\bar{x}_{1}$ point $c$.

$\overline{\mathrm{x}}_{4}-\mathrm{CAV}$ system with external and internal recirculation (room):

a. $\quad$ three air handling units in cascade at the supply: MAU + AHU + RU (RDCU);

b. MAU of outdoor air with heat recovery;

c. AHU—-thermodynamic treatment: primary heater, cooler, secondary heater and steam humidifier;

d. RU or RDCU—recirculation (recirculation with dry cooling);

e. hygienic standard: as with $\bar{x}_{1}$ point $b$;

f. installation: as with $\bar{x}_{1}$ point $c$.

In variants $\bar{x}_{3}$ and $\bar{x}_{4}$, alternatives to internal recirculation RU (RDCU) are: FFU $(\mathrm{FFU}+\mathrm{DCC})$ or FFU + FDCU.

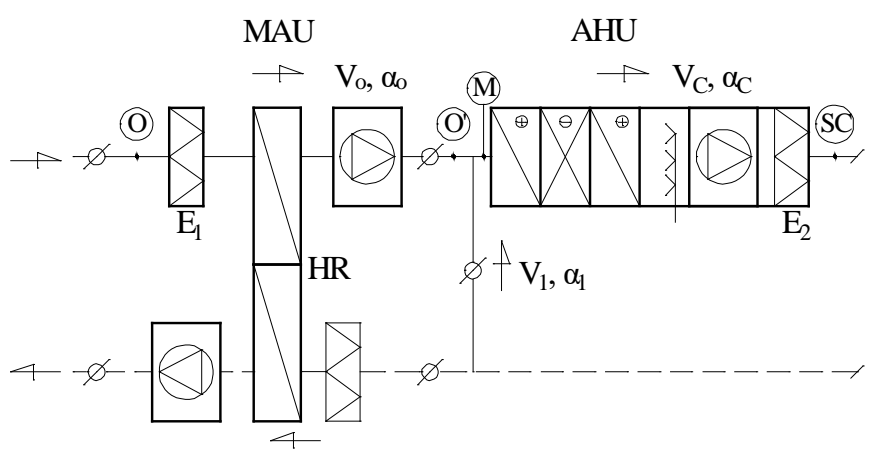

(a)

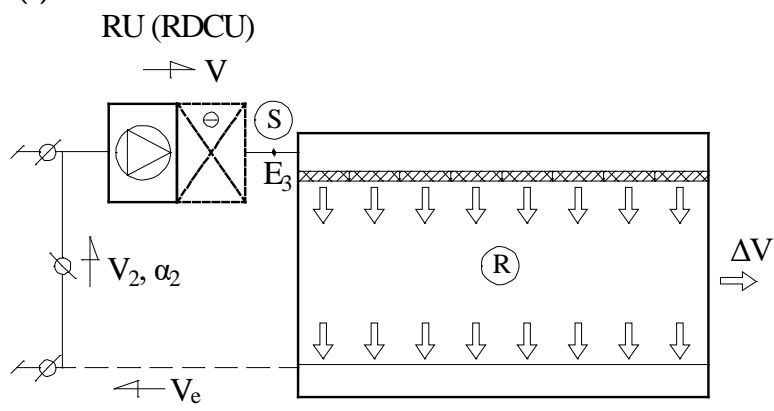

(b)

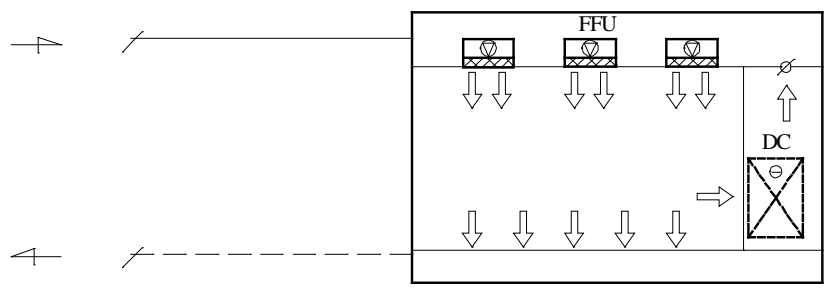

(c)

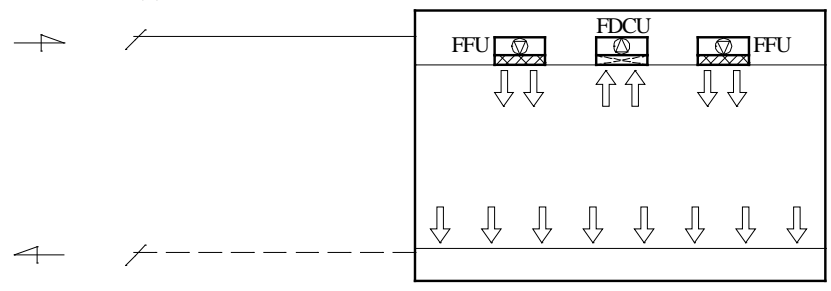

Figure 2. General model of the acceptable variants of structures of the HVAC system for cleanrooms: $\bar{x}_{1}$-without recirculation $\left(\alpha_{1}=0, \alpha_{2}=0, \alpha_{0}=1\right) ; \bar{x}_{2}$-with external recirculation $\left(\alpha_{1} \neq 0, \alpha_{2}=0\right)$; $\overline{\mathrm{x}}_{3}$-with internal recirculation $\left(\alpha_{1}=0, \alpha_{2} \neq 1\right) ; \bar{x}_{4}$-with external and internal recirculation $\left(\alpha_{1} \neq 0\right.$, $\left.\alpha_{2} \neq 0\right)$. Variants of internal recirculation $\left(\alpha_{2} \neq 0\right)$ : (a) RU or RDCU, (b) FFU or FFU + DCC, (c) FFU + FDCU.

\section{Optimal Structures of HVAC System}

4.1. Optimal Structure Selection Algorithm

The calculation algorithm of the optimal structure of the HVAC system is shown in Figure 3. The starting point includes constant parameters of the HVAC system and set of 
acceptable variants $\bar{x}_{n g} \in X$. Selection of the optimal structure of the HVAC system is a permissibility function of recirculation (hygienic function) and values of three air streams:

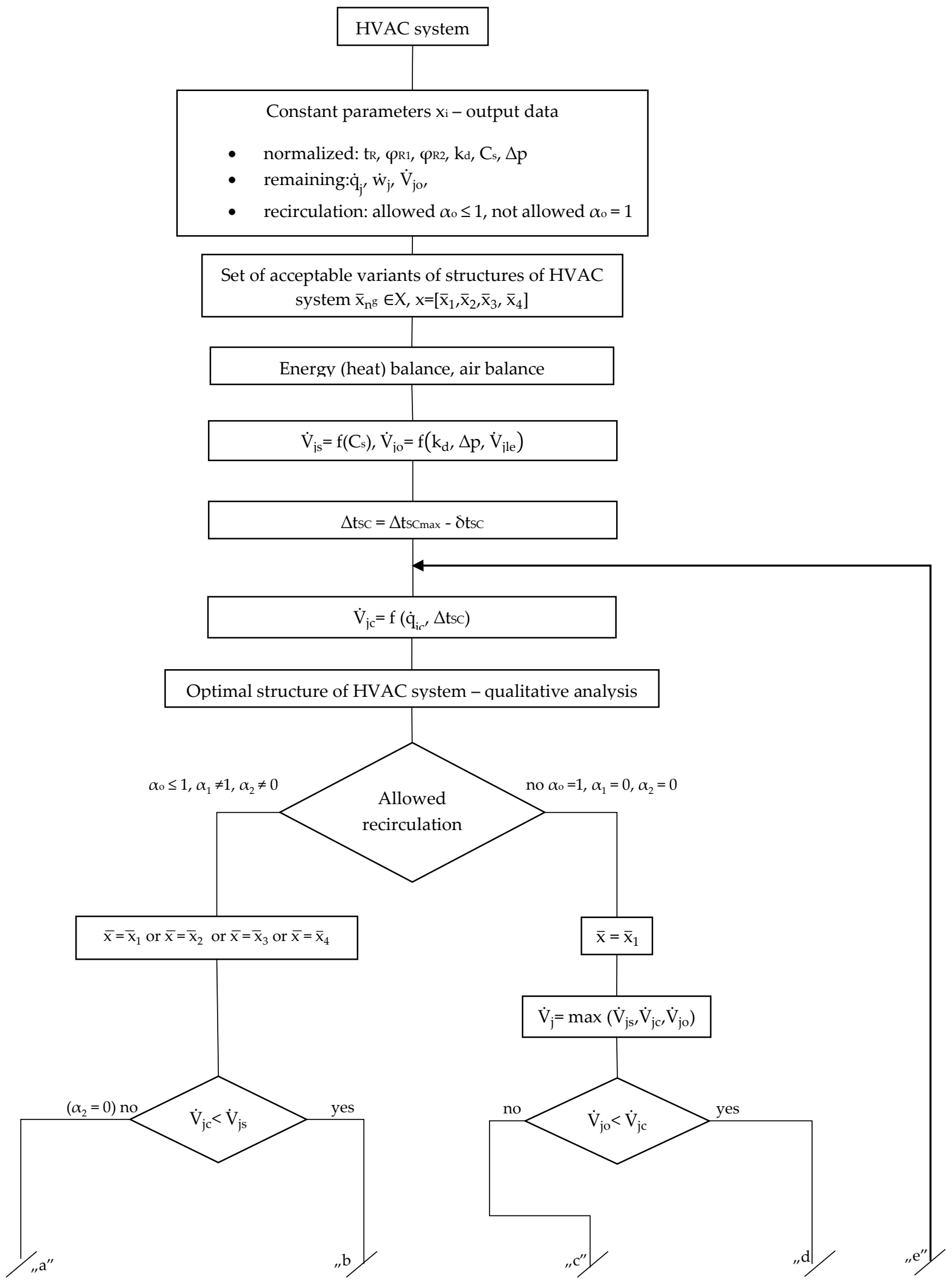

Figure 3. Cont. 


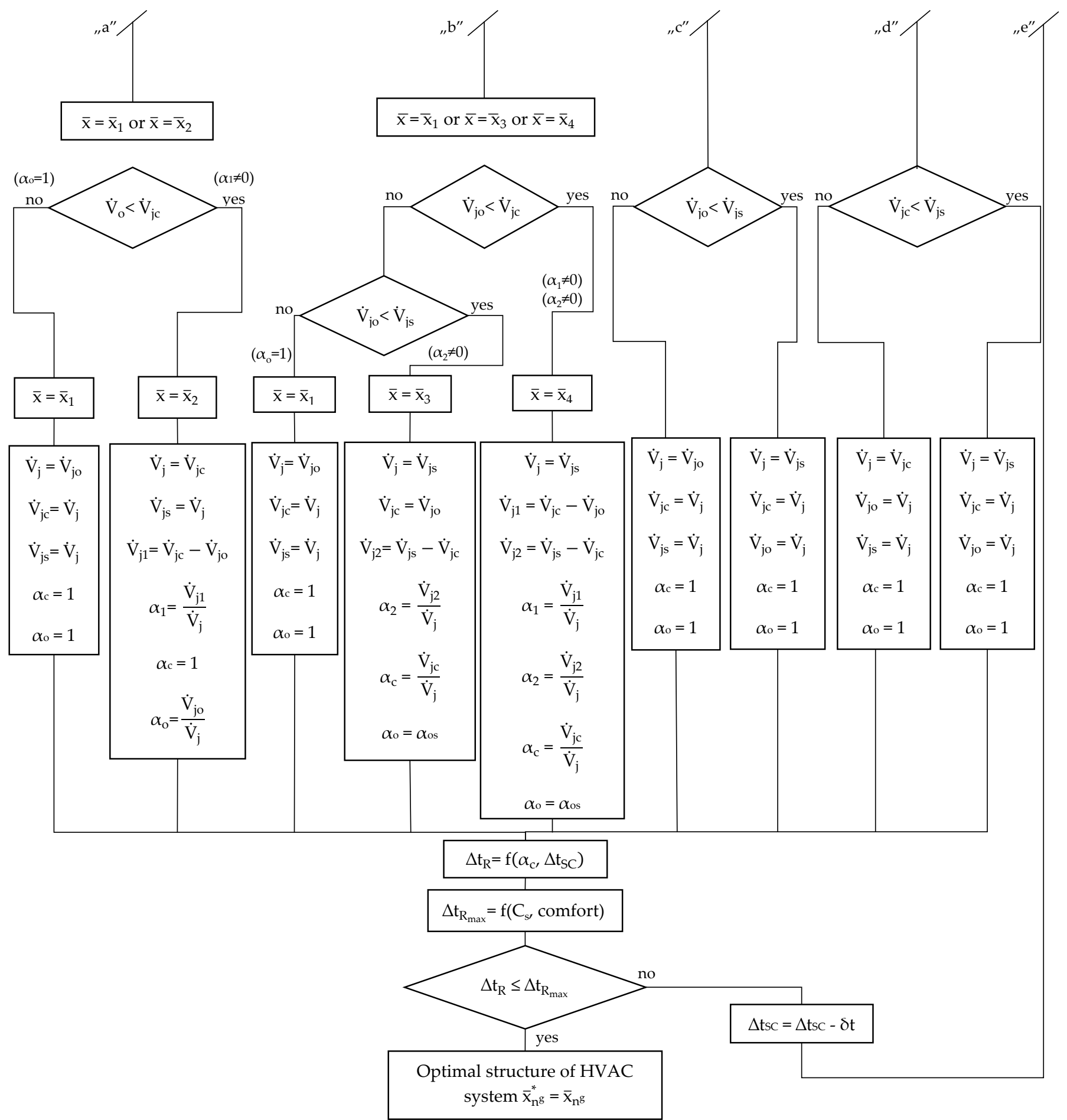

Figure 3. Calculation algorithm of the optimal structure of the HVAC system.

- $\quad \dot{\mathrm{V}}_{\mathrm{jo}}=\mathrm{f}\left(\mathrm{kd}, \Delta \mathrm{p}, \dot{\mathrm{V}}_{\mathrm{jle}}\right)$ - unit outdoor air stream as a function of hygiene requirements (the concentration of pollutants- $k_{d}$ ), overpressure $(\Delta p)$ or compensation of exhaust air from local exhausts $\left(\dot{\mathrm{V}}_{\mathrm{jle}}\right)$;

- $\quad \dot{\mathrm{V}}_{\mathrm{js}}=\mathrm{f}\left(\mathrm{C}_{\mathrm{s}}\right)$ - unit air stream as a function of the room cleanliness class;

- $\quad \dot{\mathrm{V}}_{\mathrm{jc}}=\dot{\mathrm{V}}_{\mathrm{jc}_{\text {min }}}=\mathrm{f}\left(\dot{\mathrm{q}}_{\mathrm{j}}\right)$-unit air stream as a function of the cooling loads discharged using AHU. 
In case recirculation is not allowed, the only system acceptable is $\bar{x}_{1}$; if allowed, all systems are possible: $\overline{\mathrm{x}}_{1}, \overline{\mathrm{x}}_{2}, \overline{\mathrm{x}}_{3}$ and $\overline{\mathrm{x}}_{4}$.

Unit stream of outdoor air $\dot{\mathrm{V}}_{\mathrm{jo}}$, depending on the conditions, is within the range corresponding to the percentage of outdoor air $\alpha_{0}=5 \div 100 \%$.

Unit air stream as a function of the cleanliness class $\dot{\mathrm{V}}_{\mathrm{js}}$ is calculated based on the average air speed from the range $\left(\mathrm{w}_{\min }, \mathrm{w}_{\max }\right)$ required for a specific room cleanliness class according to ASHRAE [39]. Unit air stream for discharging cooling loads using AHU is calculated-taking into consideration the designations in Figure 4-using relation:

$$
\dot{\mathrm{V}}_{\mathrm{jc}}=\frac{\dot{\mathrm{q}}_{\mathrm{jc}}}{\rho c_{\mathrm{p}} \Delta \mathrm{t}_{\mathrm{SC}}},
$$

whereby:

$$
\dot{\mathrm{q}}_{\mathrm{jc}}=\mathrm{q}_{\mathrm{j}}-\mathrm{q}_{\mathrm{j} D C}
$$

with:

qj-unit cooling loads;

$\mathrm{q}_{\mathrm{jc}}$ - unit cooling load discharged using AHU;

$\mathrm{q}_{\mathrm{j} D C}$ - unit cooling load discharged by dry coolers in the recirculation circuit (DCC, RDCU and RCU).

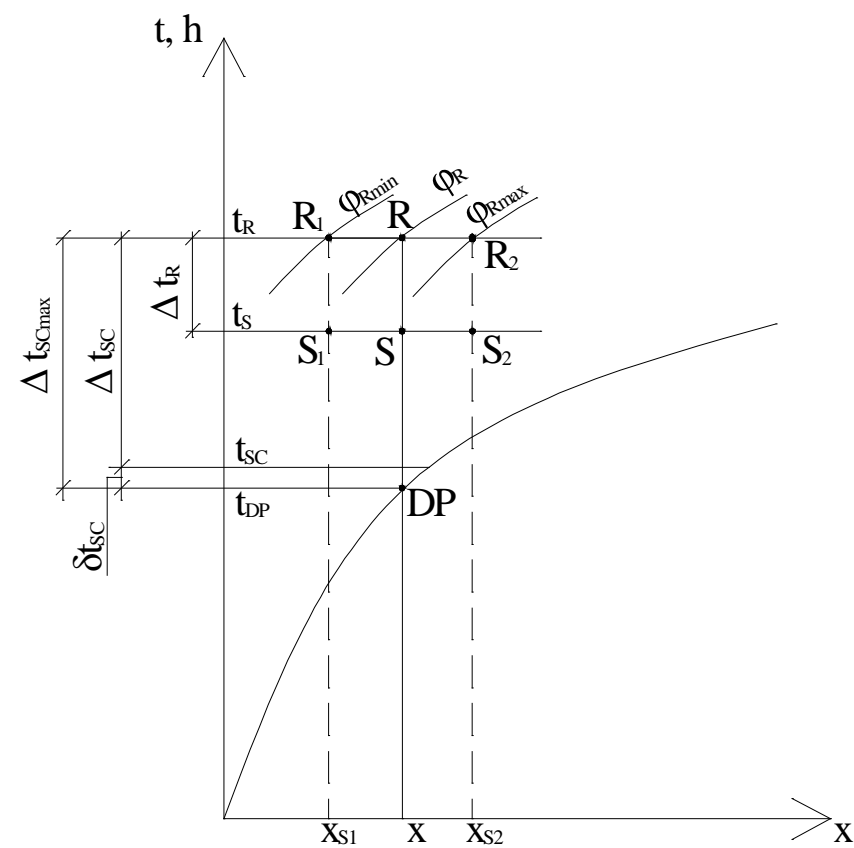

Figure 4. Isotherms characteristic for calculating the $\dot{\mathrm{V}}_{\mathrm{jc}}(\mathrm{AHU})$ air stream.

In a specific case, when $\dot{\mathrm{q}}_{\mathrm{j} \mathrm{DC}}=0$

$$
\dot{\mathrm{q}}_{\mathrm{jc}}=\dot{\mathrm{q}}_{\mathrm{j}}
$$

In the first step, requirement $\dot{V}_{j c}=\min$ (corresponding to the minimum energy consumption) implies relation:

$$
\Delta \mathrm{t}_{\mathrm{SC}}=\Delta \mathrm{t}_{\mathrm{SCmax}}-\delta \mathrm{t}_{\mathrm{SC}}=\left(\mathrm{t}_{\mathrm{R}}-\mathrm{t}_{\mathrm{DP}}\right)-\delta \mathrm{t}_{\mathrm{SC}}
$$

which means that

$$
\mathrm{t}_{\mathrm{SC}}=\mathrm{t}_{\mathrm{SCmin}}=\mathrm{t}_{\mathrm{DP}}+\delta \mathrm{t}_{\mathrm{SC}}
$$

where: 
$\delta t_{S C}$-realistic tolerance range with temperature $t_{S C}$ in relation to temperature $t_{D P}$, $\delta \mathrm{t}_{\mathrm{SC}}=(0 \div 1){ }^{\circ} \mathrm{C}$

$t_{\mathrm{DP}}$ - dew point temperature.

In the physical interpretation, this requirement means that the minimum air flow to dissipate cooling loads $\dot{V}_{\mathrm{jc}}$ is determined assuming the maximum possible temperature difference $\Delta \mathrm{t}_{\mathrm{SC}}$ between the air in the room and the supply air. In turn, the minimum supply air temperature $t_{\mathrm{SCmin}}$ is theoretically equal to the dew point temperature $t_{\mathrm{DP}}$; in practice, it should be slightly higher (here, the real tolerance range $\delta t_{S C}$ was adopted).

Then, on the basis of the values of air flows $\dot{\mathrm{V}}_{\mathrm{js}}, \dot{\mathrm{V}}_{\mathrm{jc}}$ and $\dot{\mathrm{V}}_{\mathrm{jo}}$, which are comparative terms, the algorithm determines the optimal structure of the HVAC system $\bar{x}_{1}, \bar{x}_{2}, \bar{x}_{3}$ or $\bar{x}_{4}$, and the resulting temperature difference $\Delta t_{R}$ and the supply temperature $t_{s}$ are calculated according to the relations:

- $\quad$ system $\bar{x}_{1}\left(\alpha_{1}=0, \alpha_{2}=0, \alpha_{c}=1\right)$ :

$$
\begin{aligned}
\Delta t_{\mathrm{R}} & =\Delta \mathrm{t}_{\mathrm{SC}} \\
\mathrm{t}_{\mathrm{S}} & =\mathrm{t}_{\mathrm{SC}}
\end{aligned}
$$

- $\quad$ system $\bar{x}_{2}\left(\alpha_{1} \neq 0, \alpha_{2}=0, \alpha_{c}=1\right)$ :

$$
\begin{aligned}
\Delta t_{\mathrm{R}} & =\Delta \mathrm{t}_{\mathrm{SC}} \\
\mathrm{t}_{\mathrm{S}} & =\mathrm{t}_{\mathrm{SC}}
\end{aligned}
$$

- $\quad \operatorname{system} \bar{x}_{3}\left(\alpha_{1}=0, \alpha_{2} \neq 0, \alpha_{c} \neq 0\right)$ :

$$
\begin{gathered}
\Delta \mathrm{t}_{\mathrm{R}}=\alpha_{\mathrm{C}} \cdot \Delta \mathrm{t}_{\mathrm{SC}}=\left(1-\alpha_{2}\right) \cdot \Delta \mathrm{t}_{\mathrm{SC}} \\
\mathrm{t}_{\mathrm{S}}=\alpha_{\mathrm{c}} \cdot \mathrm{t}_{\mathrm{SC}}+\left(1-\alpha_{\mathrm{c}}\right) \mathrm{t}_{\mathrm{R}} \\
\mathrm{t}_{\mathrm{SC}}=\frac{1}{\alpha_{\mathrm{c}}} \cdot \mathrm{t}_{\mathrm{S}}+\left(1-\frac{1}{\alpha_{\mathrm{c}}}\right) \cdot \mathrm{t}_{\mathrm{R}}
\end{gathered}
$$

- $\quad$ system $\bar{x}_{4}\left(\alpha_{1} \neq 0, \alpha_{2} \neq 0, \alpha_{c} \neq 0\right)$ :

$$
\begin{gathered}
\Delta \mathrm{t}_{\mathrm{R}}=\alpha_{\mathrm{C}} \cdot \Delta \mathrm{t}_{\mathrm{SC}}=\left(1-\alpha_{2}\right) \Delta \mathrm{t}_{\mathrm{SC}} \\
\mathrm{t}_{\mathrm{S}}=\alpha_{\mathrm{c}} \cdot \mathrm{t}_{\mathrm{SC}}+\left(1-\alpha_{\mathrm{C}}\right) \mathrm{t}_{\mathrm{R}} \\
\mathrm{t}_{\mathrm{SC}}=\frac{1}{\alpha_{\mathrm{c}}} \cdot \mathrm{t}_{\mathrm{S}}+\left(1-\frac{1}{\alpha_{\mathrm{c}}}\right) \cdot \mathrm{t}_{\mathrm{R}}
\end{gathered}
$$

whereby:

$$
\alpha_{c}=1-\alpha_{2}=\alpha_{o}+\alpha_{1}
$$

In the next step, a significant limitation is the relationship resulting from the air distribution system required in the room:

$$
\Delta \mathrm{t}_{\mathrm{R}} \leq \Delta \mathrm{t}_{\mathrm{SC}}
$$

indirectly related to relation:

$$
t_{S C} \leq t_{S}
$$

and a comparative section:

$$
\Delta \mathrm{t}_{\mathrm{R}} \leq \Delta \mathrm{t}_{\mathrm{Rmax}}
$$

It should be noted that the maximum value of the temperature difference

$$
\Delta \mathrm{t}_{\mathrm{Rmax}}=\mathrm{t}_{\mathrm{R}}-\mathrm{t}_{\mathrm{Smin}}
$$

is the result of comfort limitations (air supply system) and, indirectly, of the room cleanliness class. 
At this stage, it may turn out that the determined temperature difference $\Delta \mathrm{t}_{\mathrm{SC}}$, which corresponds to the air stream $\dot{V}_{\mathrm{jc}}=\mathrm{min}$, is greater than the permissible temperature difference $\Delta t_{R \max }$ for comfort or technological reasons. In such a case, the algorithm assumes a decrease in the value of the temperature difference $\Delta \mathrm{t}_{\mathrm{SC}}$ according to the relation:

$$
\Delta \mathrm{t}_{\mathrm{SC}} \equiv \Delta \mathrm{t}_{\mathrm{SC}}-\delta \mathrm{t}
$$

with:

$\delta \mathrm{t}=(0.5 \div 1.0){ }^{\circ} \mathrm{C}$-iterative temperature jump, and the procedure is repeated.

Based on the algorithm (Figure 3), the optimal variants of the HVAC system structure of cleanrooms were determined as a function of the relationship between the streams $\dot{\mathrm{V}}_{\mathrm{js}}$, $\dot{\mathrm{V}}_{\mathrm{jc}}$ and $\dot{\mathrm{V}}_{\mathrm{jo}}$; these variants are summarized in Table 1 .

Table 1. Optimal variants of the HVAC structure $\bar{x}_{n g}^{*}$ of clean air as a function of the relation of streams $\dot{\mathrm{V}}_{\mathrm{js}}, \dot{\mathrm{V}}_{\mathrm{jc}}$ and $\dot{\mathrm{V}}_{\mathrm{jo}}$.

\begin{tabular}{ccc}
\hline $\begin{array}{c}\text { Optimal Variant of the HVAC Structure } \\
\overline{\mathrm{x}}_{\mathrm{ns}}^{*}\end{array}$ & Relations: $\dot{\mathrm{V}}_{\mathrm{js}}, \dot{\mathrm{V}}_{\mathrm{jc}}$ and $\dot{\mathrm{V}}_{\mathrm{jo}}$ & Air Streams \\
\hline$\overline{\mathrm{x}}_{1}$ & $\alpha_{\mathrm{o}}=1 \mathrm{i} \alpha_{1}=0 \mathrm{i} \alpha_{2}=0$ & $\dot{\mathrm{V}}_{\mathrm{j}}=\dot{\mathrm{V}}_{\mathrm{jo}}$ \\
& $\dot{\mathrm{V}}_{\mathrm{jo}} \geq \dot{\mathrm{V}}_{\mathrm{js}}, \dot{\mathrm{V}}_{\mathrm{jo}} \geq \dot{\mathrm{V}}_{\mathrm{jc}}$ & $\dot{\mathrm{V}}_{\mathrm{jc}}=\dot{\mathrm{V}}_{\mathrm{j}}$ \\
$\overline{\mathrm{x}}_{2}$ & $\dot{\mathrm{V}}_{\mathrm{jo}}<\dot{\mathrm{V}}_{\mathrm{jc}}, \dot{\mathrm{V}}_{\mathrm{jc}} \geq \dot{\mathrm{V}}_{\mathrm{js}}$ & $\dot{\mathrm{V}}_{\mathrm{j}}=\dot{\mathrm{V}}_{\mathrm{jc}}$ \\
& $\dot{\mathrm{V}}_{\mathrm{js}}=\dot{\mathrm{V}}_{\mathrm{j}}$ \\
$\overline{\mathrm{x}}_{3}$ & $\dot{\mathrm{V}}_{\mathrm{jo}}<\dot{\mathrm{V}}_{\mathrm{js}}, \dot{\mathrm{V}}_{\mathrm{jo}} \geq \dot{\mathrm{V}}_{\mathrm{jc}}, \dot{\mathrm{V}}_{\mathrm{jc}}<\dot{\mathrm{V}}_{\mathrm{js}}$ & $\dot{\mathrm{V}}_{\mathrm{j}}=\dot{\mathrm{V}}_{\mathrm{js}}$ \\
$\overline{\mathrm{x}}_{4}$ & $\dot{\mathrm{V}}_{\mathrm{jc}}<\dot{\mathrm{V}}_{\mathrm{jo}}, \dot{\mathrm{V}}_{\mathrm{jc}}<\dot{\mathrm{V}}_{\mathrm{js}}$ & $\dot{\mathrm{V}}_{\mathrm{j}}=\dot{\mathrm{V}}_{\mathrm{js}}$ \\
\hline
\end{tabular}

\subsection{Optimal Structure Selection Algorithm}

By analyzing realistic required ranges of variability of the key constant parameters in applications for cleanrooms, the following conclusions can be made:

- dry bulb temperature changes in a narrow range of $+21 \div+23{ }^{\circ} \mathrm{C}$; on average, $\mathrm{t}_{\mathrm{R}}=+22^{\circ} \mathrm{C}$;

- relative humidity usually changes in the range of $(50 \pm 5) \%$ (sometimes, the range is wider);

- $\quad$ the most common cleanliness classes are ISO5 classes (M3.5—cl. 100), ISO7 (M5.5—cl. 10,000) and ISO8 (M6.5-cl. 100,000) [39];

- unit cooling loads are $\mathrm{q}_{\mathrm{j}}=(100 \div 500) \mathrm{W} / \mathrm{m}^{2}[40]$;

- the required percentage of outdoor air is $\alpha_{0}=(5 \div 100) \%$.

Therefore, further analyses include variants of combinations of key constant parameters of a HVAC system, in which each constant parameter takes values representing the mentioned variability ranges.

\subsection{Approximating Functions}

Optimal structures of the HVAC system for cleanrooms are calculated based on the algorithm in Figure 3 for representative variants of combinations of key constant parameters: cleanliness class $C_{s}$, unit cooling load $q_{j}\left(q_{j}=q_{j c}\right)$ and percentage of outdoor air $\alpha_{o}$ are shown in Table 2. The analyses were performed with the temperature of $t_{R}=+22{ }^{\circ} \mathrm{C}$ and relative humidity $\varphi_{R}=(50 \pm 5) \%$. 
Table 2. Optimal structures of the HVAC system for cleanrooms $\overline{\mathrm{x}}_{\mathrm{n} \text { g }}^{*}$.

\begin{tabular}{|c|c|c|c|c|c|c|c|c|c|c|c|c|}
\hline \multirow[b]{2}{*}{$\begin{array}{l}\text { Variant of } \\
\text { Constant } \\
\text { Parameters }\end{array}$} & \multirow[b]{2}{*}{$\begin{array}{l}\text { Cleanliness Class } \\
\text { ISO(US.FSd.209e) }\end{array}$} & \multirow[b]{2}{*}{$\begin{array}{c}\mathrm{q}_{\mathrm{j}}{ }^{/ 6} \\
\mathrm{~W} / \mathrm{m}^{2}\end{array}$} & \multirow[b]{2}{*}{$\underset{\%}{\alpha_{\mathrm{os}} / 4}$} & \multirow[b]{2}{*}{$\begin{array}{c}\dot{\mathrm{V}}_{\mathrm{js}} \\
\mathrm{m}^{3} / \mathrm{hm}^{2}\end{array}$} & \multirow[b]{2}{*}{$\begin{array}{c}\dot{\mathrm{V}}_{\mathrm{jo}} \\
\mathrm{m}^{3} / \mathrm{hm}^{2}\end{array}$} & \multirow[b]{2}{*}{$\begin{array}{c}\dot{\mathbf{V}}_{\mathrm{js}} / 7 \\
\mathrm{~m}^{3} / \mathrm{hm}^{2}\end{array}$} & \multicolumn{6}{|c|}{ Optimal Structure of HVAC System } \\
\hline & & & & & & & $\overline{\mathbf{x}}_{\mathrm{n} g}$ & $\begin{array}{c}\dot{V}_{j} \\
\mathbf{m}^{3} / \mathbf{h m}^{2}\end{array}$ & $\underset{\%}{\alpha_{0} / 5}$ & $\begin{array}{l}\alpha_{\mathrm{c}} \\
\%\end{array}$ & $\begin{array}{l}\alpha_{1} \\
\%\end{array}$ & $\begin{array}{l}\alpha_{2} \\
\%\end{array}$ \\
\hline 1.1.1 & \multirow{15}{*}{$\begin{array}{l}\text { ISO Class } 5^{1 /} \\
\text { (M3.5-cl. 100) }\end{array}$} & \multirow{5}{*}{100} & 5 & 900 & 45 & 27.1 & $\bar{x}_{3}$ & 900 & 5 & 5 & - & 95 \\
\hline 1.1 .2 & & & 10 & 900 & 90 & 27.1 & $\overline{\mathrm{x}}_{3}$ & 900 & 10 & 10 & - & 90 \\
\hline 1.1.3 & & & 30 & 900 & 270 & 27.1 & $\overline{\mathrm{x}}_{3}$ & 900 & 30 & 30 & - & 70 \\
\hline 1.1.4 & & & 50 & 900 & 450 & 27.1 & $\overline{\mathrm{x}}_{3}$ & 900 & 50 & 50 & - & 50 \\
\hline 1.1.5 & & & 100 & 900 & 900 & 27.1 & $\overline{\mathrm{x}}_{1}$ & 900 & 100 & 100 & - & - \\
\hline 1.2 .1 & & \multirow{5}{*}{300} & 5 & 900 & 45 & 81.4 & $\overline{\mathrm{x}}_{4}$ & 900 & 5 & 9 & 4 & 91 \\
\hline 1.2 .2 & & & 10 & 900 & 90 & 81.4 & $\bar{x}_{3}$ & 900 & 10 & 10 & - & 90 \\
\hline 1.2 .3 & & & 30 & 900 & 270 & 81.4 & $\bar{x}_{3}$ & 900 & 30 & 30 & - & 70 \\
\hline 1.2 .4 & & & 50 & 900 & 450 & 81.4 & $\bar{x}_{3}$ & 900 & 50 & 50 & - & 50 \\
\hline 1.2 .5 & & & 100 & 900 & 900 & 81.4 & $\overline{\mathrm{x}}_{1}$ & 900 & 100 & 100 & - & - \\
\hline 1.3 .1 & & \multirow{5}{*}{500} & 5 & 900 & 45 & 135.7 & $\bar{x}_{4}$ & 900 & 5 & 15 & 10 & 85 \\
\hline 1.3 .2 & & & 10 & 900 & 90 & 135.7 & $\overline{\mathrm{x}}_{4}$ & 900 & 10 & 15 & 5 & 85 \\
\hline 1.3.3 & & & 30 & 900 & 270 & 135.7 & $\bar{x}_{3}$ & 900 & 30 & 30 & - & 70 \\
\hline 1.3 .4 & & & 50 & 900 & 450 & 135.7 & $\bar{x}_{3}$ & 900 & 50 & 50 & - & 50 \\
\hline 1.3 .5 & & & 100 & 900 & 900 & 135.7 & $\bar{x}_{1}$ & 900 & 100 & 100 & - & - \\
\hline 2.1.1 & \multirow{15}{*}{$\begin{array}{l}\text { ISO Class } 7{ }^{2 /} \\
\text { (M5.5-cl.10 000) }\end{array}$} & \multirow{5}{*}{100} & 5 & 216 & 10.8 & 27.1 & $\overline{\mathrm{x}}_{4}$ & 216 & 5 & 12.5 & 7.5 & 87.5 \\
\hline 2.1 .2 & & & 10 & 216 & 21.6 & 27.1 & $\overline{\mathrm{x}}_{4}$ & 216 & 10 & 12.5 & 2.5 & 87.5 \\
\hline 2.1 .3 & & & 30 & 216 & 64.8 & 27.1 & $\bar{x}_{3}$ & 216 & 30 & 30 & - & 70 \\
\hline 2.1 .4 & & & 50 & 216 & 108 & 27.1 & $\overline{\mathrm{x}}_{3}$ & 216 & 50 & 50 & - & 50 \\
\hline 2.1 .5 & & & 100 & 216 & 216 & 27.1 & $\bar{x}_{1}$ & 216 & 100 & 100 & - & - \\
\hline 2.2 .1 & & \multirow{5}{*}{300} & 5 & 216 & 10.8 & 81.4 & $\overline{\mathrm{x}}_{4}$ & 216 & 5 & 37.7 & 32.7 & 62.3 \\
\hline 2.2 .2 & & & 10 & 216 & 21.6 & 81.4 & $\overline{\mathrm{x}}_{4}$ & 216 & 10 & 37.7 & 27.7 & 62.3 \\
\hline 2.2 .3 & & & 30 & 216 & 64.8 & 81.4 & $\overline{\mathrm{x}}_{4}$ & 216 & 30 & 37.7 & 7.7 & 62.3 \\
\hline 2.2 .4 & & & 50 & 216 & 108 & 81.4 & $\bar{x}_{3}$ & 216 & 50 & 50 & - & 50 \\
\hline 2.2 .5 & & & 100 & 216 & 216 & 81.4 & $\bar{x}_{1}$ & 216 & 100 & 100 & - & - \\
\hline 2.3 .1 & & \multirow{5}{*}{500} & 5 & 216 & 10.8 & 135.7 & $\bar{x}_{4}$ & 216 & 5 & 62.8 & 57.8 & 37.2 \\
\hline 2.3 .2 & & & 10 & 216 & 21.6 & 135.7 & $\bar{x}_{4}$ & 216 & 10 & 62.8 & 52.8 & 37.2 \\
\hline 2.3 .3 & & & 30 & 216 & 64.8 & 135.7 & $\overline{\mathrm{x}}_{4}$ & 216 & 30 & 62.8 & 32.8 & 37.2 \\
\hline 2.3 .4 & & & 50 & 216 & 108 & 135.7 & $\bar{x}_{4}$ & 216 & 50 & 62.8 & 12.8 & 37.2 \\
\hline 2.3 .5 & & & 100 & 216 & 216 & 135.7 & $\bar{x}_{1}$ & 216 & 100 & 100 & - & - \\
\hline 3.1.1 & \multirow{15}{*}{$\begin{array}{c}\text { ISO Class } 8^{3 /} \\
(\mathrm{M} 6.5-\mathrm{cl} .100000)\end{array}$} & \multirow{5}{*}{100} & 5 & 90 & 4.5 & 27.1 & $\overline{\mathrm{x}}_{4}$ & 90 & 5 & 30 & 25 & 70 \\
\hline 3.1 .2 & & & 10 & 90 & 9 & 27.1 & $\bar{x}_{4}$ & 90 & 10 & 30 & 20 & 70 \\
\hline 3.1 .3 & & & 30 & 90 & 27 & 27.1 & $\bar{x}_{3}$ & 90 & 30 & 30 & - & 70 \\
\hline 3.1 .4 & & & 50 & 90 & 45 & 27.1 & $\bar{x}_{3}$ & 90 & 50 & 50 & - & 50 \\
\hline 3.1 .5 & & & 100 & 90 & 90 & 27.1 & $\bar{x}_{1}$ & 90 & 100 & 100 & - & - \\
\hline 3.2 .1 & & \multirow{5}{*}{300} & 5 & 90 & 4.5 & 81.4 & $\overline{\mathrm{x}}_{4}$ & 90 & 5 & 90 & 85 & 10 \\
\hline 3.2 .2 & & & 10 & 90 & 9 & 81.4 & $\overline{\mathrm{x}}_{4}$ & 90 & 10 & 90 & 80 & 10 \\
\hline 3.2 .3 & & & 30 & 90 & 27 & 81.4 & $\bar{x}_{4}$ & 90 & 30 & 90 & 60 & 10 \\
\hline 3.2 .4 & & & 50 & 90 & 45 & 81.4 & $\overline{\mathrm{x}}_{4}$ & 90 & 50 & 90 & 40 & 10 \\
\hline 3.2 .5 & & & 100 & 90 & 90 & 81.4 & $\bar{x}_{1}$ & 90 & 100 & 100 & - & - \\
\hline 3.3 .1 & & & 5 & 90 & 4.5 & 135.7 & $\bar{x}_{2}$ & 135.7 & 3.3 & 100 & 96.7 & - \\
\hline 3.3 .2 & & & 10 & 90 & 9 & 135.7 & $\bar{x}_{2}$ & 135.7 & 6.6 & 100 & 93.4 & - \\
\hline 3.3 .3 & & 500 & 30 & 90 & 27 & 135.7 & $\bar{x}_{2}$ & 135.7 & 19.9 & 100 & 80.1 & - \\
\hline 3.3.4 & & & 50 & 90 & 45 & 135.7 & $\bar{x}_{2}$ & 135.7 & 33.2 & 100 & 66.8 & - \\
\hline 3.3 .5 & & & 100 & 90 & 90 & 135.7 & $\overline{\mathrm{x}}_{1}$ & 135.7 & 100 & 100 & - & - \\
\hline
\end{tabular}

$1 / \mathrm{w}=0.25 \mathrm{~m} / \mathrm{s}(3001 / \mathrm{h}, \mathrm{H}=3 \mathrm{~m}),{ }^{2 /} \mathrm{w}=0.06 \mathrm{~m} / \mathrm{s}(721 / \mathrm{h}, \mathrm{H}=3 \mathrm{~m}),{ }^{3 /} \mathrm{w}=0.025 \mathrm{~m} / \mathrm{s}(301 / \mathrm{h}, \mathrm{H}=3 \mathrm{~m})[39]$ 
The unit air stream $\dot{V}_{j \mathrm{~s}}$ as a function of the cleanliness class $\mathrm{C}_{\mathrm{s}}$ was determined by assuming the average air velocities from the compartments assigned to the ASHRAE cleanliness classes [39].

For cleanliness classes with optimal structures of the HVAC system $\bar{x}_{3}$ or $\bar{x}_{4}$ based on the results in Table 2, limit percentages of the outdoor air $\alpha_{\text {og }}$ were calculated (equal to the percentages of air of an AHU for discharging cooling loads). Value $\alpha_{\text {og }}$ is calculated using:

$$
\alpha_{\mathrm{og}}=\frac{\dot{\mathrm{V}}_{\mathrm{jc}}}{\dot{\mathrm{V}}_{\mathrm{js}}}
$$

These values represent the selection criterion of the optimal structure of the HVAC system according to relation:

$$
\begin{aligned}
& \alpha_{\mathrm{o}} \geq \alpha_{\text {og optimal structure }} \overline{\mathrm{x}}_{3} \\
& \alpha_{\mathrm{o}}<\alpha_{\text {og optimal structure }} \overline{\mathrm{x}}_{4}
\end{aligned}
$$

For cleanliness classes that include the optimal HVAC structures $\bar{x}_{2}, \bar{x}_{3}$ and $\bar{x}_{4}$ (here, ISO Class 8) -based on the results in Table 2-an additional limit unit cooling load $\dot{\mathrm{q}}_{\mathrm{jg}}$ was calculated using relation:

$$
\dot{\mathrm{q}}_{\mathrm{jg}}=\dot{\mathrm{V}}_{\mathrm{js}} \rho \mathrm{c}_{\mathrm{p}} \Delta \mathrm{tSC} \mathrm{C}_{\max }
$$

In the physical interpretation, parameter $\dot{\mathrm{q}}_{\mathrm{jg}}$ is the maximum cooling load that can be discharged by the air flow $\dot{\mathrm{V}}_{\mathrm{jc}}=\dot{\mathrm{V}}_{\mathrm{js}}$ resulting from the room cleanliness class.

Values $\dot{q}_{j g}$ represent the selection criteria of the optimal structure of the HVAC system according to relation:

$$
\begin{gathered}
\dot{\mathrm{q}}_{\mathrm{j}} \geq \dot{\mathrm{q}}_{\mathrm{jg}} \text { optimal structure } \overline{\mathrm{x}}_{2} \\
\dot{\mathrm{q}}_{\mathrm{j}}<\dot{\mathrm{q}}_{\mathrm{jg}} \text { optimal structure } \overline{\mathrm{x}}_{3} \text { or } \overline{\mathrm{x}}_{4}
\end{gathered}
$$

\begin{tabular}{|c|c|c|c|c|c|}
\hline $\begin{array}{c}\text { Cleanliness Class ISO 14644-1 } \\
\text { (USFStd 209e) }\end{array}$ & $\underset{\mathrm{W} / \mathrm{m}^{2}}{\dot{\mathrm{q}}_{\mathrm{j}}}$ & $\begin{array}{c}\dot{V}_{j s} \\
\mathbf{m}^{3} / \mathbf{h m}^{2}\end{array}$ & $\begin{array}{c}\dot{V}_{j \mathrm{c}} \\
\mathrm{m}^{3} / \mathrm{hm}^{2}\end{array}$ & $\begin{array}{c}\alpha_{\mathrm{og}} \\
\%\end{array}$ & $\underset{\mathrm{W} / \mathrm{m}^{2}}{\dot{\mathrm{q}}_{\mathrm{jg}}}$ \\
\hline \multirow{3}{*}{$\begin{array}{l}\text { ISO Class } 5 \\
\text { (M 3.5-cl. 100) }\end{array}$} & 100 & \multirow{3}{*}{900} & 27.1 & 3 & \multirow{3}{*}{$3300 * /$} \\
\hline & 300 & & 81.4 & 9 & \\
\hline & 500 & & 135.7 & 15 & \\
\hline \multirow{3}{*}{$\begin{array}{l}\text { ISO Class } 7 \\
\text { (M 5.5—cl. 10,000) }\end{array}$} & 100 & \multirow{3}{*}{216} & 27.1 & 12.5 & \multirow{3}{*}{$796 * 1$} \\
\hline & 300 & & 81.4 & 37.7 & \\
\hline & 500 & & 135.7 & 62.8 & \\
\hline \multirow{3}{*}{$\begin{array}{c}\text { ISO Class } 8 \\
\text { (M 6.5-cl. 100,000) }\end{array}$} & 100 & \multirow{3}{*}{90} & 27.1 & 30 & \multirow{3}{*}{332} \\
\hline & 300 & & 81.4 & 90 & \\
\hline & 500 & & 135.7 & $-* * 1$ & \\
\hline
\end{tabular}

The parameter calculation results $\alpha_{\mathrm{og}}$ and $\dot{\mathrm{q}}_{\mathrm{jg}}$ are shown in Table 3.

Table 3. Limit percentages of the outdoor air $\alpha_{o g}$ and limit unit cooling load $\dot{\mathrm{q}}_{\mathrm{j}}$ for optimal structures of the HVAC system.

*/ in applications $\dot{\mathrm{q}}_{\mathrm{j}}<\dot{\mathrm{q}}_{\mathrm{j}{ }^{\prime}} * * /$ is not calculated, because the optimal structure of the HVAC system is $\overline{\mathrm{x}}_{2}\left(\dot{\mathrm{V}}_{\mathrm{j}}=\dot{\mathrm{V}}_{\mathrm{jk}}\right)$.

Based on the calculation results presented in Tables 2 and 3, the authors calculated the approximating functions in the form of diagrams illustrating zones of optimal structures of the HVAC system for cleanrooms.

These functions, in coordinate system $\bar{x}_{n g}^{*}=f\left(C_{S}, \alpha_{0}, q_{j}\right)$ for cleanliness classes ISO Class 5, ISO Class 7 and ISO Class 8, are shown in Figure 5. 


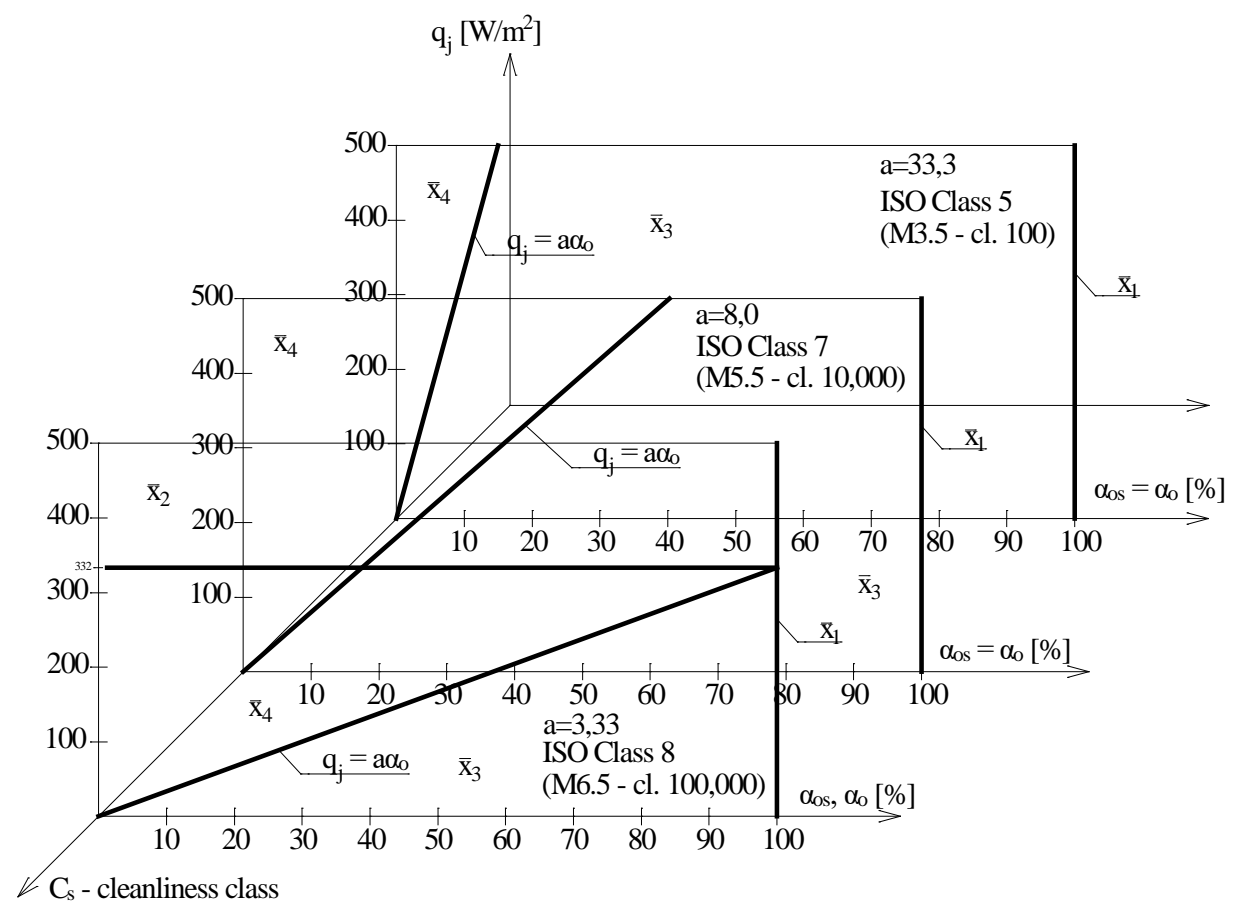

Figure 5. The function $\bar{x}_{n g}^{*}=f\left(C_{S}, \alpha_{0}, q_{j}\right)$ of the zone of optimal structures of the HVAC system for cleanrooms ISO Class 5 (M3.5-cl. 100), ISO Class 7 (M5.5-cl. 10,000) and ISO Class 8 (M6.5-cl. 100,000).

Directional coefficients of limit lines equations between zones of the optimal structures $\bar{x}_{3}$ and $\bar{x}_{4}$ in Figure 5 were calculated based on the data in Table 3 and relation:

$$
\mathrm{a}=\frac{\Delta \dot{\mathrm{q}}_{\mathrm{j}}}{\Delta \alpha_{\mathrm{og}}}
$$

$\Delta \dot{\mathrm{q}}_{\mathrm{j}}$-difference in values of the unit cooling loads in Table 3;

$\Delta \alpha_{\mathrm{og}}$-difference of the limit value of the percentage of outdoor air in Table 3 assigned to a defined difference $\Delta \dot{q}_{j}$.

Based on calculation results (Tables 2 and 3) illustrated by the approximating functions $\bar{x}_{n g}^{*}=f\left(C_{S}, \alpha_{0}, q_{j}\right)$ in Figure 5 , the following conclusions can be made:

1. The dominant optimal structures of HVAC system for cleanrooms with acceptable recirculation are systems with internal recirculation $\bar{x}_{3}$ and systems with internal and external recirculation $\bar{x}_{4}$.

2. Directional coefficients of the limit lines $\dot{q}_{j}=a \alpha_{0}$ dividing zones of optimal structures of the HVAC system HVAC $\bar{x}_{3}$ and $\bar{x}_{4}$ are inversely proportional to the cleanliness classes of rooms and equal:

- $\quad \mathrm{a}=33.3$-for ISO Class 5 (M3.5-cl.100);

- $\quad \mathrm{a}=8.0$-for ISO Class 7 (M5.5-cl.10,000);

- $\mathrm{a}=3.33$-for ISO Class 8 (M6.5-cl.100,000),

3. Systems with internal recirculation $\bar{x}_{3}$ are optimal HVAC system structures for rooms with low cooling loads $\dot{\mathrm{q}}_{j}$ and relatively high percentages of outdoor air $\alpha_{0}$.

4. Systems with internal and external recirculation $\bar{x}_{4}$ are optimal HVAC system structures for rooms with high cooling loads $\dot{q}_{j}$ and relatively low percentages of outdoor air $\alpha_{0}$.

5. Systems with external recirculation $\bar{x}_{2}$ are optimal HVAC system structures for rooms with high cooling loads $\dot{\mathrm{q}}_{j}$ and low requirements regarding cleanliness of high cleanli- 
ness classes. The limit line in system $\dot{\mathrm{q}}_{\mathrm{j}}=\mathrm{f}\left(\alpha_{\mathrm{o}}\right)$ between the zone of optimal structures $\overline{\mathrm{x}}_{2}$ and $\overline{\mathrm{x}}_{3}$ or $\overline{\mathrm{x}}_{2}$ and $\overline{\mathrm{x}}_{4}$ is ordinate $\dot{\mathrm{q}}_{\mathrm{jg}}$ (horizontal line). For cleanliness classes ISO Class 8 (M6.5-cl. 100,000) the limit unit cooling load equals $\dot{\mathrm{q}}_{\mathrm{jg}}=332 \mathrm{~W} / \mathrm{m}^{2}$. For unit cooling loads $\dot{q}_{j} \geq \dot{q}_{j g}$, the optimal structure of the HVAC system is a system with external recirculation $\overline{\mathrm{x}}_{2}$, while, for $\dot{\mathrm{q}}_{\mathrm{j}}<\dot{\mathrm{q}}_{\mathrm{jg}}$, optimal structures are systems with internal recirculation $\bar{x}_{3}$ or systems with internal and external recirculation $\bar{x}_{4}$. The limit of division of optimal zones $\bar{x}_{3}$ and $\bar{x}_{4}$ is line $\dot{q}_{j}=a \alpha_{0}$.

6. Approximating functions in the form of a graph $\bar{x}_{n g}^{*}=f\left(C_{S}, \alpha_{0}, q_{j}\right)$ with zones of optimal structures of the HVAC system for cleanrooms in Figure 5 are of great application significance at the stage of selecting and designing energy-efficient HVAC systems of such rooms. Based on cleanliness class $C_{s}$ of unit cooling loads $\dot{q}_{j}$ and the percentage of outdoor air $\alpha_{0}$, they make it possible to unambiguously calculate an energy-optimal structure of a HVAC system for a cleanroom. For "middle" cleanliness classes between ISO5 and ISO7, zones of optimal HVAC structures can be calculated using interpolation.

\section{Heat Recovery, Energy-Optimal Control}

\subsection{Objective Function, Simulation Models}

For each HVAC system with energy-optimal structure $\bar{x}_{n g}^{*}$, where heat recovery occurs as a cumulative variable, it is possible to calculate an objective function defining the quantitative optimization criterion.

Based on this criterion, the energy-optimal type of the heat recovery and energyoptimal control algorithms are determined.

The objective function defines the annual primary energy demand of the HVAC system, which is possible to calculate using relation [37]:

$$
E_{p}=\frac{w_{H}}{\eta_{H, t}} \cdot Q_{H, n}+\frac{w_{e l}}{\eta_{e l, t}} \cdot Q_{e l, n}+\frac{w_{C}}{\eta_{C, t}} \cdot Q_{C, n}+\frac{w_{B}}{\eta_{B, t}} \cdot Q_{B, n}+w_{e l} E_{e l, p o m}
$$

or

$$
\mathrm{E}_{\mathrm{p}}=\mathrm{w}_{\mathrm{H}} \mathrm{Q}_{\mathrm{K}, \mathrm{H}}+\mathrm{w}_{\mathrm{el}} \mathrm{Q}_{\mathrm{K}, \mathrm{H}_{\mathrm{el}}}+\mathrm{w}_{\mathrm{C}} \mathrm{Q}_{\mathrm{K}, \mathrm{C}}+\mathrm{w}_{\mathrm{B}} \mathrm{Q}_{\mathrm{K}, \mathrm{B}}+\mathrm{w}_{\mathrm{el}} \mathrm{E}_{\mathrm{el}, \mathrm{pom}}
$$

whereby:

$$
\begin{aligned}
\mathrm{Q}_{\mathrm{K}, \mathrm{H}} & =\frac{1}{\eta_{\mathrm{H}, \mathrm{t}}} \mathrm{Q}_{\mathrm{H}, \mathrm{n}} \\
\mathrm{Q}_{\mathrm{K}, \mathrm{H}_{\mathrm{el}}} & =\frac{1}{\eta_{\mathrm{H}_{\mathrm{el}}, \mathrm{t}}} \mathrm{Q}_{\mathrm{H}_{\mathrm{e} l}, \mathrm{n}} \\
\mathrm{Q}_{\mathrm{K}, \mathrm{C}} & =\frac{1}{\eta_{\mathrm{C}, \mathrm{t}}} \mathrm{Q}_{\mathrm{C}, \mathrm{n}} \\
\mathrm{Q}_{\mathrm{K}, \mathrm{B}} & =\frac{1}{\eta_{\mathrm{B}, \mathrm{t}}} \mathrm{Q}_{\mathrm{B}, \mathrm{n}}
\end{aligned}
$$

with:

$\mathrm{Q}_{\mathrm{H}, \mathrm{n}}\left(\mathrm{Q}_{\mathrm{Hel}, \mathrm{n}}\right)$ - annual heat demand (net) of water heaters (electric heaters), $\mathrm{kWh} / \mathrm{ym}^{2}$;

$\mathrm{Q}_{\mathrm{C}, \mathrm{n}}$-annual cold demand (net) of cooler, $\mathrm{kWh} / \mathrm{ym}^{2}$;

$\mathrm{Q}_{\mathrm{B}, \mathrm{n}}$-annual heat demand (net) of steam humidifiers, $\mathrm{kWh} / \mathrm{ym}^{2}$;

$\mathrm{Q}_{\mathrm{K}, \mathrm{H}}\left(\mathrm{Q}_{\mathrm{K}, \mathrm{Hel}}\right.$ —annual final energy demand of water heaters (electric heaters) — final heat $\mathrm{kWh} / \mathrm{ym}^{2}$;

$\mathrm{Q}_{\mathrm{K}, \mathrm{C}}$ - annual final energy demand of coolers—final cold, $\mathrm{kWh} / \mathrm{ym}^{2}$;

$\mathrm{Q}_{\mathrm{K}, \mathrm{B}}$ - annual final energy demand of steam humidifiers-final heat of humidifiers, $\mathrm{kWh} / \mathrm{ym}^{2}$;

$\mathrm{E}_{\mathrm{el}, \mathrm{pom}}$ - annual demand for final electrical energy for the drive of auxiliary devices, $\mathrm{kWh} / \mathrm{ym}^{2}$; 
$\eta_{\mathrm{H}, \mathrm{t}}$ - seasonal average total efficiency of a heating system with water air heaters, $\eta_{\mathrm{H}, \mathrm{t}}=$ $\eta_{\mathrm{H}, \mathrm{g}} \eta_{\mathrm{H}, \mathrm{s}} \eta_{\mathrm{H}, \mathrm{d}} \eta_{\mathrm{H}, \mathrm{e}}$, with $\eta_{\mathrm{H}, \mathrm{t}}=0.81\left(\eta_{\mathrm{H}, \mathrm{g}}=0.90\right.$ - generation, $\eta_{\mathrm{H}, \mathrm{s}}=1.0$-accumulation, $\eta_{\mathrm{H}, \mathrm{d}}=0.94$-distribution and $\eta_{\mathrm{H}, \mathrm{e}}=0.95$-regulation and control);

$\eta_{\mathrm{Hel}, \mathrm{t}}$ - seasonal average total efficiency of a heating system with electric heaters, with $\eta_{\mathrm{Hel}, \mathrm{t}}=0.95$

$\eta_{C, t}$-seasonal average total efficiency of a system with air coolers; $\eta_{C, t}=$ ESEER $\eta_{C, s} \eta_{C, d}$ $\eta_{C, e}$, with $\eta_{C, t}=3.0$ (ESEER $=3.5$-European Seasonal Energy Efficiency Ratio, $\eta_{\mathrm{C}, \mathrm{s}}=0.95$-accumulation, $\eta_{\mathrm{C}, \mathrm{d}}=0.94$-distribution and $\eta_{\mathrm{C}, \mathrm{e}}=0.97$-regulation and control); $\eta_{\mathrm{B}, \mathrm{t}}$ - seasonal average total efficiency of a heating system for supplying steam humidifiers, $\eta_{\mathrm{B}, \mathrm{t}}=\eta_{\mathrm{B}, \mathrm{g}} \eta_{\mathrm{B}, \mathrm{d}} \eta_{\mathrm{B}, \mathrm{e}}\left(\eta_{\mathrm{B}, \mathrm{g}}\right.$-generation, $\eta_{\mathrm{B}, \mathrm{d}}$-distribution and $\eta_{\mathrm{H}, \mathrm{e}}$-regulation and control), with $\eta_{B, t}=0.95$;

$\mathrm{w}_{\mathrm{i}}$-input coefficient of nonrenewable primary energy for generation and providing the final energy carrier (or energy) $\left(\mathrm{w}_{\mathrm{H}}\right.$ - concerns heat, $\mathrm{w}_{\mathrm{C}}$ - concerns cold, $\mathrm{w}_{\mathrm{B}}$ - concerns steam, $\mathrm{w}_{\mathrm{el}}$-concerns electrical energy) with $\mathrm{w}_{\mathrm{H}}=1.1-$ gas $/$ oil boiler, $\mathrm{w}_{\mathrm{C}}=3.0$ - chiller with electrical drive and $w_{\mathrm{B}}=3.0$-electric steam generator).

The energy demand (net) of heaters, coolers and steam humidifiers is calculated using algorithms of energy-optimal thermodynamic air treatment according to the following criterion:

$$
\mathrm{f}_{\mathrm{c}}=\sum_{\mathrm{i}=1}^{\mathrm{n}} \dot{\mathrm{m}}_{\mathrm{i}}\left|\Delta \mathrm{h}_{\mathrm{i}}\right|=\min
$$

where:

$\dot{\mathrm{m}}_{\mathrm{i}}$-mass stream in i-operation;

$\Delta \mathrm{h}_{\mathrm{i}}$-change of the specific enthalpy in i-operation.

Tools for calculating the objective function are simulation models of the operations of HVAC systems throughout the year. Algorithms of these models were presented in papers [37,38], while, for the presented application, the general algorithm of the simulation model is shown in Figure 6.

The starting point of the general algorithm are the output data on the basis of which the family of characteristic boundary isotherms is determined. Then, for each acceptable variant of the HVAC structure, algorithms for optimal air treatment are determined and the annual demand for net energy, auxiliary energy and primary energy corresponding to these algorithms. In conclusion, the optimal variant is determined.

\subsection{Objective Function, Simulation Models}

The objective functions were defined for representative variants of the HVAC system for cleanrooms with energy-optimal structures $\bar{x}_{1}^{*}, \bar{x}_{2}^{*}, \bar{x}_{3}^{*}$ and $\bar{x}_{4}^{*}$ (Figure 2), respectively; the variants are shown in Table 4.

As decision variables, the optimization algorithm includes: $\mathrm{p}$ - the type of heat recovery and q-external climate. 


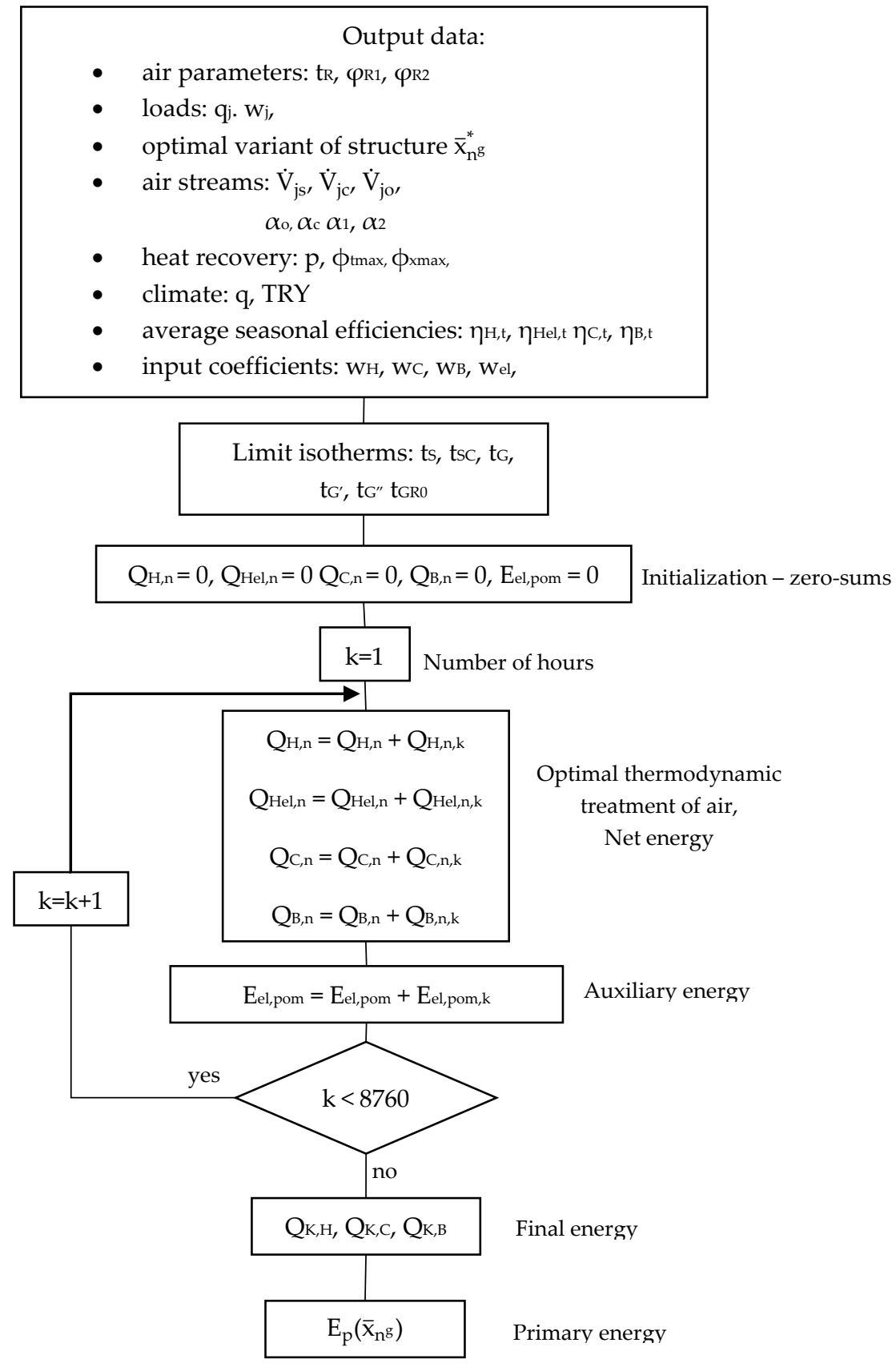

Figure 6. General algorithm of the simulation model for $\bar{x}_{n g}^{*}$ of the HVAC system.

Table 4. Representative variants of the HVAC system for cleanrooms with optimal structures.

\begin{tabular}{|c|c|c|c|c|c|c|c|c|c|}
\hline \multirow{2}{*}{$\begin{array}{c}\text { Optimal Structure } \\
\text { of HVAC System } \\
\overline{\mathbf{x}}_{\mathrm{ng}}^{*}\end{array}$} & \multirow{2}{*}{\multicolumn{2}{|c|}{$\begin{array}{l}\text { Variant Designation } \\
\text { ISO } \mathrm{N}_{\mathrm{n}^{*}}^{*}{ }_{p q}\end{array}$}} & \multirow{2}{*}{$\begin{array}{c}\text { Variant of } \\
\text { Constant } \\
\text { Parameters }\end{array}$} & \multirow{2}{*}{$\frac{\mathrm{q}_{j}}{\mathrm{~W} / \mathrm{m}^{2}}$} & \multirow{2}{*}{$\begin{array}{c}\alpha_{\mathrm{o}} \\
\%\end{array}$} & \multicolumn{3}{|c|}{ Heat Recovery } & \multirow{2}{*}{$\begin{array}{c}\text { External } \\
\text { Climate } \\
q^{3 /}\end{array}$} \\
\hline & & & & & & $\mathbf{p}^{2 /}$ & $\phi_{\mathrm{t}}, \%$ & $\phi_{x}, \%$ & \\
\hline \multirow{5}{*}{$\overline{\mathbf{x}}_{1}^{*}$} & \multirow{5}{*}{ ISO8 } & $\overline{\mathrm{x}}_{11 \mathrm{q}}^{*}$ & \multirow{5}{*}{3.1 .5} & \multirow{5}{*}{100} & \multirow{5}{*}{100} & 1 & \multirow{4}{*}{70} & 0 & \multirow{5}{*}{$1,2,3$} \\
\hline & & $\overline{\mathrm{x}}_{12 \mathrm{q}}^{*}$ & & & & 2 & & 60 & \\
\hline & & $\overline{\mathrm{x}}_{13 \mathrm{q}}^{*}$ & & & & 3 & & 0 & \\
\hline & & $\overline{\mathrm{x}}_{14 \mathrm{q}}^{*}$ & & & & 4 & & 0 & \\
\hline & & $\overline{\mathrm{x}}_{15 \mathrm{q}}^{*}$ & & & & 5 & 0 & 0 & \\
\hline
\end{tabular}


Table 4. Cont.

\begin{tabular}{|c|c|c|c|c|c|c|c|c|c|}
\hline \multirow{2}{*}{$\begin{array}{c}\text { Optimal Structure } \\
\text { of HVAC System } \\
\bar{x}_{n \mathrm{n}}^{*}\end{array}$} & \multirow{2}{*}{\multicolumn{2}{|c|}{$\begin{array}{l}\text { Variant Designation } \\
\quad \text { ISO } N \bar{x}_{n}{ }^{p} g_{p q}\end{array}$}} & \multirow{2}{*}{$\begin{array}{c}\text { Variant of } \\
\text { Constant } \\
\text { Parameters }\end{array}$} & \multirow{2}{*}{$\frac{q_{j}}{W / m^{2}}$} & \multirow{2}{*}{$\begin{array}{l}\alpha_{0} \\
\%\end{array}$} & \multicolumn{3}{|c|}{ Heat Recovery } & \multirow{2}{*}{$\begin{array}{c}\begin{array}{c}\text { External } \\
\text { Climate }\end{array} \\
q^{3 /}\end{array}$} \\
\hline & & & & & & $\mathrm{p}^{2 /}$ & $\phi_{t}, \%$ & $\phi_{x}, \%$ & \\
\hline \multirow{5}{*}{$\overline{\mathbf{x}}_{2}^{*}$} & \multirow{5}{*}{ ISO8 } & $\overline{\mathrm{x}}_{21 \mathrm{q}}^{*}$ & \multirow{5}{*}{ 3.3.3 } & \multirow{5}{*}{500} & \multirow{5}{*}{19.9} & 1 & \multirow{4}{*}{70} & 0 & \multirow{5}{*}{$1,2,3$} \\
\hline & & $\overline{\mathrm{x}}_{22 \mathrm{q}}^{*}$ & & & & 2 & & 60 & \\
\hline & & $\overline{\mathrm{x}}_{23 \mathrm{q}}^{*}$ & & & & 3 & & 0 & \\
\hline & & $\overline{\mathrm{x}}_{24 \mathrm{q}}^{*}$ & & & & 4 & & 0 & \\
\hline & & $\bar{x}_{25 q}^{*}$ & & & & 5 & 0 & 0 & \\
\hline \multirow{5}{*}{$\overline{\mathbf{x}}_{3}^{*}$} & \multirow{5}{*}{ ISO 5} & $\overline{\mathrm{x}}_{31 \mathrm{q}}^{*}$ & \multirow{5}{*}{1.2 .3} & \multirow{5}{*}{300} & \multirow{5}{*}{30} & 1 & \multirow{4}{*}{70} & 0 & \multirow{5}{*}{$1,2,3$} \\
\hline & & $\bar{x}_{32 q}^{*}$ & & & & 2 & & 60 & \\
\hline & & $\overline{\mathrm{x}}_{33 \mathrm{q}}^{*}$ & & & & 3 & & 0 & \\
\hline & & $\bar{x}_{34 q}^{*}$ & & & & 4 & & 0 & \\
\hline & & $\bar{x}_{35 q}^{*}$ & & & & 5 & 0 & 0 & \\
\hline \multirow{5}{*}{$\overline{\mathbf{x}}_{4}^{*}$} & \multirow{5}{*}{ ISO7 } & $\overline{\mathrm{x}}_{41 \mathrm{q}}^{*}$ & \multirow{5}{*}{2.2 .2} & \multirow{5}{*}{300} & \multirow{5}{*}{10} & 1 & \multirow{4}{*}{70} & 0 & \multirow{5}{*}{$1,2,3$} \\
\hline & & $\overline{\mathrm{x}}_{42 \mathrm{q}}^{*}$ & & & & 2 & & 60 & \\
\hline & & $\overline{\mathrm{x}}_{43 \mathrm{q}}^{*}$ & & & & 3 & & 0 & \\
\hline & & $\overline{\mathrm{x}}_{44 \mathrm{q}}^{*}$ & & & & 4 & & 0 & \\
\hline & & $\overline{\mathrm{x}}_{45 \mathrm{q}}^{*}$ & & & & 5 & 0 & 0 & \\
\hline
\end{tabular}

1/ According to Table $2{ }^{2 /} \mathrm{p}=1$-rotary energy regenerator $\left(\mathrm{RR}_{\mathrm{t}}\right), \phi_{\mathrm{t}} \neq$ const. (stepless regulation), $\mathrm{p}=2$-rotary enthalpy regenerator $\left(R R_{x}\right), \phi_{t} \neq$ const., $\phi_{x} \neq$ const. (stepless regulation), $p=3$-cross-flow or countercurrent exchanger with bypass (R+ bypass), $\phi_{\mathrm{t}}=\phi_{\mathrm{tmax}}$ or $\phi_{\mathrm{t}}=0, \mathrm{p}=4$-crossflow or countercurrent exchanger with bypass and electric preheater $\left(\mathrm{H}_{\mathrm{el}}+\mathrm{R}+\right.$ bypass$)$ and $\mathrm{p}=5$ - no heat recovery and ${ }^{3 /} \mathrm{q}=1,2,3$ - continental climate, subarctic and subtropical [41].

In calculations based on the simulation models [37], the following assumptions and output data were considered:

1. Air parameters in the room equal: $t_{R}=+22{ }^{\circ} \mathrm{C}, \varphi_{R}=(50 \pm 5) \%-\varphi_{R 1}=45 \%, \varphi_{R 2}=55 \%$. Further parameters are included in Table 4.

2. It is assumed that the gains in room humidity $w_{j}$ in relation to the air stream $\dot{V}_{j}$ are negligible $\left(\mathrm{x}_{\mathrm{S}}=\mathrm{x}_{\mathrm{R}}\right)$.

3. The surface temperature of the cooler was assumed to be equal to $t_{D}=t_{D P}-1 \mathrm{~K}$.

4. For HVAC systems $\bar{x}_{13}$ and $\bar{x}_{14}, \bar{x}_{23}$ and $\bar{x}_{24}, \bar{x}_{33}$ and $\bar{x}_{34}$ and $\bar{x}_{43}$ and $\bar{x}_{44}$ (with a crossflow or countercurrent exchanger), the outdoor air temperature at which frost occurs, equal to $\mathrm{t}_{\mathrm{GR} 0}=0^{\circ} \mathrm{C}$, was used.

5. The calculations were performed for three representative types of external climates according to Köppen [41]: continental with warm summer $(\mathrm{q}=1)$, subarctic $(\mathrm{q}=2)$ and subtropical $(\mathrm{q}=3)$.

6. Continuous operation of the HVAC system is assumed- $\tau=24 / 7$ with constant air streams.

7. Final and primary energy demands for forcing through air (fans) are neglected, except for heat recovery exchangers, for which a realistic pressure loss of $\Delta \mathrm{p}_{\mathrm{HR}}=150 \mathrm{~Pa}$ and a total efficiency of forcing through $\eta_{\mathrm{W}}=80 \%$ are used.

As a result, component $\mathrm{E}_{\mathrm{el} \text {,pom }}$ in Equations (29) and (30) is defined as:

$$
\mathrm{E}_{\mathrm{el}, \mathrm{pom}}=\Delta \mathrm{E}_{\mathrm{R}}=\frac{\dot{\mathrm{v}}_{\mathrm{o}} \Delta \mathrm{p}_{\mathrm{HR}}}{\eta_{\mathrm{W}}} \cdot \tau \cdot 10^{-3}, \mathrm{kWh} / \mathrm{y} / \mathrm{m}^{2}
$$

with:

$\Delta E_{R}$-final energy demand for forcing through by heat recovery exchangers. 
Considering energy inputs for forcing through air by heat recovery exchangers is necessary for evaluating the energy profitability of applying such exchangers.

Omission of the energy demand for fans as a component of the objective function (29) can be justified as follows:

- the objective function (29) is determined for each optimal structure of the HVAC system $\bar{x}_{n g}^{*}$ in which the location of the fans is specified; the energy demand of these fans does not therefore affect the selection of the optimal structure;

- determining the energy demand for fans would require assuming system pressure losses, which is not an objective parameter (such a possibility is provided for a case study);

- the purpose of the research at this stage is to determine the optimal type of heat recovery; to achieve this purpose, it is not necessary to determine the energy demand for the fans.

8. Annual demand for the final energy for the drive of auxiliary devices is neglected.

9. The following values of physical constants were used: air density $\rho=1.2 \mathrm{~kg} / \mathrm{m}^{3}$, specific heat of air $c_{p}=1.005 \mathrm{~kg} / \mathrm{kgK}$, specific heat of steam $c_{\mathrm{pp}}=1.86 \mathrm{~kg} / \mathrm{kgK}$, heat of vaporization of water with temperature $0{ }^{\circ} \mathrm{C}, \mathrm{r}_{\mathrm{o}}=2500.8 \mathrm{~kJ} / \mathrm{kg}$ and atmospheric pressure $\mathrm{p}_{\mathrm{a}}=105 \mathrm{~Pa}$.

10. Thermodynamic parameters of humid air were calculated based on Reference [42].

\subsection{Algorithms of Energy-Optimal Control}

For representative variants of the HVAC system shown in Table 4, the structures of which are shown in Figure 2, algorithms of energy-optimal control were defined in accordance with criterion (35). The algorithms are shown in Figures 7-10.

(a)

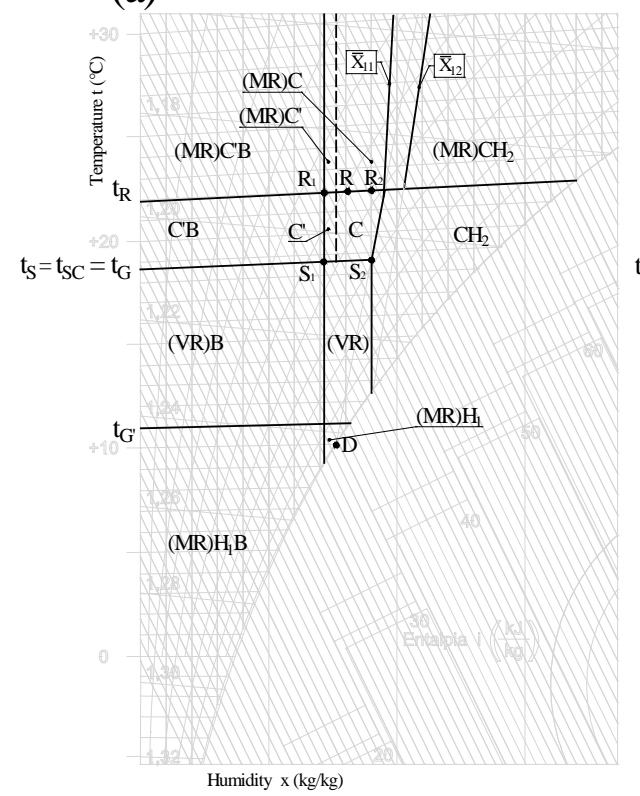

(b)

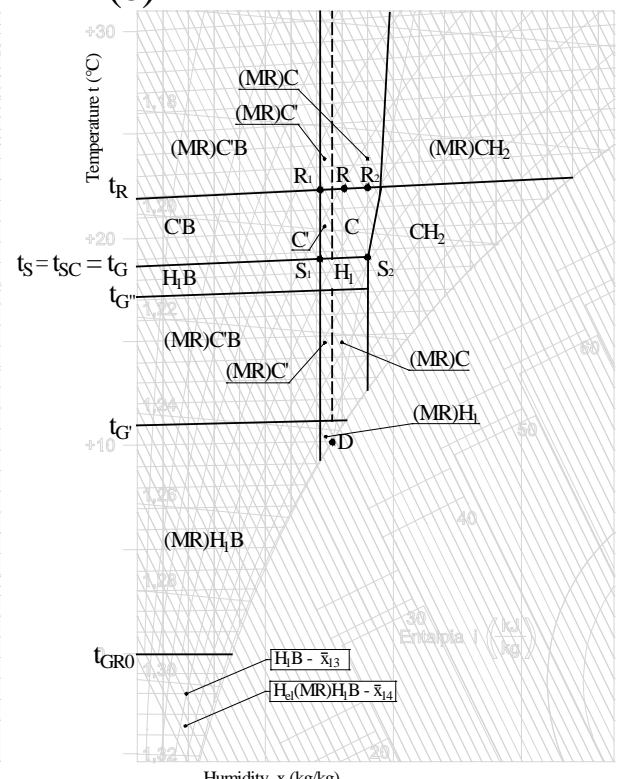

(c)

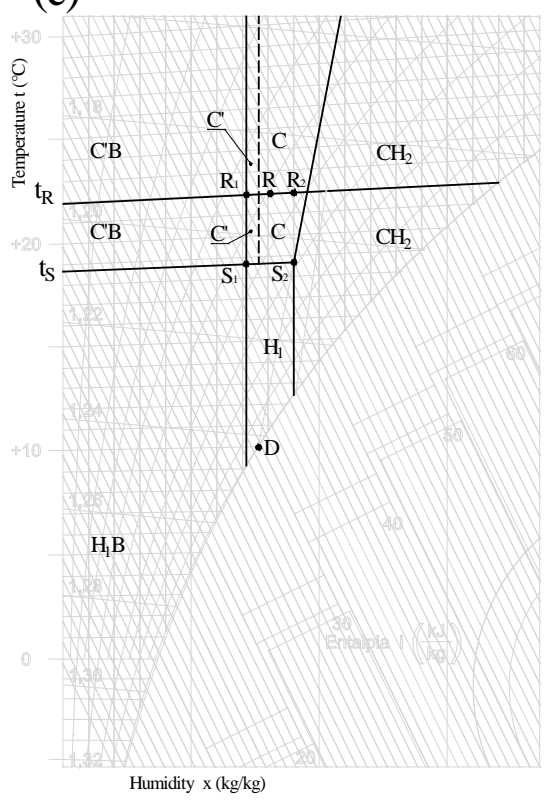

Figure 7. ISO8 variant (a) $\overline{\mathrm{x}}_{11}^{*}-\overline{\mathrm{x}}_{12}^{*}$ (b) $\overline{\mathrm{x}}_{13}^{*}-\overline{\mathrm{x}}_{14^{\prime}}^{*}$ (c) $\overline{\mathrm{x}}_{15}^{*}$ (without recirculation). 
(a)

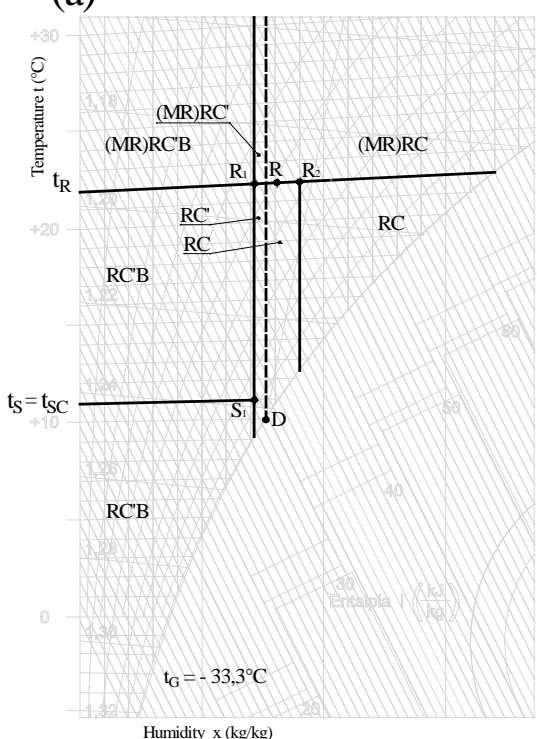

(b)

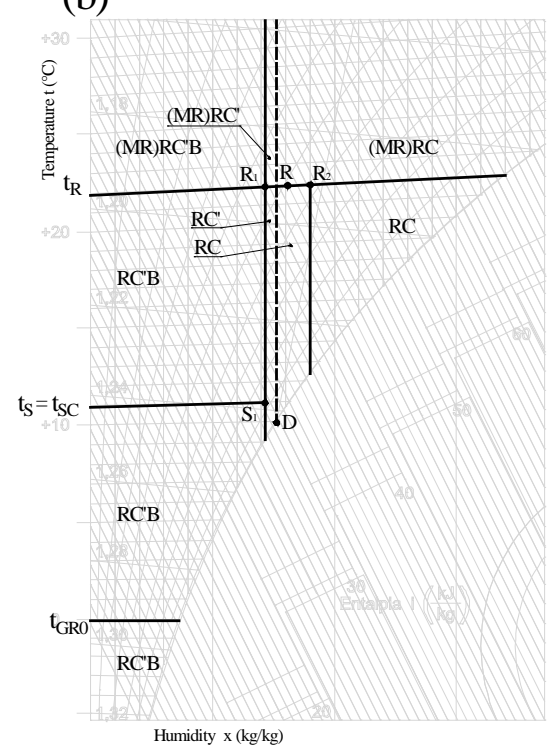

(c)

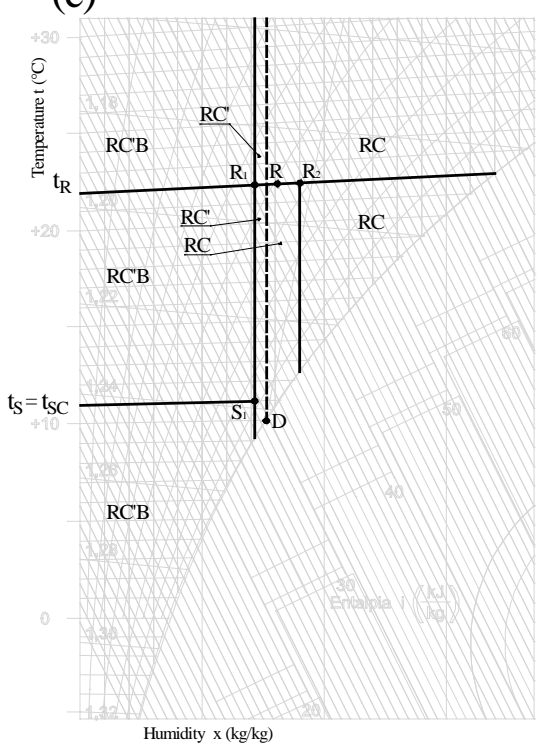

Figure 8. ISO 8 variants (a) $\overline{\mathrm{x}}_{21}^{*}-\overline{\mathrm{x}}_{22}^{*},(\mathbf{b}) \overline{\mathrm{x}}_{23}^{*}-\overline{\mathrm{x}}_{24}^{*}$ and (c) $\overline{\mathrm{x}}_{25}^{*}$ (external recirculation).

(a)

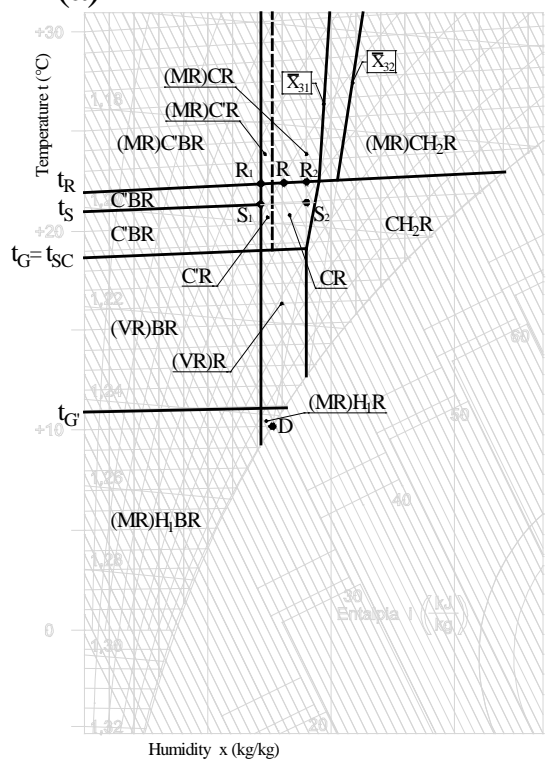

(b)

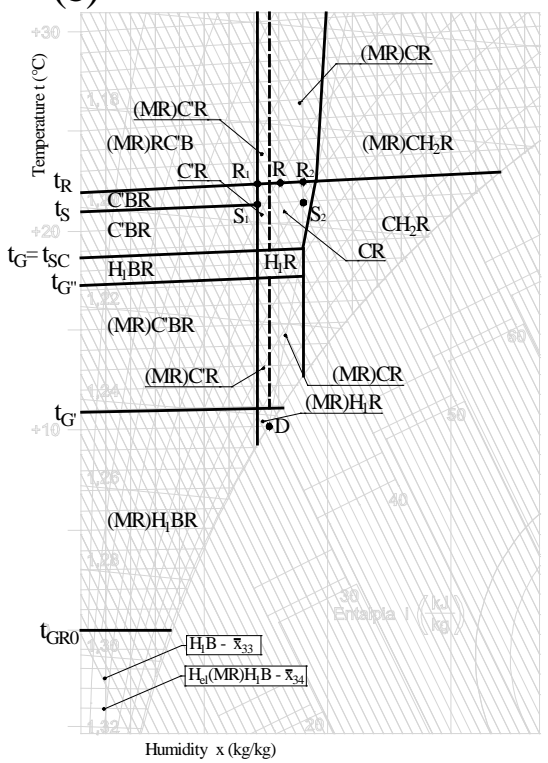

(c)

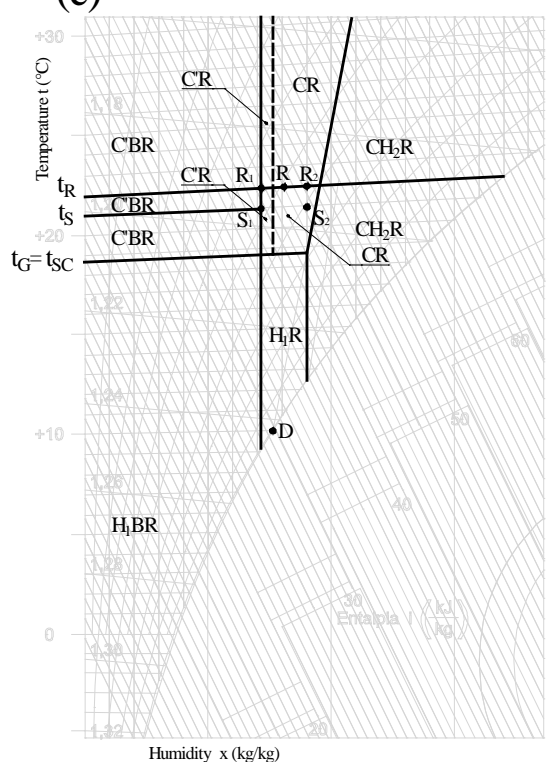

Figure 9. ISO5 variants (a) $\bar{x}_{31}^{*}-\bar{x}_{32}^{*}$, (b) $\bar{x}_{33}^{*}-\bar{x}_{34}^{*}$ and (c) $\bar{x}_{35}^{*}$ (internal recirculation).

For the identification of zones of optimal thermodynamic treatment of air in Figures $7-10 \mathrm{~h}-\mathrm{x}$, the following designations are used:

(MR) - maximum heat recovery, (VR) - regulated heat recovery, $\mathrm{H}_{1}$ - heating (preheater), $\mathrm{H}_{2}$ - heating (secondary heater), $\mathrm{H}_{\mathrm{el}}$ - heating (electric heater), $\mathrm{C}^{\prime}$ - sensible cooling (without drying), C-cooling with drying, B-steam humidification and $\mathrm{R}$-recirculation.

At the same time, the following designations of the characteristic points are used (Figure 2):

$\mathrm{R}$-air condition in the room, S-condition of air supplied to the room, SC-air condition downstream AHU and D-air condition at the cooler surface. 
(a)

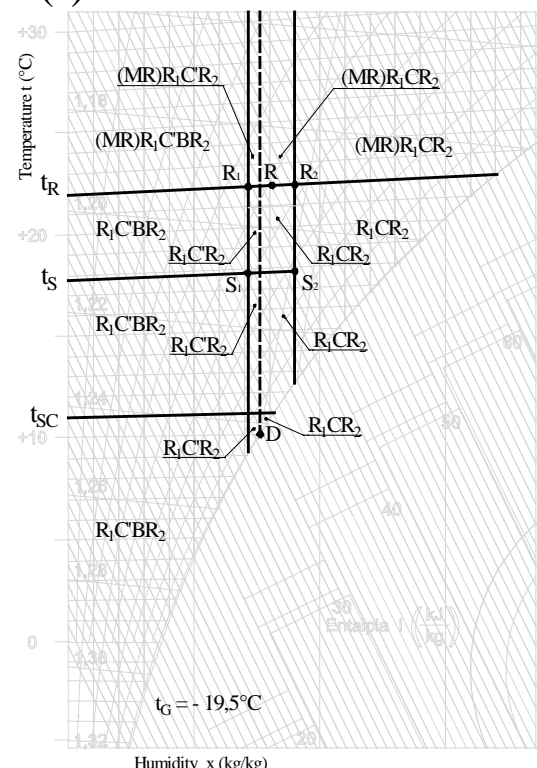

(b)

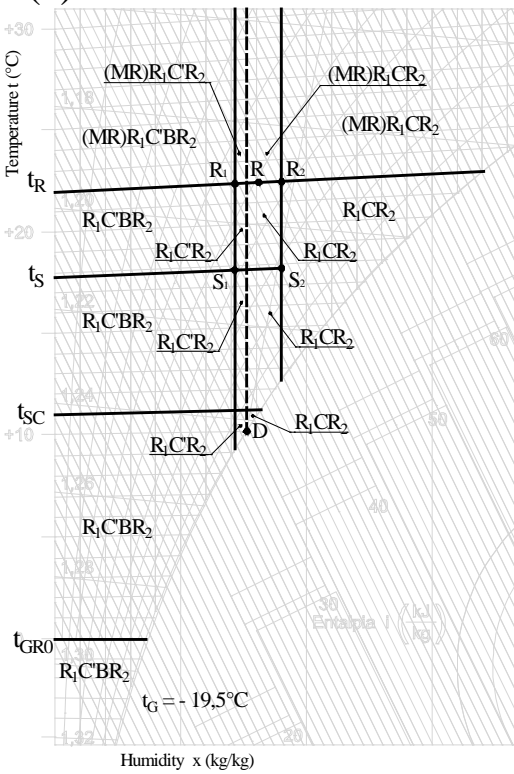

(c)

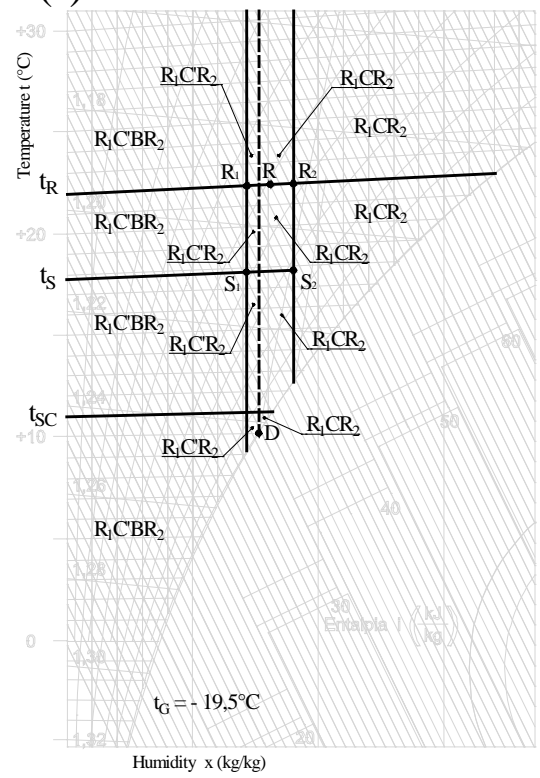

Figure 10. ISO7 variants (a) $\overline{\mathrm{x}}_{41}^{*}-\overline{\mathrm{x}}_{42}^{*}$ (b) $\overline{\mathrm{x}}_{43}^{*}-\overline{\mathrm{x}}_{44}^{*}$ and (c) $\overline{\mathrm{x}}_{45}^{*}$ (external and internal recirculation).

Equations of the limit isotherms and limit lines between the zones of optimal thermodynamic treatment of air in Figures $7-10 \mathrm{~h}-\mathrm{x}$ take the following form:

- $\quad$ isotherm $\mathrm{ts}_{\mathrm{S}}$

$$
\mathrm{t}_{\mathrm{S}}=\mathrm{t}_{\mathrm{R}}-\frac{\mathrm{q}_{\mathrm{j}}}{\dot{\mathrm{V}}_{\mathrm{j}} \rho \mathrm{c}_{\mathrm{p}}}
$$

- $\quad$ isotherm $t_{\mathrm{SC}}$

$$
\mathrm{t}_{\mathrm{SC}}=\mathrm{t}_{\mathrm{R}}-\frac{\mathrm{q}_{\mathrm{j}}}{\dot{\mathrm{V}}_{\mathrm{jc}} \rho \mathrm{c}_{\mathrm{p}}}
$$

- $\quad$ isotherm $t_{\mathrm{G}}$

$$
\mathrm{t}_{\mathrm{G}}=\mathrm{t}_{\mathrm{R}}-\frac{1}{\alpha_{\mathrm{o}}}\left(\mathrm{t}_{\mathrm{R}}-\mathrm{t}_{\mathrm{S}}\right)
$$

- $\quad$ isotherm $\mathrm{t}_{\mathrm{G}^{\prime}}$

$$
\mathrm{t}_{\mathrm{G}^{\prime}}=\mathrm{t}_{\mathrm{R}}-\frac{\mathrm{t}_{\mathrm{R}}-\mathrm{t}_{\mathrm{S}}}{\alpha_{\mathrm{o}}\left(1-\phi_{\mathrm{t}_{\max }}\right)}
$$

- $\quad$ isotherm $\mathrm{t}_{\mathrm{G}^{\prime \prime}}$

$$
\mathrm{t}_{\mathrm{G}^{\prime \prime}}=\frac{\mathrm{t}_{\mathrm{G}}\left(\frac{\mathrm{w}_{\mathrm{H}}}{\eta_{\mathrm{H}, \mathrm{t}}}+\frac{\mathrm{w}_{\mathrm{C}}}{\eta_{\mathrm{C}, \mathrm{t}}}\right)-\frac{\mathrm{w}_{\mathrm{C}}}{\eta_{\mathrm{C}, \mathrm{t}}} \phi_{\mathrm{t}} \mathrm{t}_{\mathrm{R}}}{\frac{\mathrm{w}_{\mathrm{H}}}{\eta_{\mathrm{H}, \mathrm{t}}}+\frac{\mathrm{w}_{\mathrm{C}}}{\eta_{\mathrm{C}, \mathrm{t}}}\left(1-\phi_{\mathrm{t}}\right)}
$$

- limit line (MR)C/(MR) $\mathrm{CH}_{2}-\overline{\mathrm{x}}_{11}$

$$
\mathrm{t}_{\mathrm{zg}}=\frac{1}{1-\phi_{\mathrm{t}}}\left(\frac{\mathrm{x}-\mathrm{x}_{\mathrm{D}}}{\mathrm{x}_{\mathrm{S}_{2}}-\mathrm{x}_{\mathrm{D}}} \mathrm{t}_{\mathrm{s}}-\frac{\mathrm{x}-\mathrm{x}_{\mathrm{S}_{2}}}{\mathrm{x}_{\mathrm{S}_{2}}-\mathrm{x}_{\mathrm{D}}} \mathrm{t}_{\mathrm{D}}\right)-\frac{\phi_{\mathrm{t}}}{1-\phi_{\mathrm{t}}} \mathrm{t}_{\mathrm{R}}
$$


- limit line $(\mathrm{MR}) \mathrm{C} /(\mathrm{MR}) \mathrm{CH}_{2}-\overline{\mathrm{x}}_{12}$

$$
t_{\mathrm{zg}}=\frac{\left(\mathrm{t}_{\mathrm{S}}-\mathrm{t}_{\mathrm{D}}\right)\left[\mathrm{x}-\phi_{\mathrm{x}}\left(\mathrm{x}-\mathrm{x}_{\mathrm{R}_{2}}\right)-\mathrm{x}_{\mathrm{D}}\right]-\left(\phi_{\mathrm{t}} \mathrm{t}_{\mathrm{R}}-\mathrm{t}_{\mathrm{D}}\right)\left(\mathrm{x}_{\mathrm{S}_{2}}-\mathrm{x}_{\mathrm{D}}\right)}{\left(1-\phi_{\mathrm{t}}\right)\left(\mathrm{x}_{\mathrm{S}_{2}}-\mathrm{x}_{\mathrm{D}}\right)}
$$

- limit line $\mathrm{C} / \mathrm{CH}_{2}$

$$
t_{\mathrm{zg}}=t_{D}+\left(t_{S}-t_{D}\right) \frac{x-x_{D}}{x_{S_{2}}-x_{D}}
$$

- limit line $(\mathrm{MR}) \mathrm{C} /(\mathrm{MR}) \mathrm{CH}_{2} \mathrm{R}-\overline{\mathrm{x}}_{31}$

$$
\begin{gathered}
t_{\mathrm{zg}}=\frac{1}{1-\phi_{\mathrm{t}}}\left(\frac{\mathrm{x}-\mathrm{x}_{\mathrm{D}}}{\mathrm{x}_{\mathrm{R}_{3}}-\mathrm{x}_{\mathrm{D}}} \mathrm{t}_{\mathrm{R}}-\frac{\mathrm{x}-\mathrm{x}_{\mathrm{R}_{3}}}{\mathrm{x}_{\mathrm{R}_{3}}-\mathrm{x}_{\mathrm{D}}} \mathrm{t}_{\mathrm{D}}\right)-\frac{\phi_{\mathrm{t}}}{1-\phi_{\mathrm{t}}} \mathrm{t}_{\mathrm{R}} \\
\mathrm{x}_{\mathrm{R}_{3}}=\mathrm{x}_{\mathrm{D}}+\left(\mathrm{x}_{\mathrm{S}_{2}}-\mathrm{x}_{\mathrm{D}}\right) \frac{\mathrm{t}_{\mathrm{R}}-\mathrm{t}_{\mathrm{D}}}{\mathrm{t}_{\mathrm{SC}}-\mathrm{t}_{\mathrm{D}}}
\end{gathered}
$$

- $\quad$ limit line $(\mathrm{MR}) \mathrm{C} /(\mathrm{MR}) \mathrm{CH}_{2} \mathrm{R}-\overline{\mathrm{x}}_{32}$

$$
t_{\mathrm{zg}}=\frac{\left(\mathrm{t}_{\mathrm{SC}}-\mathrm{t}_{\mathrm{D}}\right)\left[\mathrm{x}-\phi_{\mathrm{x}}\left(\mathrm{x}-\mathrm{x}_{\mathrm{R}_{2}}\right)-\mathrm{x}_{\mathrm{D}}\right]-\left(\phi_{\mathrm{t}} \mathrm{t}_{\mathrm{R}}-\mathrm{t}_{\mathrm{D}}\right)\left(\mathrm{x}_{\mathrm{R}_{2}}-\mathrm{x}_{\mathrm{D}}\right)}{\left(1-\phi_{\mathrm{t}}\right)\left(\mathrm{x}_{\mathrm{R}_{2}}-\mathrm{x}_{\mathrm{D}}\right)}
$$

- limit line $\mathrm{CR} / \mathrm{CH}_{2} \mathrm{R}$

$$
t_{\mathrm{zg}}=t_{D}+\frac{t_{S C}-t_{D}}{x_{S_{2}}-x_{D}}\left(x-x_{D}\right)
$$

\begin{tabular}{|c|c|c|c|c|c|}
\hline \multirow{2}{*}{\multicolumn{2}{|c|}{$\begin{array}{c}\text { Optimal Structure of } \\
\text { HVAC System } \\
\overline{\mathbf{x}}_{\mathbf{n}}^{*}\end{array}$}} & \multirow[b]{2}{*}{$\begin{array}{l}\text { Heat Recovery } \\
\text { (p) }\end{array}$} & \multicolumn{3}{|c|}{ Primary Energy $E_{p}, k W h / m^{2} y$} \\
\hline & & & $\begin{array}{c}\text { Continental Climate } \\
\text { (Poland) } \\
q=1\end{array}$ & $\begin{array}{l}\text { Subarctic Climate } \\
\text { (Russia) } \\
q=2\end{array}$ & $\begin{array}{c}\text { Subtropical Climate } \\
\text { (Brazil) } \\
q=3\end{array}$ \\
\hline$\overline{\mathrm{x}}_{11}$ & \multirow{5}{*}{ ISO8 } & $\begin{array}{c}\mathrm{RO}_{\mathrm{t}} \\
(\mathrm{p}=1)\end{array}$ & 6354.0 & 9554.0 & 4877.0 \\
\hline$\overline{\mathrm{x}}_{12}$ & & $\begin{array}{c}\mathrm{RO}_{\mathrm{x}} \\
(\mathrm{p}=2)\end{array}$ & 3464.0 & 5013.0 & 3915.0 \\
\hline $\bar{x}_{13}$ & & $\begin{array}{c}R+\text { by-pass } \\
(p=3)\end{array}$ & 7643.0 & $13,693.0$ & 4921.0 \\
\hline$\overline{\mathrm{x}}_{14}$ & & $\begin{array}{c}\mathrm{H}_{\mathrm{el}}+\mathrm{R}+\text { by-pass } \\
(\mathrm{p}=4)\end{array}$ & 6901.0 & $13,943.0$ & 4921.0 \\
\hline$\overline{\mathrm{x}}_{15}$ & & $\begin{array}{l}\text { Without } \\
\text { heat recovery } \\
(p=5)\end{array}$ & 9426.0 & $14,733.0$ & 5118.0 \\
\hline
\end{tabular}

\subsection{Calculation Results, Interpretation}

Results of the calculations of the annual demands for primary energy for the representative HVAC systems shown in Table 4 are presented in Table 5.

Table 5. Primary energy demand for the representative HVAC systems $\bar{x}_{n g}^{*}$. 
Table 5. Cont.

\begin{tabular}{|c|c|c|c|c|c|}
\hline \multirow{2}{*}{\multicolumn{2}{|c|}{$\begin{array}{c}\text { Optimal Structure of HVAC } \\
\text { System } \\
\overline{\mathbf{x}}_{\mathrm{ng}}^{*}\end{array}$}} & \multirow[b]{2}{*}{$\begin{array}{l}\text { Heat Recovery } \\
\text { (p) }\end{array}$} & \multicolumn{3}{|c|}{ Primary Energy $E_{p}, k W h / m^{2} y$} \\
\hline & & & $\begin{array}{c}\text { Continental Climate } \\
\text { (Poland) } \\
q=1\end{array}$ & $\begin{array}{c}\text { Subarctic Climate } \\
\text { (Russia) } \\
\text { q = } 2\end{array}$ & $\begin{array}{c}\text { Subtropical Climate } \\
\text { (Brazil) } \\
\mathrm{q}=3 \\
\end{array}$ \\
\hline $\bar{x}_{21}$ & \multirow{5}{*}{ ISO8 } & $\begin{array}{c}\mathrm{RO}_{\mathrm{t}} \\
(\mathrm{p}=1)\end{array}$ & 4965.0 & 5078.0 & 5118.0 \\
\hline $\bar{x}_{22}$ & & $\begin{array}{c}\mathrm{RO}_{\mathrm{x}} \\
(\mathrm{p}=2)\end{array}$ & 4930.0 & 5055.0 & 4945.0 \\
\hline $\bar{x}_{23}$ & & $\begin{array}{c}R+\text { by-pass } \\
(p=3)\end{array}$ & 4965.0 & 5078.0 & 5118.0 \\
\hline $\bar{x}_{24}$ & & $\begin{array}{c}\mathrm{H}_{\mathrm{el}}+\mathrm{R}+\text { by-pass } \\
(\mathrm{p}=4)\end{array}$ & 4965.0 & 5078.0 & 5118.0 \\
\hline $\bar{x}_{25}$ & & $\begin{array}{l}\text { Without } \\
\text { heat recovery } \\
\quad(\mathrm{p}=5)\end{array}$ & 4898.0 & 5010.0 & 5091.0 \\
\hline $\bar{x}_{31}$ & \multirow{5}{*}{ ISO5 } & $\begin{array}{c}\mathrm{RO}_{\mathrm{t}} \\
(\mathrm{p}=1)\end{array}$ & $19,053.0$ & $28,656.0$ & $14,634.0$ \\
\hline $\bar{x}_{32}$ & & $\begin{array}{c}\mathrm{RO}_{\mathrm{x}} \\
(\mathrm{p}=2)\end{array}$ & $10,382.0$ & $15,014.0$ & $11,747.0$ \\
\hline $\bar{x}_{33}$ & & $\begin{array}{c}R+\text { by-pass } \\
(p=3)\end{array}$ & $22,883.0$ & $41,033.0$ & $14,686.0$ \\
\hline $\bar{x}_{34}$ & & $\begin{array}{c}\mathrm{H}_{\mathrm{el}}+\mathrm{R}+\text { by-pass } \\
(\mathrm{p}=4)\end{array}$ & $20,703.0$ & $41,830.0$ & $14,686.0$ \\
\hline $\bar{x}_{35}$ & & $\begin{array}{l}\text { Without } \\
\text { heat recovery } \\
\quad(p=5)\end{array}$ & $28,278.0$ & $44,198.0$ & $15,354.0$ \\
\hline$\overline{\mathrm{x}}_{41}$ & \multirow{5}{*}{ ISO7 } & $\begin{array}{c}\mathrm{RO}_{\mathrm{t}} \\
(\mathrm{p}=1)\end{array}$ & 3071.0 & 3203.0 & 3159.0 \\
\hline $\bar{x}_{42}$ & & $\begin{array}{c}\mathrm{RO}_{\mathrm{x}} \\
(\mathrm{p}=2) \\
\end{array}$ & 3040.0 & 2950.0 & 3000.0 \\
\hline$\overline{\mathrm{x}}_{43}$ & & $\begin{array}{c}R+\text { by-pass } \\
(p=3)\end{array}$ & 3070.0 & 3477.0 & 3159.0 \\
\hline $\bar{x}_{44}$ & & $\begin{array}{c}\mathrm{H}_{\mathrm{el}}+\mathrm{R}+\text { by-pass } \\
(\mathrm{p}=4)\end{array}$ & 3070.0 & 3477.0 & 3159.0 \\
\hline$\overline{\mathrm{x}}_{45}$ & & $\begin{array}{l}\text { Without } \\
\text { heat recovery } \\
\quad(p=5)\end{array}$ & 3018.0 & 3322.0 & 3134.0 \\
\hline
\end{tabular}

A percentage comparison of the unit annual demand for the primary energy of variants of the HVAC system for various external climates and types of heat recovery, compared to variants without heat recovery, are shown in Figures 11-14. The subject of the assessment is the impact of the type of heat recovery and the external climate-as decision variables-for the selection of the energy-optimal variant. 


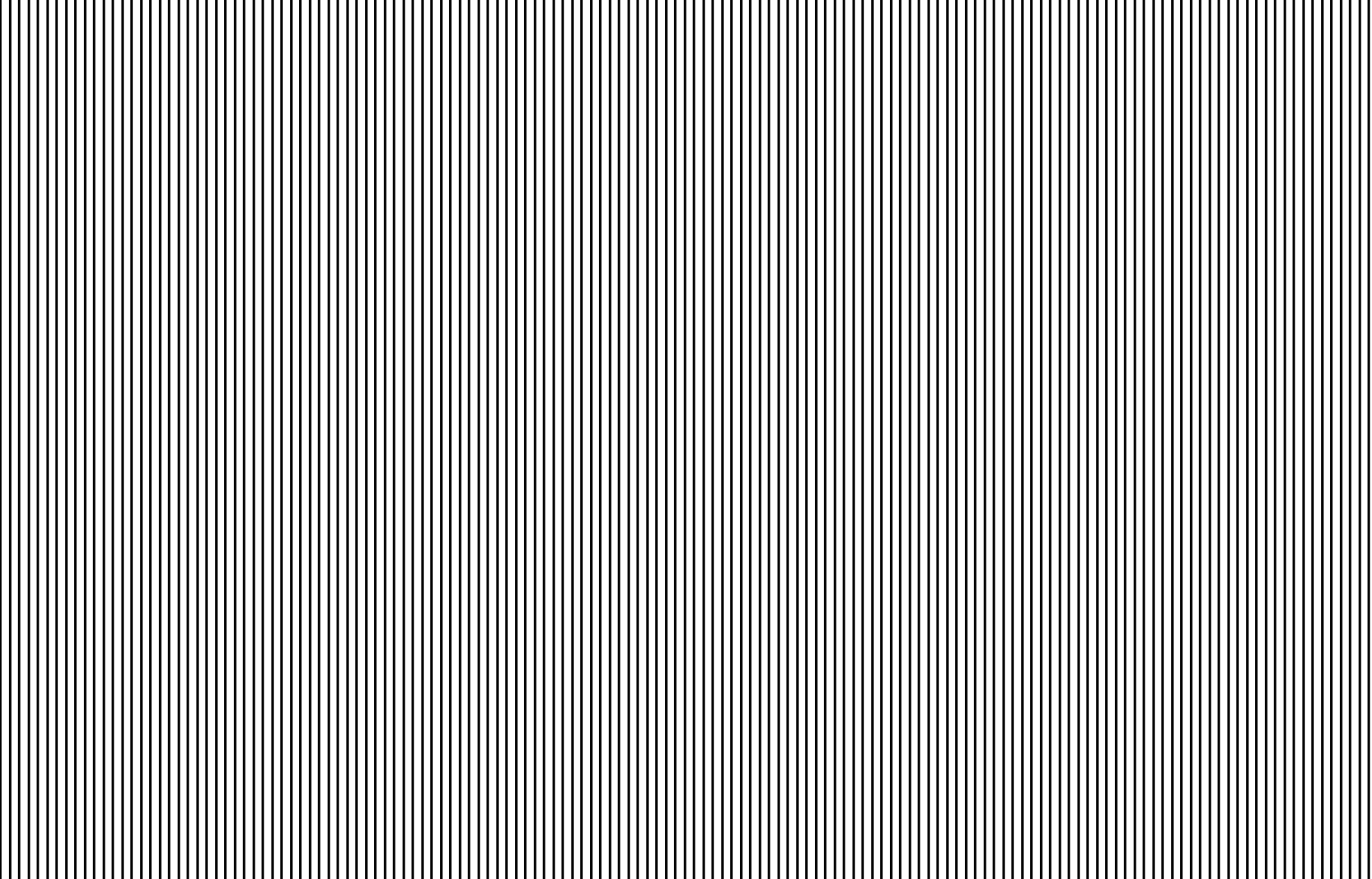

Figure 11. Annual relative demand for the primary energy of the variants of HVAC system ISO8 $\bar{x}_{1_{\mathrm{pq}}}$ (without recirculation) for various external climates and types of heat recovery compared to the variants without heat recovery.

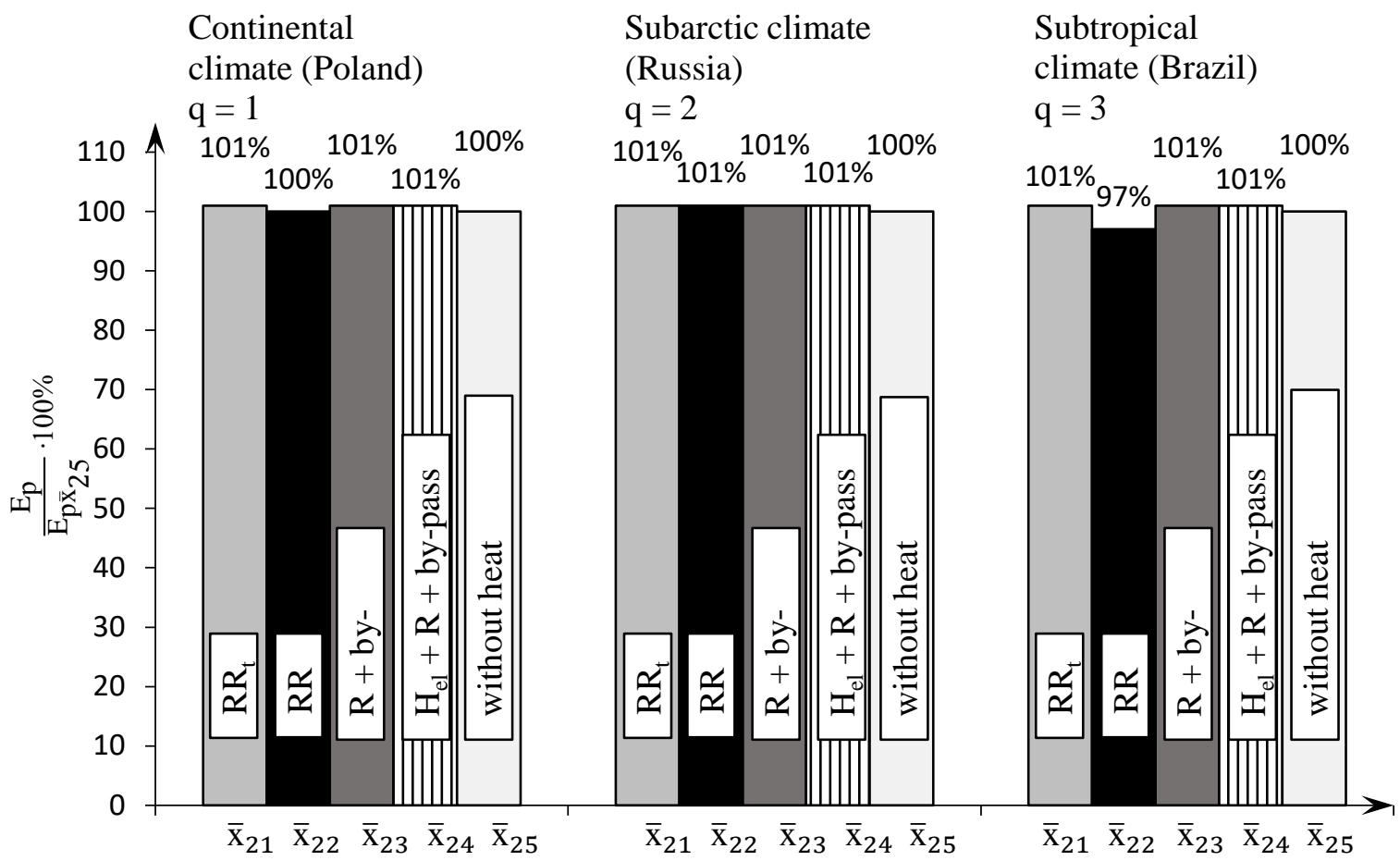

Figure 12. Annual relative demand for the primary energy of the variants of HVAC system ISO8 $\overline{\mathrm{x}}_{2_{\mathrm{pq}}}$ (external recirculation) for various external climates and types of heat recovery compared to the variants without heat recovery. 


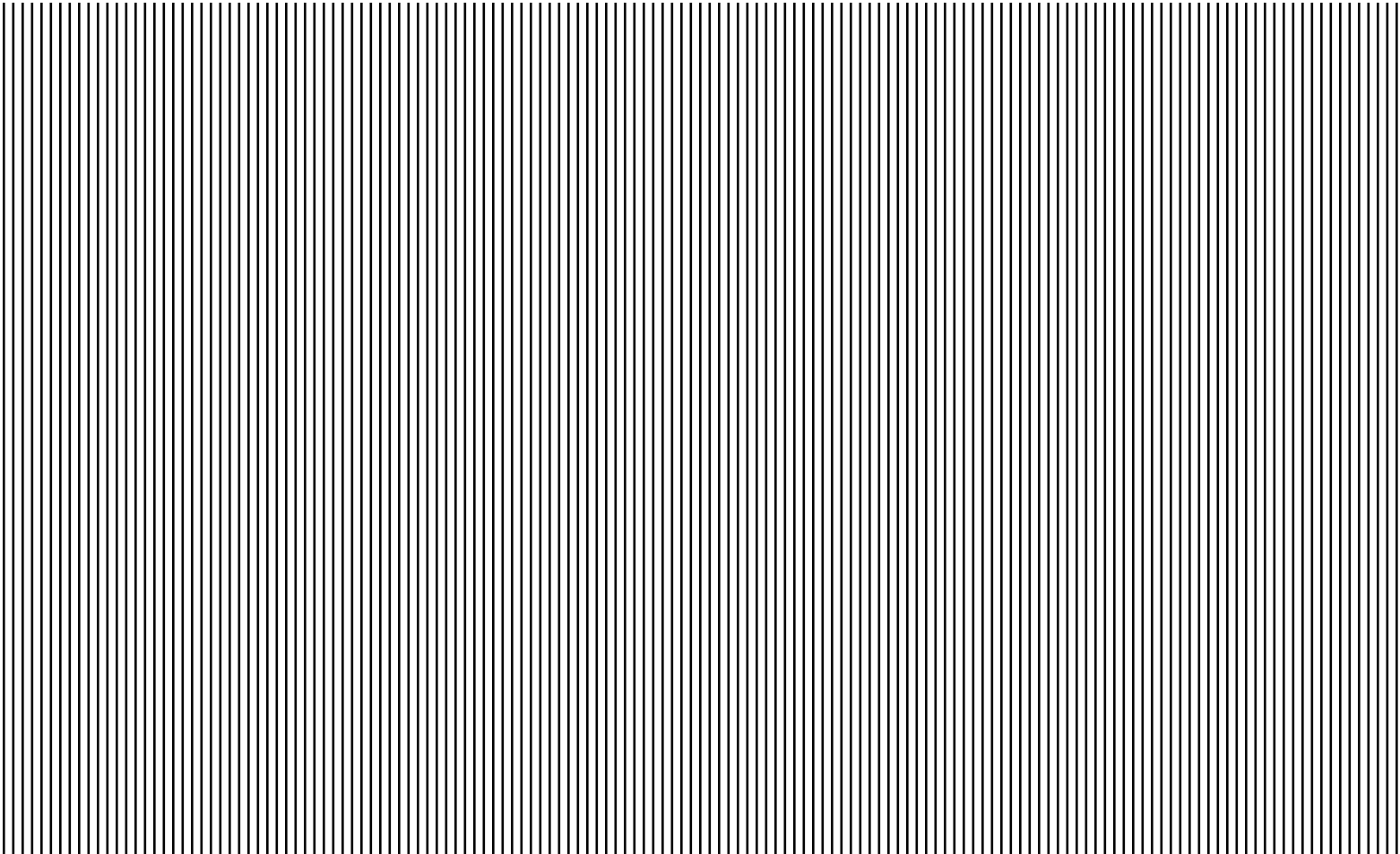

Figure 13. Annual relative demand for the primary energy of the variants of HVAC system ISO8 $\overline{\mathrm{X}}_{3_{\mathrm{pq}}}$ (internal recirculation) for various external climates and types of heat recovery compared to the variants without heat recovery.

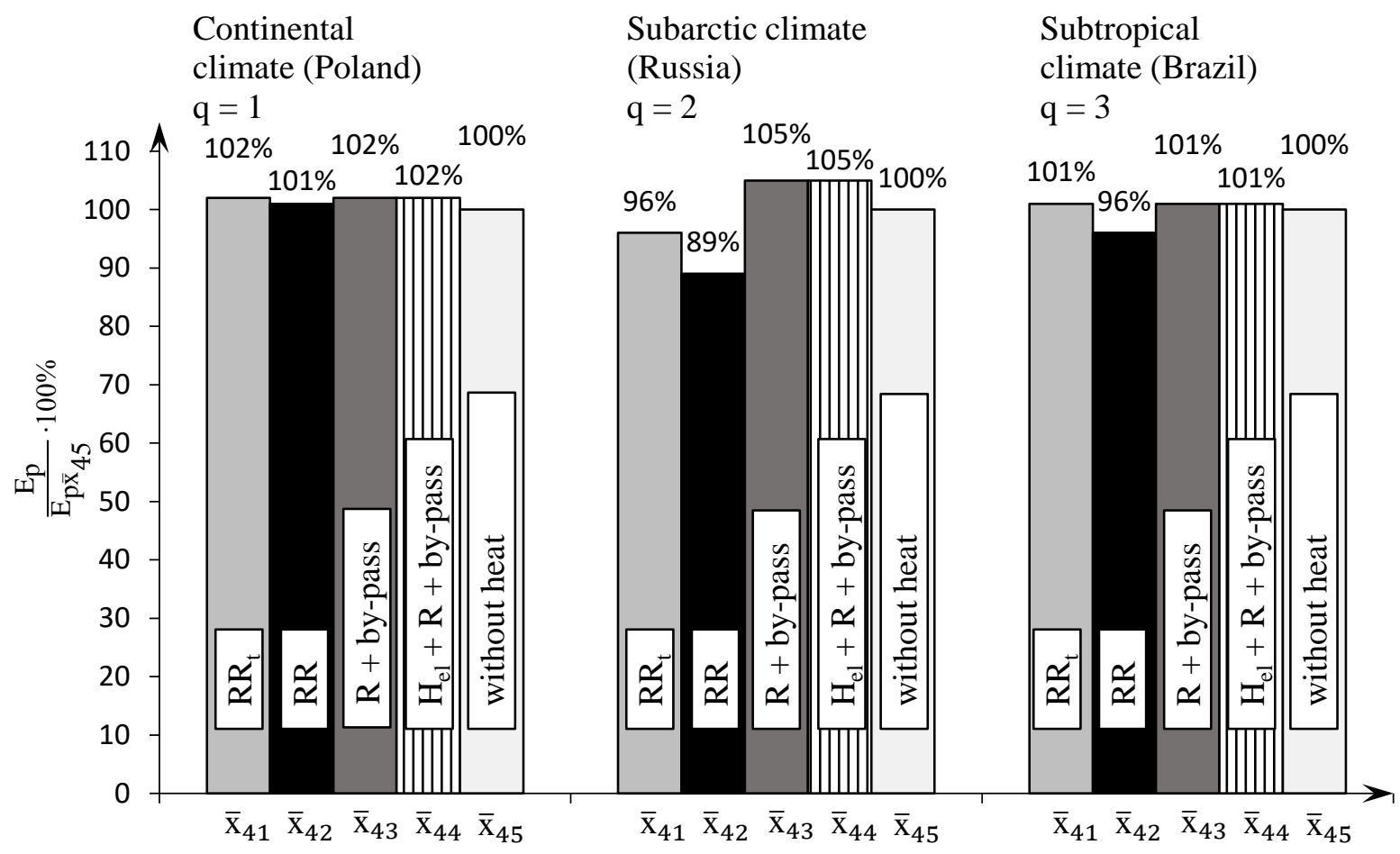

Figure 14. Annual relative demand for the primary energy of the variants of HVAC system ISO8 $\overline{\mathrm{x}}_{4_{\mathrm{pq}}}$ (external and internal recirculation) for various external climates and types of heat recovery compared to the variants without heat recovery.

Based on the analysis of the calculation results, the following can be stated: 
1. For HVAC systems without air recirculation $\bar{x}_{1}$ the optimal device for heat recovery is a rotary sorption regenerator $(p=2)$ and, then, an energy regenerator $(p=1)$ and a crossflow exchanger $(p=3$ or $p=4)$. The obtained energy savings are here a function of climate-Figure 11 and Table 5. Using the rotary sorption regenerator in the analyzed HVAC system ISO $8 \bar{x}_{1}$ makes it possible to decrease the annual primary energy demand by $63 \%, 64 \%$ and $24 \%$ in relation to the system without heat recovery, respectively, for continental $(q=1)$, subarctic $(q=2)$ and subtropical $(q=3)$ climates. For the rotary energy regenerator, the values are lower and equal 33\%, 35\% and 5\%, respectively. For the crossflow exchanger, the savings are significantly lower and equal $19 \div 27 \%$ for the continental climate, $5 \div 7 \%$ for the subarctic climate and $4 \%$ for the subtropical climate. Therefore, in the subtropical climate, the only rational device for heat recovery is the rotary sorption regenerator, and the savings effect is mainly achieved by drying air.

The representative percentages of the annual primary energy demand for thermodynamic air treatment for individual components and optimal variant ISO8 $\bar{x}_{12}$ (with a rotary sorption regenerator) are shown in Figure 15.

(a)

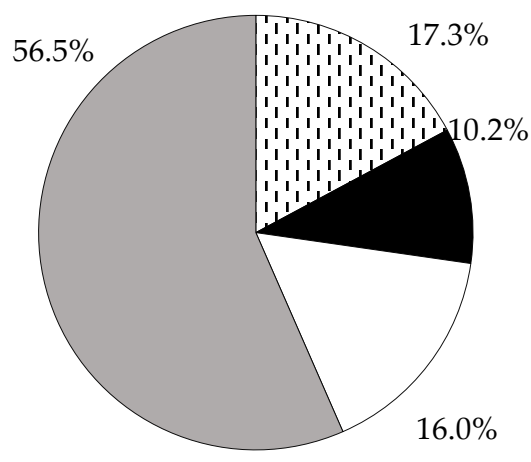

(b)

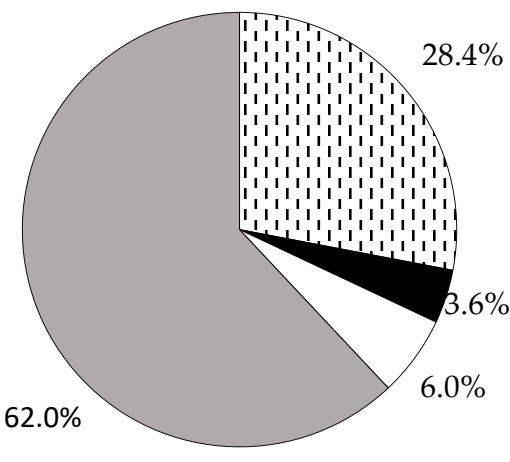

Secondary heater $\mathrm{H}_{2}$

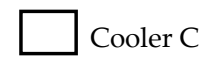

(c)

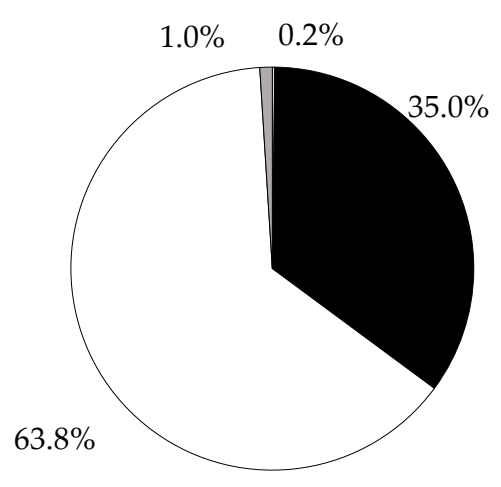

Primary heater $\mathrm{H}_{1}$

Steam humidifier B

Figure 15. Percentages of the annual primary energy demand for thermodynamic air treatment for individual components and optimal variant ISO8 $\bar{x}_{12}$ (without recirculation, rotary sorption regenerator): (a) continental climate $(q=1),(b)$ subarctic climate $(q=2)$ and $(\mathbf{c})$ subtropical climate $(q=3)$.

For the continental climate $(q=1)$ and subarctic climate $(q=2)$, the dominant is the percentage of the demand for air humidification $-56.5 \%$ and $62.0 \%$, respectively; then, for heating air- $27.5 \%$ and $32 \%$, respectively, and cooling- $16.0 \%$ and $6.0 \%$, respectively. While, for the subtropical climate $(q=3)$, the dominant is the percentage of cooling- $63.8 \%$, then heating at $35.2 \%$, including $35 \%$ of reheating after drying and, marginally, humidification$1 \%$. The conclusions resulting from the results of the calculations of representative shares of the annual primary energy demand for thermodynamic air treatment correlate directly with the conclusions concerning the optimal type of heat recovery.

2. For HVAC systems with external recirculation $\bar{x}_{2}$ (optimal for cleanrooms with high unit cooling loads $\mathrm{q}_{\mathrm{j}}$ and relatively low requirements of cleanliness class $\mathrm{C}_{\mathrm{s}}$ ), using additional heat recovery has no energy justification for any of the considered devices and external climates (savings between $1 \div 3 \%$ for ISO $8 \bar{x}_{2}$ ) -Figure 12 and Table 5 .

3. For systems with internal recirculation $\bar{x}_{3}$ (optimal for cleanrooms with low cooling loads $q_{j}$ and relatively large percentages of outdoor air $\alpha_{o}$ ), using devices for heat recovery is definitely energetically justified, especially for the continental climate $(q=1)$ and the subarctic climate $(q=2)$-Figure 13 and Table 5. The optimal device 
for heat recovery is, similar to the system without recirculation, a rotary sorption regenerator and, then, an energy regenerator and a crossflow exchanger. For the considered system ISO5 $\bar{x}_{3}$ energy savings related to a system without heat recovery, primary energy and using the sorption regenerator equal $63 \%, 66 \%$ and $23 \%$, respectively, for the continental, subarctic and subtropical climates-Figure 13. Lower savings are obtained by using an energy regenerator: $33 \%, 35 \%$ and $5 \%$ or a crossflow exchanger: $19 \div 27 \%, 5 \div 7 \%$ and $4 \%$, respectively, for the continental, subarctic and subtropical climates. The percentages of the annual primary energy demand for thermodynamic air treatment for individual components (heaters, cooler and steam humidifier) of optimal variant ISO5 $\overline{\mathrm{x}}_{32}$ (with a sorption regenerator) and external climates are practically identical as for HVAC system $\bar{x}_{12}$ (Figure 15).

4. For HVAC systems with external and internal recirculation $\bar{x}_{4}$ (optimal for cleanrooms with high cooling loads $\mathrm{q}_{j}$ and relatively low percentages of outdoor air $\alpha_{\mathrm{o}}$ ), additionally using heat recovery is energetically justified only for the subarctic climate and concerns only the rotary sorption regenerator-Figure 14 and Table 5. Savings in the primary energy demand for the analyzed HVAC system ISO7 $\bar{x}_{42}$ (with a sorption regenerator) and the subarctic climate equal 11\% related to a system without heat recovery.

It should be noted that, in the other analyzed use cases of devices for heat recovery, especially the crossflow exchanger, the energy effect was opposite to what was expected; the primary energy demand increased $1 \div 5 \%$, because the heat or cold recovery was lower than the inputs for forcing through by heat recovery exchangers.

\subsection{Validation of the Calculation Results}

Validation of the calculation results with the existing energy simulation tools is possible under the following conditions:

- $\quad$ it must be possible to implement the system structure in the program (in the case under consideration, four variants: $\bar{x}_{1}, \bar{x}_{2}, \bar{x}_{3}$ and $\bar{x}_{4}$ );

- $\quad$ it must be possible to implement various types of heat recovery along with control options: two-position control (maximum efficiency/0) and smooth control (variable energy-optimal efficiency);

- $\quad$ it must be possible to implement control algorithms (open code).

In this article, a simulation model was developed for each HVAC system structure. In these models, for each hour of the comparative year TRY (est. Reference Year), the optimal course of thermodynamic air treatment was determined, and on this basis, the energy consumption was obtained-after summing $(8760 \mathrm{~h})$, the annual energy consumption. The available energy simulation programs are universal, but also limited, among others:

- $\quad$ no possibility to implement any HVAC system structure;

- no possibility to implement any control algorithms;

- frequently closed program code.

The validation of the calculation results in this article was carried out by taking into account the above-mentioned limitations and the available other tool for energy simulationthe HAP (Hourly Analysis Program) program developed by the CARRIER company. It is a closed-source program.

The possible scope of the simulation included CAV systems (constant air volume) with heat recovery (excluding the option of a recuperator with an electric preheater before the recuperator $-\bar{x}_{14}$ and $\left.\bar{x}_{24}\right)$ with or without external recirculation $\left(\bar{x}_{1}\right.$ and $\bar{x}_{2}$ in the article). The calculation results are presented in Table 6. 
Table 6. Primary energy demand for the representative HVAC systems $\bar{x}_{n g}^{*}$ calculation results according to the HAP program (Hourly Analysis Program).

\begin{tabular}{|c|c|c|c|c|c|c|c|c|c|c|c|}
\hline \multirow{4}{*}{\multicolumn{2}{|c|}{$\begin{array}{c}\text { Optimal } \\
\text { Structure of } \\
\text { HVAC System } \\
\overline{\mathbf{x}}_{\mathrm{ng}}^{*}\end{array}$}} & \multirow{4}{*}{$\begin{array}{l}\text { Heat } \\
\text { Recovery } \\
\text { (p) }\end{array}$} & \multicolumn{9}{|c|}{ Primary Energy $\mathrm{E}_{\mathrm{p}}, \mathrm{kWh} / \mathrm{m}^{2} \mathrm{y}$} \\
\hline & & & \multicolumn{9}{|c|}{ External Climate (q) } \\
\hline & & & \multicolumn{3}{|c|}{$\begin{array}{c}\begin{array}{c}\text { Continental Climate } \\
\text { (Poland) } \\
q=1\end{array} \\
\end{array}$} & \multicolumn{3}{|c|}{$\begin{array}{c}\text { Subarctic Climate } \\
\text { (Russia) } \\
q=2 \\
\end{array}$} & \multicolumn{3}{|c|}{$\begin{array}{c}\text { Subtropical Climate } \\
\text { (Brazil) } \\
q=3 \\
\end{array}$} \\
\hline & & & Simulation & $\underset{\text { Carrier }}{\text { HAP }}$ & $\underset{\%}{\text { Difference }}{ }^{* /}$ & Simulation & $\begin{array}{c}\text { HAP } \\
\text { Carrier }\end{array}$ & $\underset{\%}{\text { Difference }}{ }^{* /}$ & Simulation & $\begin{array}{c}\text { HAP } \\
\text { Carrier }\end{array}$ & $\underset{\%}{\text { Difference }}{ }^{* /}$ \\
\hline $\bar{x}_{11}$ & \multirow{4}{*}{ IOS8 } & $\begin{array}{c}\mathrm{RO}_{\mathrm{t}} \\
(\mathrm{p}=1)\end{array}$ & 6354.0 & 6402.0 & +0.75 & 9554.0 & $10,408.0$ & +8.2 & 4877.0 & 4466.0 & -8.4 \\
\hline $\bar{x}_{12}$ & & $\begin{array}{c}\mathrm{RO}_{\mathrm{x}} \\
(\mathrm{p}=2)\end{array}$ & 3464.0 & 3212.0 & -7.3 & 5013.0 & 4623.0 & -7.8 & 3915.0 & 3656.0 & -6.6 \\
\hline $\bar{x}_{13}$ & & $\begin{array}{c}\mathrm{R}+ \\
\text { by-pass } \\
(\mathrm{p}=3)\end{array}$ & 7643.0 & 7231.0 & -5.3 & $13,693.0$ & $14,530.0$ & +5.7 & 4921.0 & 4466.0 & -9.2 \\
\hline$\overline{\mathrm{x}}_{15}$ & & $\begin{array}{l}\text { Without } \\
\text { heat } \\
\text { recovery } \\
(\mathrm{p}=5)\end{array}$ & 9426.0 & 9408.0 & -0.2 & $14,733.0$ & $15,961.0$ & +7.7 & 5118.0 & 4819.0 & -6.0 \\
\hline$\overline{\mathrm{x}}_{21}$ & \multirow{4}{*}{ IOS8 } & $\begin{array}{c}\mathrm{RO}_{\mathrm{t}} \\
(\mathrm{p}=1)\end{array}$ & 4965.0 & 5231.0 & +5.0 & 5078.0 & 4849.0 & -4.5 & 5118.0 & 5106.0 & -0.2 \\
\hline$\overline{\mathrm{x}}_{22}$ & & $\begin{array}{c}\mathrm{RO}_{\mathrm{x}} \\
(\mathrm{p}=2)\end{array}$ & 4930.0 & 5178.0 & +4.8 & 5055.0 & 4592.0 & -9.2 & 4945.0 & 4533.0 & -8.3 \\
\hline $\bar{x}_{23}$ & & $\begin{array}{c}\mathrm{R}+ \\
\text { by-pass } \\
(\mathrm{p}=3)\end{array}$ & 4965.0 & 5244.0 & +5.3 & 5078.0 & 4849.0 & -4.5 & 5118.0 & 5106.0 & -0.2 \\
\hline$\overline{\mathrm{x}}_{25}$ & & $\begin{array}{l}\text { Without } \\
\text { heat } \\
\text { recovery } \\
(\mathrm{p}=5)\end{array}$ & 4898.0 & 5170.0 & +5.3 & 5010.0 & 4886.0 & -2.5 & 5091.0 & 5084.0 & -0.1 \\
\hline
\end{tabular}

*/ Related to own simulation.

Taking into account the above-mentioned conditions and limitations, it can be concluded that the obtained results of the calculations are satisfactory, and the differences in the annual energy demand according to our own calculations and the HAP program, related to the values obtained in our own calculations, are acceptable. These differences range from $-9.2 \%$ to $+8.2 \%$ (minimal differences: $-0.2 \%$ to $+0.75 \%$ ). The mean absolute percentage of the differences in the results of these calculations is $5.1 \%$. Taking into account that the simulation models of the other systems included in the article $\left(\bar{x}_{3}-\right.$ with internal recirculation and $\bar{x}_{4}$-with internal and external recirculation) are a modification of the models for the validated systems $\overline{\mathrm{x}}_{1}$ and $\overline{\mathrm{x}}_{2}$, it can be assumed that the obtained calculation results are also acceptable.

\section{Conclusions}

This article presents the original results of research on the optimization of HVAC systems for cleanrooms. The HVAC systems were described by vectors with coordinates defined by constant parameters and decision variables. Then, the authors defined, based on limitations, a set of acceptable variants covering the following structures of HVAC system: $\overline{\mathrm{x}}_{1}$-without recirculation, $\overline{\mathrm{x}}_{2}$-with external recirculation, $\overline{\mathrm{x}}_{3}$-with internal recirculation and $\bar{x}_{4}$-with external and internal recirculation.

In the next stage, based on the optimization algorithm, the authors defined a set of energy-optimal structures of the HVAC system for cleanrooms as a function of key constant parameters and wide representative variability ranges of these parameters: cleanliness classes $\mathrm{C}_{\mathrm{s}}$-ISO5, ISO7 and ISO8; $\mathrm{u}$ nit cooling loads $\mathrm{q}_{j}=(100 \div 500) \mathrm{W} / \mathrm{m}^{2}$ and percentage of outdoor air $\alpha_{0}=(5 \div 100) \%$.

The original achievement of the research, which constitutes a new cognitive quality, is the development of relations approximating $\bar{x}_{n g}^{*}=f\left(C_{S}, \alpha_{0}, q_{j}\right)$ defining the zones of energyoptimal structures of cleanroom HVAC systems; the equations derived the boundary lines separating these zones. 
It was proven that HVAC systems with external recirculation $\left(\overline{\mathrm{x}}_{2}\right)$ are optimal structures for rooms with high cooling loads $\mathrm{q}_{j}$ and low requirements concerning keeping the cleanliness class, HVAC systems with internal recirculation $\left(\bar{x}_{3}\right)$ are optimal for rooms with low cooling loads $\mathrm{q}_{j}$ and relatively high percentages of outdoor air $\alpha_{0}$, while HVAC systems with external and internal recirculation $\left(\bar{x}_{4}\right)$ are optimal structures for rooms with high cooling loads $q_{j}$ and relatively low percentages of outdoor air $\alpha_{0}$.

The obtained results, due to the used wide ranges of variability of key constant parameters, are general in nature and have great application value.

An important result of the research was defining energy-optimal control algorithms and the type of heat recovery as an element of optimal structures of the HVAC system. At this stage, the equations of the boundary lines between the zones of optimal thermodynamic air treatment were determined, which is of great application importance.

In the optimization procedure based on simulation models, the objective function was defined as the minimum unit annual primary energy demand for thermodynamic air treatment of the HVAC system $\left(\mathrm{E}_{\mathrm{p}}\left(\overline{\mathrm{x}}_{\mathrm{n} g}^{*}=\mathrm{min}\right)\right.$. The algorithms take into account the energy demand for forcing through by heat recovery exchangers.

Summarizing the results of the analyses and calculations concerning the energetic profitability of using heat recovery in optimal structures of HVAC systems for cleanrooms, it can be stated that:

- it is energetically profitable to use heat recovery, especially for HVAC systems without recirculation $\left(\overline{\mathrm{x}}_{1}\right)$ or with internal recirculation $\left(\overline{\mathrm{x}}_{3}\right)$, whereby the biggest energy savings are achieved for the continental climate (Poland) and the subarctic climate (Russia).

- in any case, the biggest savings in primary energy demand are the result of using, as heat recovery, a rotary sorption regenerator and, then, an energy regenerator and a crossflow (or countercurrent) exchanger.

- quantitatively, using a sorption regenerator in the energy-optimal structures of HVAC system ISO $8 \bar{x}_{1}$ (without recirculation) and ISO5 $\bar{x}_{3}$ (with internal recirculation) resulted in a decrease in the primary energy demand for thermodynamic treatment by $63 \%, 64 \div 66 \%$ and $23 \div 24 \%$, respectively, for the continental, subarctic and subtropical climates. For an energy regenerator and a crossflow exchanger, these savings were significantly lower and equaled about $33 \%, 35 \%$ and $5 \%$, respectively.

- for energy-optimal structures of HVAC systems with external recirculation $\bar{x}_{2}$ or with external and internal recirculation $\bar{x}_{4}$, using devices for heat recovery is generally energetically not justified and, in all cases, causes an increase in the energy demand (heat or cold recovery is lower than the energy inputs for forcing through by the heat recovery exchanger). The only debatable exception is the application of a sorption regenerator in the HVAC system $\bar{x}_{4}$ for the subarctic climate-primary energy savings for thermodynamic air treatment of $11 \%$ in the ISO7 application $\bar{x}_{42}$.

Author Contributions: Conceptualization, M.P.; methodology, M.P.; software, M.J.; validation, M.P. and M.J.; formal analysis, M.P. and M.J.; investigation, M.P. and M.J.; resources, M.P. and M.J.; data curation, M.P.; writing—original draft preparation, M.P.; writing-review and editing, M.J.; visualization, M.P.; supervision, M.P.; project administration, M.P. and funding acquisition, M.P. All authors have read and agreed to the published version of the manuscript.

Funding: This research was funded by the Polish Ministry of Education and Science, grant number 504101/0713/SBAD/0948.

Institutional Review Board Statement: Not applicable.

Informed Consent Statement: Not applicable.

Data Availability Statement: Not applicable.

Conflicts of Interest: The authors declare no conflict of interest. 


\section{Abbreviations}

The following abbreviations are used in this manuscript:

AHU

Air-Handling Unit

MAU

Make-up Air-Handling Unit

RU (RDCU)

FFU (FDCU)

DCC

Return Unit (Return Dry Cooling Unit)

Dry Cooling Coil

The following contractual values are used in this manuscript:

$\mathrm{C}_{\mathrm{S}}$ cleanliness class

$E_{1}, E_{2}, E_{3}$

efficiency of air filter of 1st, 2nd and 3rd stage

$\mathrm{E}_{\mathrm{el}, \mathrm{pom}}$

$\mathrm{E}_{\mathrm{P}}$

annual demand for final electrical energy for the drive of auxiliary devices of

HVAC system

$g_{()_{k}\left(x_{j}\right)}$

annual primary energy demand of HVAC system

k-limitation (T) - technological, (H) - hygienic, (A) - acoustic, (E) - energetic,

\section{G}

$\mathrm{G}^{\mathrm{i}}$

(M) material, (AK) —architectural and constructional and (BN)—concerning

safety and reliability [37]

binary matrix of limitation conditions for matrix $\mathbf{X}^{\mathrm{J}}$

$\mathbf{G}^{\mathrm{j}}$

$\mathrm{k}_{\mathrm{d}}$

$\dot{\mathrm{m}}$

$\dot{\mathrm{q}}_{\mathrm{j}}$

$\dot{\mathrm{q}}_{\mathrm{jc}}$

$\dot{\mathrm{q}}_{\mathrm{DC}}$

$\mathrm{Q}_{\mathrm{H}, \mathrm{n}}, \mathrm{Q}_{\mathrm{Hel}, \mathrm{n}}$,

$\mathrm{Q}_{\mathrm{C}, \mathrm{n}}, \mathrm{Q}_{\mathrm{B}, \mathrm{n}}$

$\mathrm{Q}_{\mathrm{K}, \mathrm{H}}, \mathrm{Q}_{\mathrm{K}, \mathrm{C}}$,

$\mathrm{Q}_{\mathrm{K}, \mathrm{B}}$

$\mathrm{t}$

binary matrix of limitation conditions for matrix $\mathbf{W}$

binary matrix of elimination of unnecessary decision variables for matrix

$\left(\mathbf{G}^{\mathrm{i}} \times \mathbf{W}\right)$

acceptable concentration of contaminants in room

air mass stream

unit cooling load of room, $\mathrm{W} / \mathrm{m}^{2}$

unit cooling load discharged using $\mathrm{AHU}, \mathrm{W} / \mathrm{m}^{2}$

unit cooling load of room discharged by the dry cooler in the internal

recirculation circuit, $\mathrm{W} / \mathrm{m}^{2}$

net annual energy demand of heaters, electric heaters, coolers and steam

humidifiers

annual final energy demand of heaters (final heat), coolers (final cold) and steam humidifiers (final heat for humidifiers)

temperature, ${ }^{\circ} \mathrm{C}$

$t_{\mathrm{DP}}$

dew point temperature

outdoor air temperature (with percentage $\alpha_{\mathrm{o}}$ ) for which the sensible heat gains are transferred without heat recovery $\left(\phi_{t}=0\right)$, heating or cooling in AHU

outdoor air temperature (with percentage $\alpha_{0}$ ) for which the sensible heat gains

$\mathrm{t}_{\mathrm{G}^{\prime}}$

are transferred at maximal efficiency of heat recovery $\phi_{\mathrm{t}}=\phi_{\mathrm{tmax}}$ but without heating air or cooling in AHU

outdoor air temperature at which primary energy demand for the option of

$\mathrm{t}_{\mathrm{G}^{\prime \prime}}$ maximal heat and cold recovery $\left(\phi_{\mathrm{t}}=\phi_{\mathrm{tmax}}\right)$ is equal to this demand for the heating-only option

$\mathrm{t}_{\mathrm{GR} 0}$

$\mathrm{t}_{\mathrm{S}}$

outdoor air temperature limit below which the recuperator freezes

air supply temperature

air supply temperature downstream AHU for which sensible heat gains are

$t_{S C}$

discharged from room as a result of mixing this air (with percentage $\alpha_{\mathrm{o}}$ ) with

internally recirculated air

$t_{R} \quad$ air temperature in room

$\mathrm{Tu} \quad$ turbulence degree

$\dot{\mathrm{V}}_{\mathrm{j}}$

unit calculation ventilation air stream for cleanroom, $\mathrm{m}^{3} / \mathrm{hm}^{2}$

unit required air stream as function of room cleanliness class, $\mathrm{m}^{3} / \mathrm{hm}^{2}$

unit required air stream as function of cooling loads discharged using $\mathrm{AHU}$,

$\mathrm{m}^{3} / \mathrm{hm}^{2}$

$\dot{\mathrm{V}}_{\mathrm{jc}}$

unit required outdoor air stream, $\mathrm{m}^{3} / \mathrm{hm}^{2}$

$\mathrm{V}_{\text {jo }}$

W

average air speed in room 
$\mathrm{w}_{\mathrm{i}}$

$\mathbf{W}_{\mathrm{i}}$

$\mathbf{W}\left(\mathbf{W}^{\mathrm{g}}\right)$

$\mathrm{x}_{\mathrm{i}}$

$x_{j}$

$\bar{x}$

$\overline{\mathrm{X}}_{\mathrm{n}} \mathrm{g}$

$\overline{\mathrm{X}}^{*}$

$\mathbf{X}^{\mathrm{J}}(\mathbf{X})$

$\alpha_{\mathrm{o}}\left(\alpha_{\mathrm{os}}\right)$

$\alpha_{\mathrm{C}}$

$\alpha_{1}, \alpha_{2}$

$\varepsilon_{\text {sdop }}$

$\eta_{\mathrm{H}, \mathrm{t}}, \eta_{\mathrm{Hel}, \mathrm{t}}$,

$\eta_{\mathrm{C}, \mathrm{t}}, \eta_{\mathrm{B}, \mathrm{t}}$

$\varphi_{\mathrm{R}}$

$\Delta \mathrm{p}$

$\Delta \mathrm{h}$

$\phi_{\mathrm{t}}, \phi_{\mathrm{x}}$

The foll

I

$\mathrm{I}^{*}$

J

k

K

K

$\mathrm{k}_{\mathrm{d}}$

N input coefficient of nonrenewable primary energy for generation and supply of final energy carrier (or energy) — for balance boundary of building

$\left(\mathrm{w}_{\mathrm{H}}\right.$ - concerns heat for heaters, $\mathrm{w}_{\mathrm{C}}$-concerns cold for coolers, $\mathrm{w}_{\mathrm{B}}-$ concerns heat for steam humidifiers and $\mathrm{w}_{\mathrm{el}}$ - concerns electrical energy)

binary matrix of all possible variants of combinations of decision variables

values $x_{j}$ for normalizing constant parameter $x_{i}$

binary matrix of all possible variants (of acceptable variants) of combinations of decision variables values $x_{j}$ for normalizing all constant parameters $x_{i}$ of $a$ HVAC system

constant parameter of a HVAC system

decision variable of a HVAC system

vector of a HVAC system

binary vector defining the $\mathrm{n}$-variant ( $\mathrm{n}^{\mathrm{g}}$-acceptable variant) of structure of a

HVAC system used for normalizing all constant parameters

vector of the optimal variant of HVAC system

binary matrix of all possible variants (of acceptable variants) of a HVAC

system for normalizing constant parameters

percentage of outdoor air compared to unit calculation air stream supplied to

cleanroom $\dot{\mathrm{V}}_{\mathrm{j}}$ (of unit required air stream as function of cleanliness class $-\dot{\mathrm{V}}_{\mathrm{js}}$ )

percentage of air being thermodynamically treated in AHU in air stream

supplied to room $-\dot{\mathrm{V}}_{\mathrm{j}}$

percentage of air under external recirculation, internal recirculation in air

stream supplied to room $-\dot{\mathrm{V}}_{\mathrm{j}}$

relative concentration of microorganisms

seasonal average total efficiency of heating system for water heaters, heating system for electric heaters, cold system for coolers and heating system for steam humidifiers

relative air humidity in room

differential pressure (overpressure and underpressure in a room)

change in specific enthalpy of the air

efficiency of sensible heat recovery, humidity

dices are used in this manuscript:

index of constant parameter of HVAC system

number of constant parameters of HVAC system

number of normalized constant parameters of HVAC system

number of decision variables of HVAC system

index of k-combination of values of key constant parameters of HVAC system number of combinations of values of key constant parameters of HVAC system k-hour of reference year (TRY-Test Reference Year, $\mathrm{k}=1 \div 8760$ )

permissible concentration of pollutants

number of all possible variants of HVAC system for normalizing constant

parameters

\section{Appendix A. Procedure for Determining the Matrix of Acceptable Variants of the HVAC System}

The matrix of normalized constant parameters is defined as:

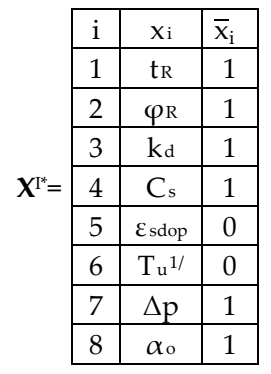


where:

1/_correlation with cleanliness class CS applies to special cases (DIN 1946-4:201809 [43]).

$\mathbf{X}^{\mathrm{I}^{*}}$-binary matrix of normalized constant parameters $\mathrm{x}_{\mathrm{i}}$ of HVAC system,

$\mathrm{i}=1 \ldots \mathrm{I}^{*}$-number of normalized constant parameter,

$\mathrm{I}^{*}$ - number of normalized constant parameters of HVAC system,

$\mathrm{x}_{\mathrm{i}}$ - constant parameter of HVAC system,

$\bar{x}_{i}$-vector of normalized constant parameters of HVAC system.

Matrix $\mathbf{W}$ of all possible variants of combinations of decision variables for normalizing all constant parameters of HVAC system is defined as:

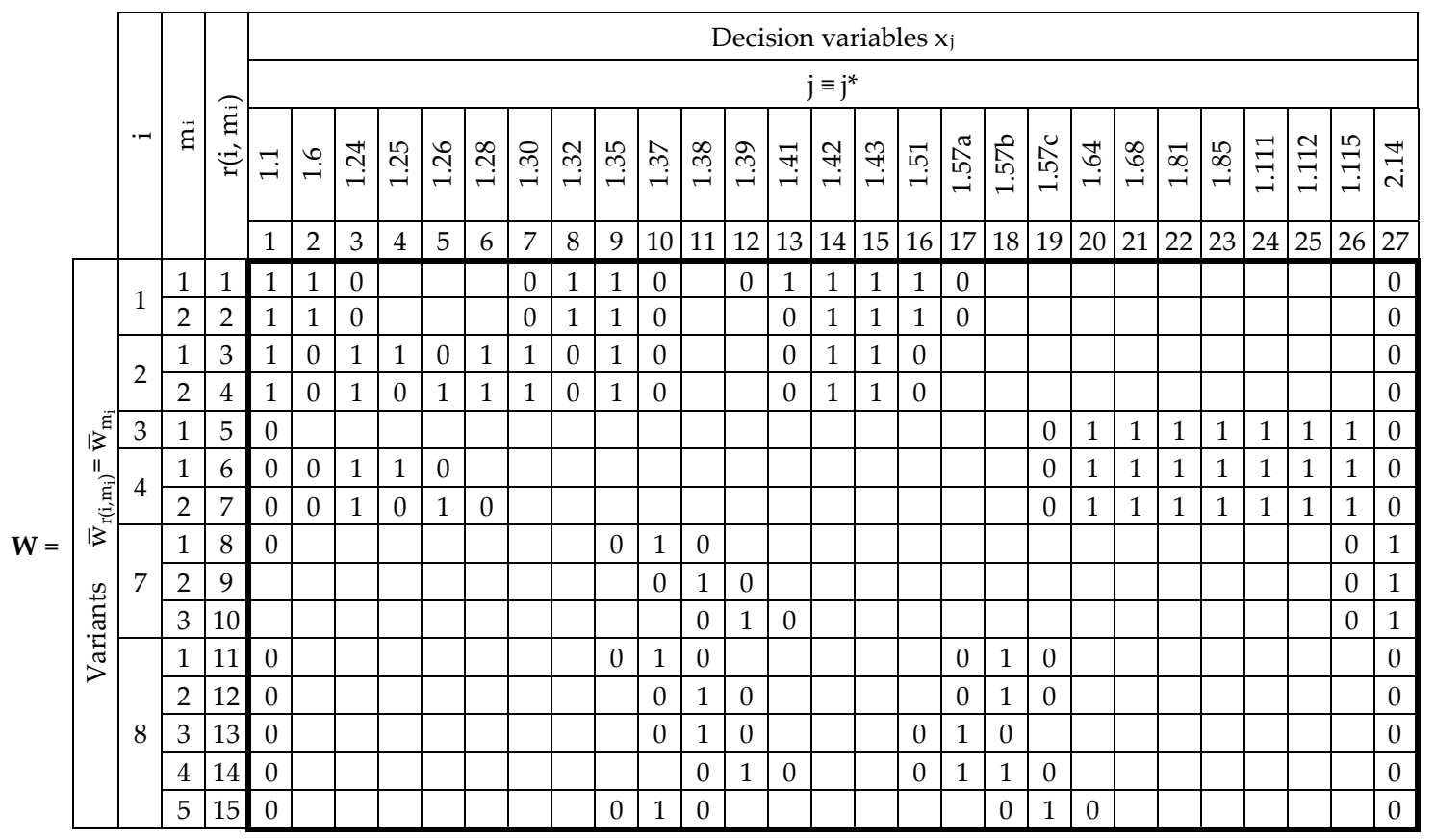

where:

W-binary matrix of all possible variants of combinations of decision variables values $\mathrm{x}_{\mathrm{j}}$ for normalizing all constant parameters $\mathrm{x}_{\mathrm{i}}$ of HVAC system,

$\mathrm{x}_{j}$-decision variable of HVAC system,

$\mathrm{j}$-index of decision variable of HVAC system,

$\mathrm{j}^{*}$-index of decision variable of HVAC system from a universal set in Tables A2 and A3 [37],

$\mathrm{m}_{\mathrm{i}}$ or $\mathrm{r}\left(\mathrm{i}, \mathrm{m}_{\mathrm{i}}\right)$-index of $\mathrm{m}_{\mathrm{i}}-$ or $\mathrm{r}\left(\mathrm{i}, \mathrm{m}_{\mathrm{i}}\right)$-variant of combinations of decision variables values $x_{j}$ for normalizing $x_{i}$-constant parameter of HVAC system,

$\mathrm{M}_{\mathrm{i}}$-number of all possible variants of combinations of decision variables values $x_{j}$ for normalizing $\mathrm{x}_{\mathrm{i}}$-constant parameter of HVAC system,

$\overline{\mathrm{w}}_{\mathrm{m}_{\mathrm{i}}}$ or $\overline{\mathrm{w}}_{\mathrm{r}\left(\mathrm{i}, \mathrm{m}_{\mathrm{i}}\right)}$-binary vector defining $\mathrm{m}_{\mathrm{i}}-$ or $\mathrm{r}\left(\mathrm{i}, \mathrm{m}_{\mathrm{i}}\right)$-variant of combinations of decision variables values $x_{j}$ for normalizing $x_{i}$-constant parameter of HVAC system (matrix element $\mathbf{W}$ ).

$\mathrm{m}_{\mathrm{i}}=1 \ldots \mathrm{M}_{\mathrm{i}}$

$$
r\left(i, m_{i}\right)=\left\{\begin{array}{c}
m_{i}, i=1 \\
\sum_{k=1}^{i=1}\left(M_{k}\right)+m_{i}, i=2 \ldots I^{*}
\end{array}\right.
$$

whereby:

$\mathrm{r}\left(\mathrm{i}, \mathrm{m}_{\mathrm{i}}\right)=1 \ldots \mathrm{M}$

$$
\mathrm{M}=\mathrm{r}\left(\mathrm{I}^{*}, \mathrm{M}_{\mathrm{i}}\right)=\sum_{\mathrm{i}=1}^{\mathrm{I}^{*}} \mathrm{M}_{\mathrm{i}}
$$


The rows of the $\mathbf{W}$ matrix are variants $\left(\mathrm{m}_{\mathrm{i}}\right.$ or $\left.\mathrm{r}\left(\mathrm{i}, \mathrm{m}_{\mathrm{i}}\right)\right)$ of combinations of decision variables for the normalization of successive of the constants parameters included in the matrix $\mathbf{X}^{\mathrm{I}^{*}}$ :

$\left(\mathrm{i}=1, \mathrm{x}_{1} \equiv \mathrm{t}_{\mathrm{R}}\right.$ ) -two variants including the CAV (Constant Air Volume) system with AHU with heat recovery (1.51-here cumulative variable), primary heater (option), cooler and secondary heater.

$\left(\mathrm{i}=2, \mathrm{x}_{2} \equiv \varphi_{\mathrm{R}}\right)$-two variants including AHU with cooler, secondary heater and steam humidifier in the unit or in the duct (option),

$\left(\mathrm{i}=3, \mathrm{x}_{3} \equiv \mathrm{k}_{\mathrm{d}}\right.$ )—one variant with the hygienic design of AHU, three stages of filtration at the supply, 3rd stage filter integrated with a supply diffuser,

$\left(\mathrm{i}=4, \mathrm{x}_{4} \equiv \mathrm{C}_{\mathrm{s}}\right)$ - two variants as for $\left(\mathrm{i}=3, \mathrm{x}_{3} \equiv \mathrm{k}_{\mathrm{d}}\right)$ and a steam humidifier in the AHU unit or in the duct,

$\left(\mathrm{i}=5, \mathrm{x}_{5} \equiv \alpha\right)$-five variants depending on the number of units in the cascade (one, two or three) and the recirculation option:

$\mathrm{x}_{1.57 \mathrm{a}}$-internal (room) recirculation, cumulative variable,

$\mathrm{x}_{1.57 \mathrm{~b}}$ - external recirculation (in front of the AHU),

$\mathrm{x}_{1.57 \mathrm{c}}$-without recirculation,

Matrix $\mathbf{W}$ is of type $(15,27)$. Matrix with limitations $\mathbf{G}^{\mathrm{i}}$ for matrix $\mathbf{W}$ is of type $(15,15)$ and is defined as:

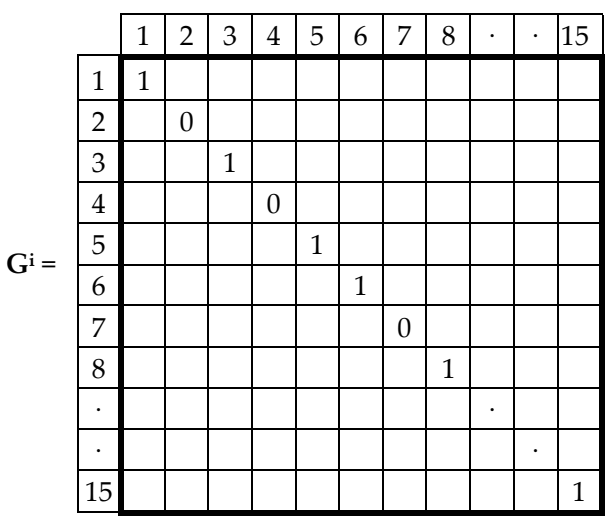

where:

$\mathbf{G}^{\mathrm{i}}$-binary matrix of limitation conditions for matrix $\mathbf{W}$,

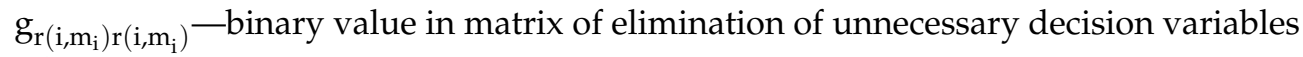

$\mathrm{G}^{\mathrm{i}}$ for $\mathrm{r}\left(\mathrm{i}, \mathrm{m}_{\mathrm{i}}\right)$-variant of combinations of decision variables values $\mathrm{x}_{\mathrm{j}}$ for normalizing $\mathrm{x}_{\mathrm{i}}$-constant parameter defined by vector $\overline{\mathrm{W}}_{\mathrm{r}\left(\mathrm{i}, \mathrm{m}_{\mathrm{i}}\right)}$ in matrix $\mathbf{W}$.

The words $g_{r\left(i, m_{i}\right) r\left(i, m_{i}\right)}$ correspond to the eliminated variants in matrix $W$ and result from limitations. Taking into account the notations in the table of restrictions A9 [37], the assignment here is as follows: $r\left(\mathrm{i}, \mathrm{m}_{\mathrm{i}}\right)=2-\mathrm{g}_{\mathrm{T} 6}, \mathrm{~g}_{\mathrm{T} 19}, \mathrm{r}\left(\mathrm{i}, \mathrm{m}_{\mathrm{i}}\right)=4-\mathrm{g}_{\mathrm{T} 11}, \mathrm{~g}_{\mathrm{T} 28}, \mathrm{r}\left(\mathrm{i}, \mathrm{m}_{\mathrm{i}}\right)=7-$ $\mathrm{g}_{\mathrm{T} 1} 1, \mathrm{~g}_{\mathrm{T} 28}$.

Interpretation of elements $g_{r\left(i, m_{i}\right) r\left(i, m_{i}\right)}=0$ - of eliminated variants in matrix $W$ is shown in Table A1.

After taking into account the constraints, redundant decision variables can be identified, which in the adopted methodology are eliminated in order to reduce the description of the mathematical problem. 
Table A1. Interpretation of elements $g_{r\left(i, m_{i}\right) r\left(i, m_{i}\right)}=0$ in matrix $\mathbf{G}$.

\begin{tabular}{|c|c|c|}
\hline $\mathbf{r}\left(\mathbf{i}, \mathbf{m}_{\mathbf{i}}\right)$ & Limitations $\mathrm{g}_{(\mathbf{k}(\mathrm{xj})} * /$ & Comments \\
\hline 2 & $\mathrm{~g}_{\mathrm{T} 6}$ & $\begin{array}{l}\text { lack of a primary heater, with a large power differentiation for summer and winter, } \\
\text { prevents the optimal selection of } \mathrm{k}_{\mathrm{V}} \text { output coefficients of control valves for the } \\
\text { secondary heater-and as a consequence causes unstable operation of control valves } \\
\text { and extends the range of tolerance of the supply air temperature }\end{array}$ \\
\hline & $\mathrm{g}_{\mathrm{T} 19}$ & lack of a primary heater poses a risk of freezing of the water cooler \\
\hline 4 & $\begin{array}{l}\mathrm{g}_{\mathrm{T} 11} \\
\mathrm{~g}_{\mathrm{T} 28}\end{array}$ & $\begin{array}{l}\text { steam humidifier with lance in channel does not provide easy operational access to } \\
\text { the humidification block for control and disinfection-difficulties in maintenance } \\
\text { and decrease in safety }\end{array}$ \\
\hline 7 & $\begin{array}{l}\mathrm{g}_{\mathrm{T} 11} \\
\mathrm{~g}_{\mathrm{T} 28}\end{array}$ & $\begin{array}{l}\text { steam humidifier with lance in channel does not provide easy operational access to } \\
\text { the humidification block for control and disinfection-difficulties in maintenance } \\
\text { and decrease in safety }\end{array}$ \\
\hline
\end{tabular}

*/ Designation of restrictions according to [37].

Matrix $\mathrm{G}^{\mathrm{j}}$ of type $(27,27)$ of elimination of unnecessary decision variables is defined as:

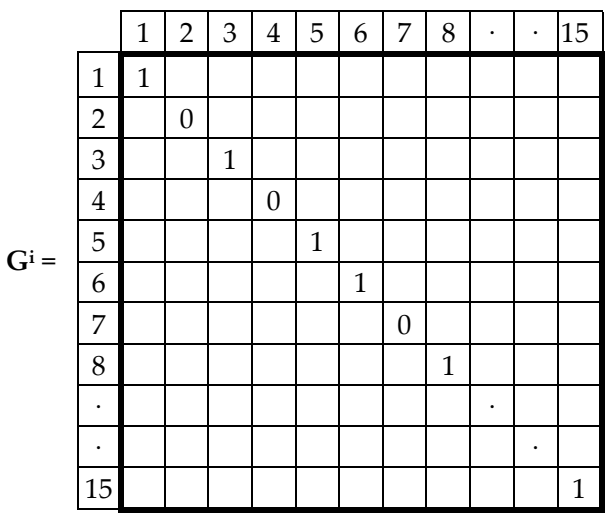

where:

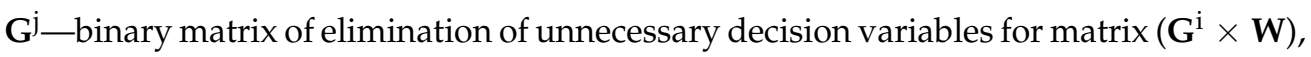

Matrix $\mathrm{W}^{\mathrm{g}}$ - after considering limitations and eliminating unnecessary decision variables is obtained as the product of matrices defined as:

$$
\mathbf{W}^{\mathrm{g}}=\mathrm{G}^{\mathrm{i}} \times \mathbf{W} \times \mathbf{G}^{\mathrm{j}}
$$

After eliminating zero rows and columns-matrix $\mathbf{W}^{\mathrm{g}}$ is defined as: 


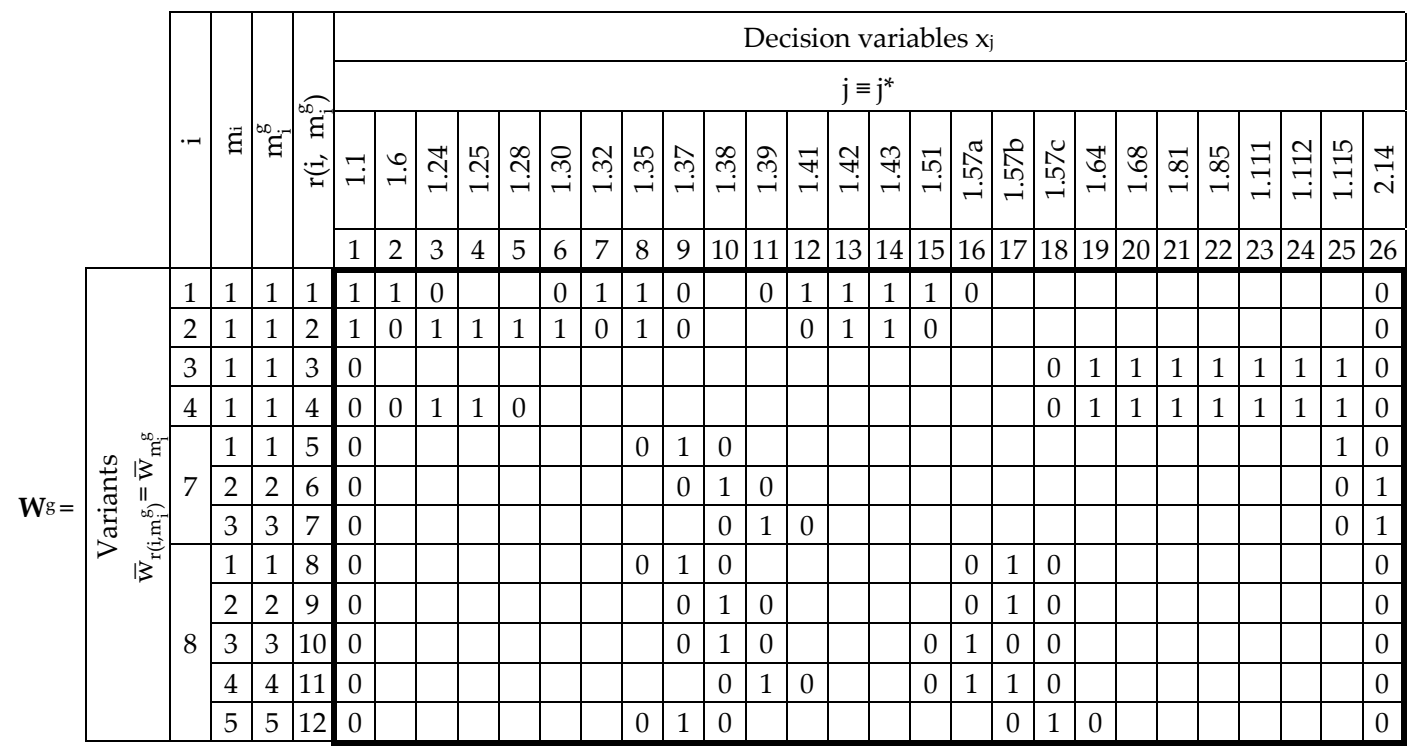

where:

$\mathbf{W}^{\mathrm{g}}$ - binary matrix of acceptable variants of combinations of decision variables values $x_{j}$ for normalizing all constant parameters $x_{i}$ of HVAC system,

$\overline{\mathrm{w}}_{\mathrm{m}_{\mathrm{i}}^{\mathrm{g}}}$ or $\overline{\mathrm{w}}_{\mathrm{r}\left(\mathrm{i}, \mathrm{m}_{\mathrm{i}}^{\mathrm{g}}\right)}$-binary vector defining $\mathrm{m}_{\mathrm{i}^{-}}$or $\mathrm{r}\left(\mathrm{i}, \mathrm{m}_{\mathrm{i}}\right)$-variant $\mathrm{r}\left(\mathrm{i}, \mathrm{m}_{\mathrm{i}}^{\mathrm{g}}\right)$-acceptable variant) of combinations of decision variables values $x_{j}$ for normalizing $x_{i}$-constant parameter of HVAC system (matrix element $\mathbf{W}^{\mathrm{g}}$ ),

$\mathrm{m}_{\mathrm{i}}^{\mathrm{g}}$ or $\mathrm{r}\left(\mathrm{i}, \mathrm{m}_{\mathrm{i}}^{\mathrm{g}}\right)$-index of $\mathrm{m}_{\mathrm{i}}^{\mathrm{g}}$ - or $\mathrm{r}\left(\mathrm{i}, \mathrm{m}_{\mathrm{i}}^{\mathrm{g}}\right)$-variant of combinations of decision variables values $x_{j}$ for normalizing $x_{i}$-constant parameter of HVAC system, after considering limitations.

Matrix $\mathbf{X}^{\mathrm{J}}$ of all possible variants of HVAC system is defined as:

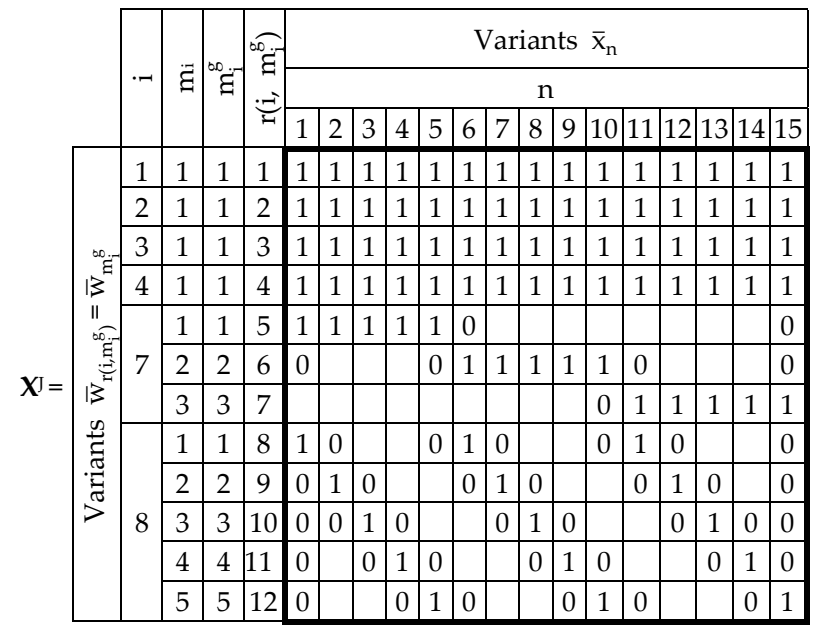

where:

$\mathrm{X}$ _-binary matrix of acceptable variants of HVAC system for normalizing constant parameters,

$\bar{x}_{n}$-binary vector defining the n-variant of structure of HVAC system used for normalizing all constant parameters, 
$\mathrm{x}_{\mathrm{m}_{\mathrm{i}}^{\mathrm{g}} \mathrm{n}}$ or $\mathrm{x}_{\mathrm{r}\left(\mathrm{i}, \mathrm{m}_{\mathrm{i}}^{\mathrm{g}}\right) \mathrm{n}}$ - binary value in the n-variant structures of HVAC system for $\mathrm{m}_{\mathrm{i}}^{\mathrm{g}}$ or $\mathrm{r}\left(\mathrm{i}, \mathrm{m}_{\mathrm{i}}^{\mathrm{g}}\right)$-variant of combinations of decision variables values for normalizing $\mathrm{x}_{\mathrm{i}^{-}}$ constant parameter defined by vector $\overline{\mathrm{w}}_{\mathrm{m}_{\mathrm{i}}^{\mathrm{g}}}$ or $\overline{\mathrm{w}}_{\mathrm{r}\left(\mathrm{i}, \mathrm{m}_{\mathrm{i}}^{\mathrm{g}}\right)}$ in matrix $\mathbf{W}^{\mathrm{g}}$, matrix element $\mathbf{X}^{\mathrm{J}}$, $\mathrm{M}_{\mathrm{i}}^{\mathrm{g}}$-number of all possible variants of combinations of decision variables values $\mathrm{x}_{\mathrm{j}}$ for normalizing xi-constant parameter of HVAC system, after considering limitations.

Vector $\bar{x}_{n}$ is created by selecting from matrix $\mathbf{W}^{\mathrm{g}}$ a single variant of combinations of decision variables $\overline{\mathrm{w}}_{\mathrm{r}\left(\mathrm{i}, \mathrm{m}_{\mathrm{i}}^{\mathrm{g}}\right)}=\overline{\mathrm{w}}_{\mathrm{m}_{\mathrm{i}}^{\mathrm{g}}}$ from ranges $\mathrm{m}_{\mathrm{i}}^{\mathrm{g}}=1 \ldots \mathrm{M}_{\mathrm{i}}^{\mathrm{g}}$ for each of normalized constant parameters $x_{i}, I=1 \ldots I^{*}$ and by assigning this variant value $x_{r\left(i, m_{i}^{g}\right)}=1$, and by assigning the remaining variants from range $\mathrm{m}_{\mathrm{i}}^{\mathrm{g}}=1 \ldots \mathrm{M}_{\mathrm{i}}^{\mathrm{g}}$ each of normalized constant parameters $x_{i}$ value $x_{r\left(i, m_{i}^{g}\right)}=0$.

The number of all, defined in this particular way, possible vectors $\bar{x}_{n}$ - of all possible variants of HVAC system for cleanroom equals:

$$
\mathrm{N}=\prod_{\mathrm{i}=1}^{8} \mathrm{M}_{\mathrm{i}}^{\mathrm{g}}=1 \cdot 1 \cdot 1 \cdot 1 \cdot 3 \cdot 5=15
$$

By identifying the values of the words of the vector $\bar{x}_{n}$ (column of the $X^{J}$ matrix), the structure of the HVAC system is identified for the normalization of successive constant parameters.

\section{Limiting Conditions, Set of Acceptable Variants}

Matrix $\mathbf{G}$ of type $(15,15)$ of limiting conditions for matrix $\mathbf{X}^{\mathrm{J}}$ of all possible variants of HVAC system for cleanroom is defined as:

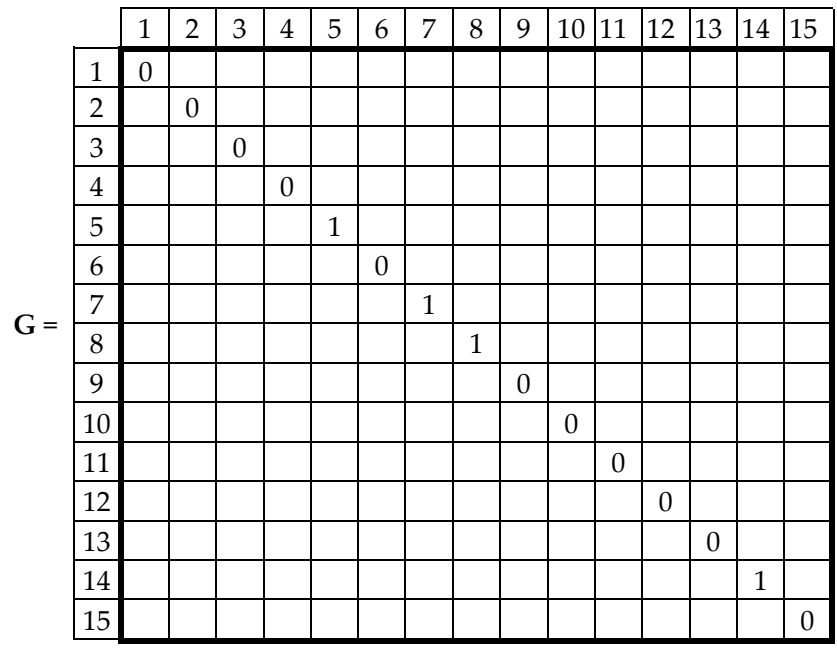

where:

G-binary matrix of limitation conditions for matrix $\mathbf{X}^{\mathrm{J}}$,

$\mathrm{g}_{\mathrm{nn}}$ - binary value in matrix with limitations $\mathbf{G}$ for the n-variant of structure of HVAC system defined by vector $\bar{x}_{n}$ in matrix $\mathbf{X}^{\mathrm{J}}$,

The words $g_{n, n}=0$ correspond to eliminating variants (vectors $\bar{x}_{n}$ ) in the matrix $\mathbf{X}^{J}$. Variants that are internally inconsistent or identical to other variants are eliminated.

Interpretation of elements $g_{n, n}=0$ - of eliminated vectors $\bar{x}_{n}$ in matrix $X^{\top}$-is shown in Table A2. 
Table A2. Interpretation of vectors $g_{n, n}=0$ in matrix $X^{J}$.

\section{n}

1

2

3

4

6

9

10

11

12

13

15

\section{Comments}

Variant thermodynamically identical to variant $\bar{x}_{7}(n=7)$, variant $\bar{x}_{7}$ more favorable for the regulation of overpressure in the room

No consistency $-\Delta p$ regulation - one air handling unit, $\alpha$ regulation - two air handling units No consistency $-\Delta p$ regulation-one air handling unit, $\alpha$ regulation-two air handling units No consistency $-\Delta p$ regulation — one air handling unit, $\alpha$ regulation — three air handling units No consistency $-\Delta$ p regulation - two air handling units in cascade, $\alpha$ regulation-one air handling unit No consistency $-\Delta \mathrm{p}$ regulation - two air handling units in cascade, $\alpha$ regulation-three air handling units Irrational variant - two air handling units (fans) in cascade in a system without recirculation No consistency $-\Delta$ p regulation - three air handling units, $\alpha$ regulation — one air handling unit No consistency $-\Delta$ p regulation - three air handling units, $\alpha$ regulation-two air handling units No consistency $-\Delta$ p regulation - three air handling units, $\alpha$ regulation-two air handling units Irrational variant - three air handling units (fans) in cascade in a system without recirculation

Matrix $\mathbf{X}$ of acceptable variants of the structure of HVAC system $\bar{x}_{n}$ for cleanroom is the product of:

$$
\mathbf{X}=\mathbf{X}^{\mathrm{J}} \times \mathbf{G}
$$

after eliminating zero columns.

Matrix $\mathbf{X}$ is defined as:

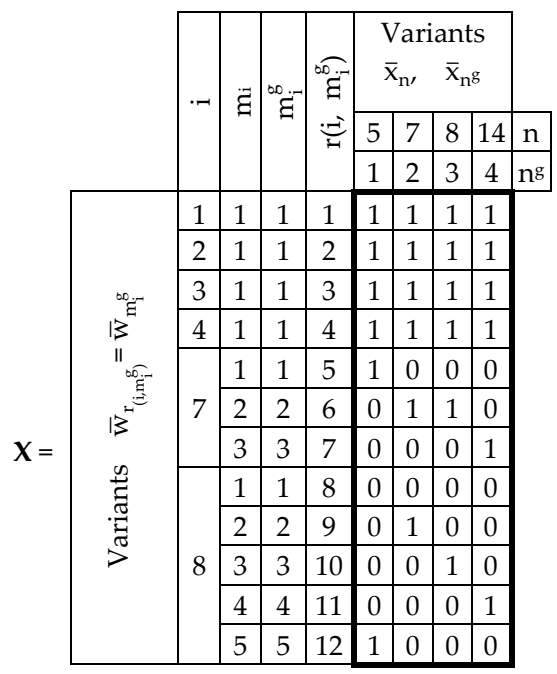

where:

X-binary matrix of acceptable variants of HVAC system for normalizing constant parameters,

$\left(\mathrm{x}_{\mathrm{m}_{\mathrm{i}}^{\mathrm{g}} \mathrm{n}^{\mathrm{g}}}\right.$ or $\left.\mathrm{x}_{\mathrm{r}\left(\mathrm{i}, \mathrm{m}_{\mathrm{i}}^{\mathrm{g}}\right) \mathrm{ng}}\right)$-binary value in the $\mathrm{ng}$-acceptable variant structures of HVAC system for $\mathrm{m}_{\mathrm{i}}^{\mathrm{g}}$ - or $\mathrm{r}\left(\mathrm{i}, \mathrm{m}_{\mathrm{i}}^{\mathrm{g}}\right)$-variant of combinations of decision variables values for nor-malizing $\mathrm{x}_{\mathrm{i}}$-constant parameter defined by vector $\overline{\mathrm{w}}_{\mathrm{m}_{\mathrm{i}}^{\mathrm{g}}}$ or $\overline{\mathrm{w}}_{\mathrm{r}\left(\mathrm{i}, \mathrm{m}_{\mathrm{i}}^{\mathrm{g}}\right)}$ in matrix $\mathrm{W}^{\mathrm{g}}$, matrix element $\mathrm{X}^{\mathrm{J}}$,

$\overline{\mathrm{x}}_{\mathrm{n}} \mathrm{g}$ - binary vector defining the $\mathrm{n}^{\mathrm{g}}$-acceptable variant of structure of HVAC system used for normalizing all constant parameters,

$\mathrm{n}\left(\mathrm{n}^{\mathrm{g}}\right)$-index of the $\mathrm{n}$-variant (of the $\mathrm{n}^{\mathrm{g}}$-acceptable variant) of HVAC system.

By analyzing and interpreting backwards values of elements of subsequent matrices $X$, $\mathrm{X}^{\mathrm{J}}$ and $\mathrm{W}^{\mathrm{g}}$ defining a function of constant parameters and decision variables, it is possible to identify the full structure of acceptable variants of HVAC system. 


\section{References}

1. Kircher, K.; Shi, X.; Patil, S.; Zhang, K.M. Cleanroom energy efficiency strategies: Modeling and simulation. Energy Build. 2010, 42, 282-289. [CrossRef]

2. Tschudi, W.; Xu, T. Cleanroom Energy Benchmarking Results. ASHREA Trans. 2003, 109, 733-739.

3. Zhuang, C.; Shan, K.; Wang, S. Coordinated demand-controlled ventilation strategy for energy-efficient operation in multi-zone cleanroom air-conditioning systems. Build. Environ. 2021, 191, 107588. [CrossRef]

4. Shan, K.; Wang, S. Energy efficient design and control of cleanroom environment control systems in subtropical regions-A comparative analysis and on-site validation. Appl. Energy 2017, 204, 582-595. [CrossRef]

5. Tsao, J.-M.; Hu, S.-C.; Xu, T.; Chan David, Y.L. Capturing energy-saving opportunities in make-up air systems for cleanrooms of high-technology fabrication plant in subtropical climate. Energy Build. 2010, 42, 2005-2013. [CrossRef]

6. Tsao, J.J.M.; Hu, S.-C.; Kao, W.-C.; Chien, L.-H. Clean Room Exhaust Energy Recovery Optimization Design. ASHRAE Trans. 2010, 116, 81-86.

7. Hu, S.-C.; Chuah, Y.K. Power consumption of semiconductor fabs in Taiwan. Energy-Int. J. 2003, 28, 895-907. [CrossRef]

8. Zhao, Y.; Li, N.; Tao, C.; Chen, Q.; Jiang, M. A comparative study on energy performance assessment for HVAC systems in high-tech fabs. J. Build. Eng. 2021, 39, 102188. [CrossRef]

9. Hu, S.-C.; Lin, T.; Fu, B.-R.; Chang, C.-K.; Cheng, I.-Y. Analysis of energy efficiency improvement of high-tech fabrication plants. Int. J. Low-Carbon Technol. 2019, 14, 508-515. [CrossRef]

10. Hu, S.-C.; Tsai, Y.-W.; Fu, B.-R.; Chang, C.-K. Assessment of the SEMI energy conversion factor and its application for semiconductor and LCD fabs. Appl. Therm. Eng. 2017, 121, 39-47. [CrossRef]

11. Hu, S.-C.; Lin, T.; Huang, S.-H.; Fu, B.-R.; Hu, M.-H. Energy savings approaches for high-tech manufacturing factories. Case Stud. Therm. Eng. 2020, 17, 100569. [CrossRef]

12. Lin, T.; Hu, S.-C.; Xu, T. Developing an innovative fan dry coil unit (FDCU) return system toimprove energy efficiency of environmental control for missioncritical cleanrooms. Energy Build. 2015, 90, 94-105. [CrossRef]

13. Hu, S.-C.; Tsao, J.-M. A comparative study on energy consumption for HVAC systems of high-tech FABs. Appl. Therm. Eng. 2007, 27, 2758-2766. [CrossRef]

14. Tsao, J.-M.; Hu, S.-C.; Chan, D.Y.L.; Hsu, R.T.C.; Lee, J.C.C. Saving Energy in the make-up unit (MAU) for semiconductor clean rooms in subtropical areas. Energy Build. 2007, 40, 1387-1393. [CrossRef]

15. Kim, M.-H.; Kwon, O.-H.; Jin, J.-T.; Choi, A.-S.; Jeong, J.-W. Energy Saving Potentials of a 100\% Outdoor Air System Integrated with Indirect and Direct Evaporative Coolers for Clean Rooms. J. Asian Archit. Build. Eng. 2012, 405, 1279-1285. [CrossRef]

16. Yin, J.; Liu, X.; Guan, B.; Zhang, T. Performance and improvement of cleanroom environment control system related to cold-heat offset in clean semiconductor fabss. Energy Build. 2020, 224, 110294. [CrossRef]

17. Yin, J.; Zhang, T.; Ma, Z.; Liu, X. Feasibility analysis of canceling reheating after condensation dehumidification in semiconductor cleanrooms. J. Build. Eng. 2021, 43, 102589. [CrossRef]

18. Ma, Z.; Liu, X.; Zhang, T. Measurement and optimization on the energy consumption of fans in semiconductor cleanrooms. Build. Environ. 2021, 197, 107842. [CrossRef]

19. Ma, Z.; Guan, B.; Liu, X.; Zhang, T. Performance analysis and improvement of air filtration and ventilation process in semiconductor clean air-conditioning system. Energy Build. 2020, 228, 110489. [CrossRef]

20. Yin, J.; Liu, X.; Guan, B.; Ma, Z.; Zhang, T. Performance analysis and Energy saving potential of air conditioning system in semiconductor cleanrooms. J. Build. Eng. 2021, 37, 102158. [CrossRef]

21. Chen, J.; Hu, S.-C.; Chien, L.-H.; Tsao, J.J.M.; Lin, T. Humidification of Large-Scale Cleanrooms by Adiabatic Humidification Method in Subtropical Areas: An Industrial Case Study. ASHRAE Trans. 2009, 115, 299-305.

22. Xu, T.; Lan, C.-H.; Jeng, M.-S. Performance of large fan-filter units for cleanroom applications. Build. Environ. 2007, 42, 2299-2304. [CrossRef]

23. Fan, M.; Cao, G.; Pedersen, C.; Lu, S.; Stenstad, L.-I.; Skogås, J.G. Suitability evaluation on laminar airflow and mixing airflow distribution strategies in operating rooms: A case study at St. Olavs Hospital. Build. Environ. 2021, 194, 107677. [CrossRef]

24. Ozyogurtcu, G.; Mobedi, M.; Ozerdem, B. Economical assessment of different HVAC systems for an operating room: Case study for different Turkish climate regions. Energy Build. 2011, 43, 1536-1543. [CrossRef]

25. Jia, L.; Liu, J.; Wei, S.; Xu, J. Study on the performance of two water-side free cooling methods in a semiconductor manufacturing factory. Energy Build. 2021, 243, 110977. [CrossRef]

26. Zheng, G.; Li, X. Construction method for air cooling/heating process in HVAC system based on grade match between energy and load. Int. J. Refrig. 2021, 131, 10-19. [CrossRef]

27. Wang, K.-J.; Dagne, T.B.; Lin, C.J.; Woldegiorgis, B.H.; Nguyen, H.-P. Intelligent control for energy conservation of air conditioning system in manufacturing systems. Energy Rep. 2021, 7, 2125-2137. [CrossRef]

28. Zhuang, C.; Wang, S. Risk-based online robust optimal control of air-conditioning systems for buildings requiring strict humidity control considering measurement uncertainties. Appl. Energy 2020, 261, 114451. [CrossRef]

29. Zhuang, C.; Wang, S.; Shan, K. Probabilistic optimal design of cleanroom air-conditioning systems facilitating optimal ventilation control under uncertainties. Appl. Energy 2019, 253, 113576. [CrossRef]

30. Zhuang, C.; Wang, S.; Shan, K. Adaptive full-range decoupled ventilation strategy and air-conditioning systems for cleanrooms and buildings requiring strict humidity control and their performance evaluation. Energy 2019, 168, 883-896. [CrossRef] 
31. Zhuang, C.; Wang, S. An adaptive full-range decoupled ventilation strategy for buildings with spaces requiring strict humidity control and its applications in different climatic conditions. Sustain. Cities Soc. 2020, 52, 101838. [CrossRef]

32. Chang, C.-K.; Lin, T.; Hu, S.-C.; Fu, B.-R.; Hsu, J.-S. Various Energy-Saving Approaches to a TFT-LCD Panel Fab. Sustainability 2016, 8, 907. [CrossRef]

33. Loomans, M.G.L.C.; Molenaar, P.C.A.; Kort, H.S.M.; Joostenb, P.H.J. Energy demand reduction in pharmaceutical cleanrooms through optimization of ventilation. Energy Build. 2019, 202, 109346. [CrossRef]

34. Loomans, M.G.L.C.; Ludlage, T.B.J.; van den Oever, H.; Molenaar, P.C.A.; Kort, H.S.M.; Joosten, P.H.J. Experimental investigation into cleanroom contamination build-up when applying reduced ventilation and pressure hierarchy conditions as part of demand controlled filtration. Build. Environ. 2020, 176, 106861. [CrossRef]

35. Molenaar, P. Ventilation Efficiency Improvement in Pharmaceutical Cleanrooms for Energy Demand Reduction. Master's Thesis, Eindhoven University of Technology, Eindhoven, The Netherlands, 2017. Available online: https:/ / research.tue.nl/en/ studentTheses/ventilation-efficiency-improvement-in-pharmaceutical-cleanrooms-f (accessed on 7 October 2021).

36. Shao, X.; Liang, S.; Zhao, J.; Wang, H.; Fan, H.; Zhang, H.; Cao, G.; Li, X. Experimental investigation of particle dispersion in cleanrooms of electronic industry under different area ratios and speeds of fan filter units. J. Build. Eng. 2021, 43, 102590. [CrossRef]

37. Porowski, M. The optimization method of HVAC system from a holistic perspective according to energy criterion. Energy Convers. Manag. 2019, 181, 621-644. [CrossRef]

38. Porowski, M. Energy optimization of HVAC system from a holistic perspective: Operating theater application. Energy Convers. Manag. 2019, 182, 461-496. [CrossRef]

39. ASHRAE. Chapter 18-Clean space. In ASHRAE Application Handbook; American Society of Heating, Refrigerating and AirConditioning Engineers Inc.: Atlanta, GA, USA, 2011.

40. $\mathrm{Xu}, \mathrm{T}$. Characterization of minienvironments in a cleanroom: Assessing energy performance and its implications. Build. Environ. 2008, 43, 1545-1552. [CrossRef]

41. Chen, D.; Chen, H. Using the Köppen classification to quantify climate variationand change: An example for 1901-2010. Environ. Dev. 2013, 6, 69-79. [CrossRef]

42. Szczechowiak, E. Analityczne obliczanie parametrów powietrza wilgotnego. Chłodnictwo 1985, $20,8$.

43. DIN 1946-4:2018-09 Ventilation and Air Conditioning-Part 4: Ventilation in Buildings and Rooms of Health Care. Available online: https:/ / standards.globalspec.com/std/13389630/DIN1946-4 (accessed on 10 October 2021). 